Daniela Silva Martinez

\title{
Investigação do comprimento telomérico em famílias com vários afetados pelo transtorno bipolar
}

\author{
Dissertação apresentada à Faculdade de \\ Medicina da Universidade de São Paulo para \\ obtenção do título de Mestre em Ciências. \\ Programa de Psiquiatria \\ Orientador: Prof. Dr. Homero Pinto Vallada \\ Filho
}

(Versão corrigida. Resolução CoPGr 6018/11, de 1 de novembro de 2011. A versão original está disponível na Biblioteca da FMUSP)

São Paulo 
Daniela Silva Martinez

\title{
Investigação do comprimento telomérico em famílias com vários afetados pelo transtorno bipolar
}

\author{
Dissertação apresentada à Faculdade de \\ Medicina da Universidade de São Paulo para \\ obtenção do título de Mestre em Ciências. \\ Programa de Psiquiatria \\ Orientador: Prof. Dr. Homero Pinto Vallada \\ Filho
}

(Versão corrigida. Resolução CoPGr 6018/11, de 1 de novembro de 2011. A versão original está disponível na Biblioteca da FMUSP)

São Paulo 
Dados Internacionais de Catalogação na Publicaçăo (CIP)

Preparada pela Biblioteca da

Faculdade de Medicina da Universidade de Săo Paulo

Creprodução autorizada pelo autor

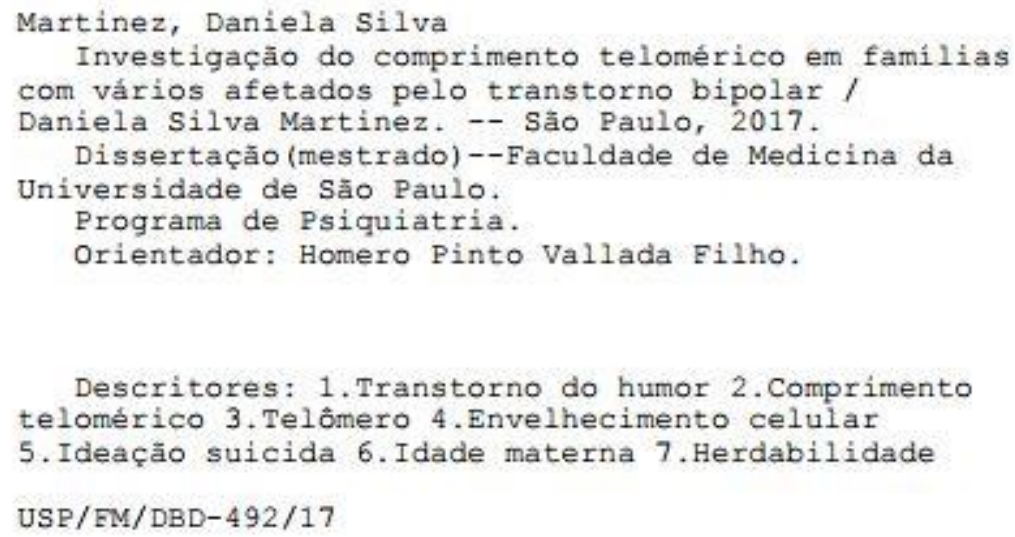


A Deus - Autor da minha história - e aqueles que deram e dariam a vida por mim: meus pais, Fernando Gregorato Martinez e Evelise Silva Martinez, e meu irmão, Lucas Antônio Silva Martinez. 


\section{AGRADECIMENTOS}

Como não saberia fazer nada sozinha, muitas são as pessoas que me ajudaram para que esse trabalho fosse concluído e, por isso, muitos são os agradecimentos. Minha sincera gratidão:

Ao meu orientador, Prof. Dr. Homero, por toda a acolhida, incentivo, apoio, paciência, puxões de orelha e ensinamentos transmitidos durante todos esses anos. Por muitas vezes acreditar em mim muito mais do que eu mesma. Com certeza, eu pude perceber meu crescimento durante esses anos e muito devo ao senhor! Muitíssimo obrigada por tudo!

A todos os pesquisadores do grupo do CMM (Centro de Medicina Molecular) do Instituto Karolinska por me acolherem tão bem durante os dois meses que estive em Estocolmo em 2015, logo no início do mestrado. Em especial, ao Prof. Martin Schalling que me acolheu no apartamento de sua filha e me ensinou como ser e se comportar como uma "quase sueca". Ao Vincent Millischer, aluno de doutorado do grupo, que me ensinou toda a técnica experimental padronizada no laboratório para análise do comprimento telomérico e me transmitiu muita garra e energia. Um agradecimento mais do que especial à querida Prof. ${ }^{a}$ Catharina Lavebratt, que me acompanhou diretamente durante o período com muito carinho, cuidado e atenção. Agradeço aos ensinamentos, à acolhida, ao estímulo e incentivo que me foi dado e que permitiu com que eu produzisse muito em tão pouco tempo. Realmente, tive nesse tempo uma maravilhosa experiência de trabalho em grupo e do que é ser de fato cientista! A todos: Tack så mycket!

A todos os membros da banca examinadora da qualificação: Prof. Dr. Beny Lafer, Prof. Dr. Orestes Forlenza e Prof. a Dr. ${ }^{-}$Marília Smith, que gentilmente aceitaram o convite e muito contribuíram com sugestões e correções para lapidar esse trabalho de mestrado! Muitíssimo obrigada!

À Kátia Ichi, Eliza Fukushima e Isabel Ataíde, as secretárias mais eficientes que já conheci! Muito obrigada a todas pela ajuda, auxílio, disponibilidade e eficiência de sempre! Vocês são ótimas!

Ao grupo do LGCM (Laboratório de Genética e Cardiologia Molecular) do Incor (Instituto do Coração), por terem me dado todo o suporte para analisar os 
dados das famílias do meu estudo. Em especial ao Prof. Dr. Alexandre Pereira, por todo acompanhamento, sugestões, ensinamentos e suporte, e às queridas estatísticas Núbia Esteban e Marina Luz, por serem tão pacientes, humildes, prestativas e gentis! Vocês me ensinaram muito!

Aos pós-docs do LGCM, Dr. ․ Francieli Ruiz e Dr. André Negrão, pelo cuidado de sempre, por terem acompanhado meu andamento e pelas valiosíssimas correções e sugestões na dissertação. Fran, obrigada pelo seu companheirismo, pelo suporte durante o tempo que estive no Incor e pelas aventuras em Orlando! Você é demais!

Ao estatístico Thiago Pires também do LGCM, mais conhecido como "anjo da guarda", pois sempre me salvou nos momentos que mais precisei! Obrigada por todo o apoio desde o período da qualificação até a finalização da dissertação. Obrigada não só pela sua ajuda na parte estatística - que pacientemente me ensinou tudo - como também pelas contínuas revisões, formatações, correções de inglês e português e pelo estímulo e incentivo principalmente nos momentos mais difíceis. Muito devo a você e você sabe disso!

Ao grupo do LIM-23, em especial à Prof. ${ }^{\text {a }}$ Helena Brentani e todo o seu grupo, por me apoiarem principalmente no começo do mestrado, com sugestões, ideias e correções do projeto inicial. A Prof. ${ }^{a}$ Helena é para mim um exemplo e referência de mulher na ciência. Saiba que a admiro muito!

Ao Dr. Leandro Michelon do LIM-23 pela parceria, pelo apoio e paciência nas explicações da parte clínica do Transtorno Bipolar.

À Caroline Camillo, Camilla Braghetta e Juliane Gonçalves, também do LIM-23, pelo companheirismo e ajuda de sempre! À Carol, por ter sido meu primeiro contato logo que entrei para o grupo e por ter generosamente me ajudado muito do início ao fim do mestrado! Você foi muito importante! Cá e Ju, muito obrigada pelo suporte nessa reta final!

À "panelinha" do CEAPESQ (Centro de Apoio à Pesquisa) do IPq, em especial aos queridos: Luciana, Edna, Roberta, Josy, Alessandra, Carol, Amanda e Robson, pelas risadas e cafés mensais, por todas as conversas e suportes emocionais que vocês me deram! 
À Dr. $\stackrel{a}{ }$ Carol Cappi, que me acompanhou nesse último ano e generosamente corrigiu minha dissertação!

À Fundação de Amparo à Pesquisa do Estado de São Paulo, pela concessão da bolsa de mestrado (Processo FAPESP: 2015/14614-6) e ao Conselho Nacional de Desenvolvimento Científico e Tecnológico (CNPq) pelo apoio financeiro para a realização desta pesquisa (MCTI/CNPq No 14/2014).

Por fim e mais importante agradecimento: a Deus, que permitiu com que eu chegasse até aqui e à minha família! Sem esse suporte jamais teria chegado aonde cheguei! Obrigada por todo apoio financeiro, emocional, pelo incentivo e por acreditarem em mim! Eu amo muito vocês! 
"Não é a ciência, mas o amor que transformará o mundo".

Giuseppe Moscatti (médico, italiano) 


\section{NORMATIZAÇÃO ADOTADA}

Esta dissertação está de acordo com as seguintes normas, em vigor no momento desta publicação:

Referências: adaptado de International Committee of Medical Journals Editors (Vancouver).

Universidade de São Paulo. Faculdade de Medicina. Divisão de Biblioteca e Documentação. Guia de apresentação de dissertações, teses e monografias. Elaborado por Anneliese Carneiro da Cunha, Maria Julia de A. L. Freddi, Maria F. Crestana, Marinalva de Souza Aragão, Suely Campos Cardoso, Valéria Vilhena. 3a ed. São Paulo: Divisão de Biblioteca e Documentação; 2011.

Abreviaturas dos títulos dos periódicos de acordo com List of Journals Indexed in Index Medicus. 


\section{RESUMO}

Martinez DS. Investigação do comprimento telomérico em famílias com vários afetados pelo transtorno bipolar [dissertação]. São Paulo: Faculdade de Medicina, Universidade de São Paulo; 2017.

INTRODUÇÃO: O Transtorno Bipolar (TB) é um transtorno psiquiátrico crônico e debilitante e sua etiologia e patologia ainda não são completamente conhecidos, apesar de um componente genético importante ser evidenciado em estudos de família, adoção e gêmeos. Recentemente, o TB tem sido relacionado a um processo de envelhecimento acelerado, com alguns estudos mostrando telômeros encurtados nesta população. O objetivo do presente estudo foi investigar a associação entre o comprimento telomérico, um dos parâmetros do processo de envelhecimento celular, com a ausência ou presença de TB em famílias com muitos membros afetados, além de associar a sintomatologia clínica e outras variáveis a esse parâmetro. Procurou-se também avaliar as influências genéticas e ambientais sobre o comprimento telomérico nessas famílias, estimando-se a herdabilidade desta característica. MÉTODOS: O comprimento telomérico $(\mathrm{T})$ foi mensurado em uma amostra de 143 indivíduos de 22 famílias (60 deles com TB), em relação a um gene de cópia única $(S)$ - $\beta$-globina, através do método de PCR (Polymerase Chain Reaction) em tempo real quantitativo, no qual forneceu uma proporção do número de cópias de $\mathrm{T}$ por $\mathrm{S}$ (razão $\mathrm{T} / \mathrm{S}$ ). Considerando a estrutura familiar na análise estatística foi ajustado para cada análise o modelo misto poligênico. RESULTADOS: O efeito do TB no comprimento dos telômeros foi pequeno, não tendo sido observada uma associação estatisticamente significante entre TB e comprimento telomérico quando comparado com familiares saudáveis ( $p$ $>0,05)$. No entanto, observou-se associação do comprimento telomérico à covariável ideação suicida $(p=0,02)$ e à interação entre ideação suicida e curso da doença $(p=0,02)$. Associação do comprimento telomérico com idade materna e TB também foi observada $(p<0,05)$. Por fim, estimou-se em $68 \%$ a herdabilidade do comprimento telomérico nas 22 famílias do estudo. CONCLUSÕES: A teoria do envelhecimento acelerado em TB, vista pela óptica 
do comprimento dos telômeros, não pôde ser confirmada no presente estudo, pois não foi encontrada diferença no comprimento telomérico entre indivíduos saudáveis e com TB nas famílias. Por outro lado, covariáveis que indicam gravidade da doença, como a ideação suicida e a interação entre ideação suicida e curso da doença foram associadas ao comprimento telomérico $(\mathrm{p}<$ 0,05 ), ou seja, um encurtamento telomérico foi correlacionado à gravidade clínica do TB. Associação do comprimento telomérico com idade materna e TB $(p<0,05)$ sugeriu que a idade materna avançada não só pode ser um marcador de longevidade, como também o fenótipo TB pareceu reforçar essa condição. Por fim, a alta herdabilidade estimada do comprimento telomérico $(0,68)$ revelou uma importante variabilidade genética desse fenótipo entre as famílias do estudo. Em súmula, este é o primeiro estudo que relatou uma associação entre ideação suicida, curso da doença, idade materna e comprimento telomérico em famílias com vários membros afetados pelo TB. Outras investigações independentes são necessárias para confirmar esses resultados preliminares.

Descritores: Transtornos do humor; Comprimento telomérico; Telômero; Envelhecimento celular; Ideação suicida; Curso da doença; Idade materna; Herdabilidade. 


\section{ABSTRACT}

Martinez DS. Investigation of telomere length in families with several affected by bipolar disorder [dissertation]. São Paulo: "Faculdade de Medicina, Universidade de São Paulo"; 2017.

BACKGROUND: Bipolar Disorder (BD) is a debilitating and chronic mental illness. It is etiology and pathology are not completely known yet, despite the evidence of an important genetic component from family, twin and adoption studies. Recently, BD has been related to a process of accelerated aging, with some studies showing shortened leukocyte telomeres in this population. The purpose of the present study was to investigate the association between leucocyte telomere length (LTL) in BD patients compared with healthy relatives of 22 families with several affected members by this illness, besides associating clinical symptomatology and other covariates with this parameter. It was also examined the genetic and environmental influences on telomere length trait in these BD families, using a variance component approach, by estimating the heritability of this trait as well as covariate effects. METHODS: Telomere length (T) was estimated in a sample of 143 individuals, including $60 \mathrm{BD}$ patients from 22 families, which was measured in relation to the single copy gene (S) - $\beta$ globin gene, using a singleplex real time PCR (Polymerase Chain Reaction), providing a ratio of number of copies of $T$ by $S$ (T/S ratio). Taking in consideration the family structure, the statistical analysis was adjusted for the polygenic mixed model. RESULTS: The effect of BD illness in telomere length was small and we found no association between BD group and LTL $(p>0.05)$. However, LTL was associated with the variable suicidal ideation $(p=0.02)$ and interaction between suicidal ideation and course of disorder $(p=0.02)$. Association of LTL and maternal age and BD was also observed $(p<0.05)$. In addition, an important genetic component for telomere length was also observed (heritability $=0.68$ ) in these families. CONCLUSIONS: The hypothesis of accelerated aging in $\mathrm{BD}$, investigating the telomere length as one of its components, was not confirmed in our study. We found no difference between LTL and BD in our family group. However, using covariates that indicate 
severity of disease, both suicidal ideation and interaction between suicidal ideation and course of disorder were statistically significant with $L T L$, showing that shorter LTL was associated with worse clinical course $(p<0.05)$ and suicidal ideation $(p<0.05)$ in BD patients. Association of LTL with maternal age and BD $(p<0.05)$ suggests that advanced maternal age may not only be a marker of longevity, but also the BD phenotype may reinforce this condition. A high heritability for telomere length (0.68) also suggests an important genetic variability of this trait presented among those families. To our knowledge, this is the first study that found association between suicidal ideation, course of disorder, maternal age and LTL in families with several members affected by BD. Further investigations, including replication studies in other BD families, are needed to confirm these new findings.

Descriptors: Mood disorders; Telomere length; Telomere; Cell aging; Suicidal ideation; Course of disorder; Maternal age; Heritability. 


\section{LISTA DE ILUSTRAÇÕES}

Figura 1 - Progressão e diferentes estágios do TB

Figura 2 - Fases do encurtamento telomérico em leucócitos do sangue

periférico. .12

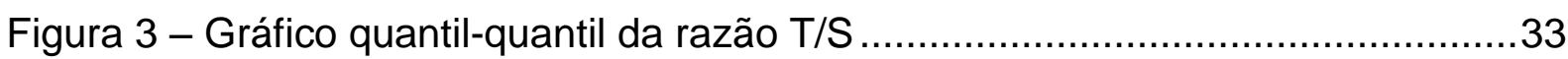

Figura 4 - Comparação da razão T/S entre homens e mulheres.............................34

Figura 5 - Gráfico de dispersão da idade em relação à razão T/S ............................35

Figura 6 - Comparação da razão T/S entre bipolares e saudáveis..........................36

Figura 7 - Comparação da razão T/S entre todos os indivíduos com doença psiquiátrica (doentes) e saudáveis

Figura 8 - Comparação da razão T/S entre bipolares, saudáveis e indivíduos com outras doenças psiquiátricas

Figura 9 - Comparação da razão T/S e ideação suicida 39

Figura 10 - Comparação da razão T/S e curso da doença

Figura 11 - Gráfico da associação entre razão T/S e interação entre ideação suicida e curso da doença

Figura 12 - Gráfico de dispersão da interação entre idade materna e TB e a associação com a razão T/S

Figura 13 - Gráfico de dispersão da interação entre idade paterna e TB e a associação com a razão $\mathrm{T} / \mathrm{S}$

Figura 14 - Comparação da média do comprimento telomérico com a porcentagem de indivíduos afetados por família. 


\section{LISTA DE TABELAS}

Tabela 1 - Sequência dos primers utilizados na reação de PCR em tempo real .

Tabela 2 - Caracterização da população de estudo ........................................ 31

Tabela 3 - Comparação da razão T/S entre homens e mulheres ..................... 34

Tabela 4 - Modelo Geral Final do comprimento telomérico (razão T/S) .......... 42

Tabela 5 - Modelo Idade Materna: Associação da razão T/S e interação entre

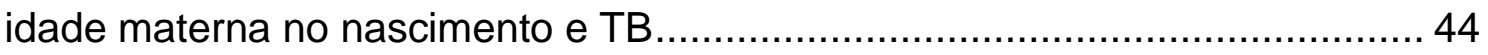

Tabela 6 - Modelo Idade Paterna: Razão T/S e interação entre idade paterna

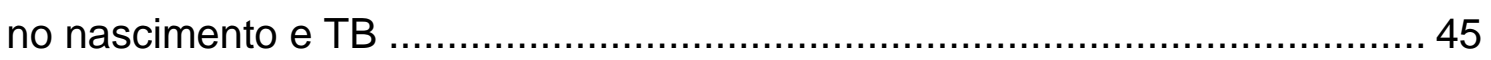

Tabela 7 - Herdabilidade do comprimento telomérico ……........................... 46

Tabela 8 - Herdabilidade do comprimento telomérico no modelo final ............ 47 


\section{LISTA DE ABREVIATURAS E SIGLAS}

5-HT2AR

5-HT4R

5-HTT

BD

BDNF

CACNA1C

$\mathrm{CD}^{+} \mathrm{CD}^{-} 8^{-}$

CID-10

COMT

Ct

D2R

D4R

DAT

DCC

DISC-1

DLPFC

DM

DMDA

DNA

DP

DSM-V

EDTA

et al.

GRIN1

GWAS

HBG

IPq-HC-FMUSP

Serotonin 2A Receptor

Serotonin 4 Receptor

5-hydroxytryptamine

Bipolar Disorder

Brain-derived Neurotrophic Factor

Calcium Voltage-Gated Channel Subunit Alpha1 C

Cluster of Differentiation

Classificação Internacional de Doenças - $10^{a}$ edição

Catechol-O-methyltransferase

Cycle Threshold

Dopamine 2 Receptor

Dopamine 4 Receptor

Dopamine Active Transporter

Doença Crônica Contínua

Disrupted in schizophrenia-1

Dorsolateral Prefrontal Cortex

Depressão Maior

National Depressive and Manic-Depressive Association

Deoxyribonucleic Acid

Doenças Psiquiátricas

Diagnostic and Statistical Manual of Mental Disorders - $5^{\text {a }}$

Edição

Epidemiological Catchment Area Study

Ethylenediamine tetraacetic acid

"e outros", do latim et alii

Glutamate lonotropic 6 Receptor NMDA Type Subunit 1

Genome-wide Association Studies

Primer do gene da $\beta$-globina

Instituto de Psiquiatria do Hospital das Clínicas da

Faculdade de Medicina da Universidade de São Paulo

LTL

Leucocyte Telomere Length 


$\begin{array}{ll}\text { MAO } & \text { L-Monoamine Oxidases } \\ \text { NMDA } & \text { N-methyl-D-aspartate Receptor } \\ \text { NRG-1 } & \text { Neuregulina-1 } \\ \text { ODZ4 } & \text { Gene homólogo ao Drosophila Pair-rule Gene ODZ } \\ \text { OPCRIT } & \text { Operational Criteria } \\ \text { PCR } & \text { Polymerase Chain Reaction } \\ \text { POT1 } & \text { Protection of Telomeres 1 } \\ \text { ProGene } & \text { Programa de Genética e Farmacogenética } \\ \text { RDC } & \text { Research Diagnostic Criteria } \\ \text { RNA } & \text { Ribonucleic Acid } \\ \text { SADS-L } & \text { Schedule for Affective Disorders and Schizophrenia - } \\ \text { SNP } & \text { Lifetime } \\ \text { SOLAR } & \text { Single Nucleotide Polymorphism } \\ \text { TB } & \text { Sequential Oligogenic Linkage Analysis Routines } \\ \text { TDAH } & \text { Transtorno Bipolar } \\ \text { Tel } & \text { Transtorno de Déficit de Atenção e Hiperatividade } \\ \text { TERC } & \text { Primers de telômero } \\ \text { TERT } & \text { Telomerase RNA Component } \\ \text { TPH2 } & \text { Telominal Restriction Fragment } \\ \text { TRF } & \end{array}$




\section{LISTA DE SÍMBOLOS}

$\begin{array}{ll}h^{2} & \text { Herdabilidade } \\ \boldsymbol{\mu l} & \text { Microlitro } \\ \boldsymbol{\mu M} & \text { Micro molar } \\ \mathbf{C V} & \text { Coeficiente de variação } \\ \mathbf{D} & \text { Teste estatístico de Kolmogorov-Smirnov } \\ \mathbf{n g} & \text { Nanogramas } \\ \mathbf{n m} & \text { Nanômetros } \\ \mathbf{p} & \text { Valor de p (probabilidade de significância) } \\ \mathbf{p b} & \text { Pares de base } \\ \mathbf{R} & \text { Linguagem e ambiente para computação estatística } \\ \mathbf{S} & \text { Número de cópias de um gene de cópia única } \\ \mathbf{T} & \text { Número de cópias da região telomérica } \\ \mathbf{\alpha} & \text { Nível de significância } \\ \beta & \text { Efeitos fixos ambientais (covariáveis) }\end{array}$




\section{SUMÁRIO}

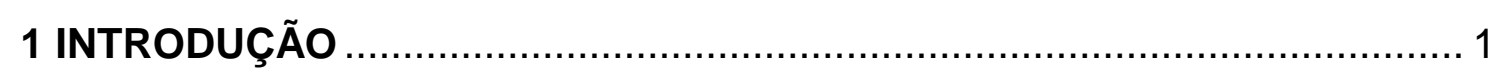

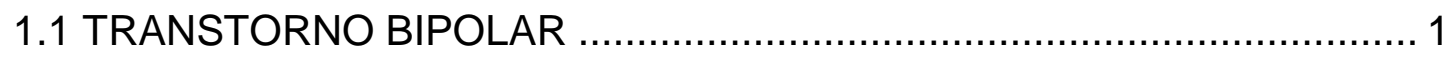

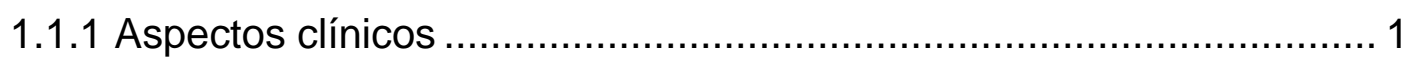

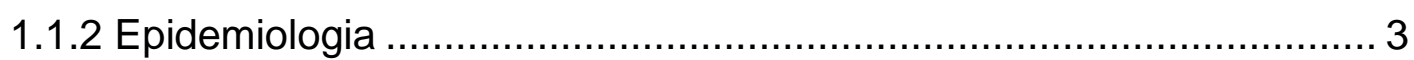

1.1.3 Prognóstico, comorbidades e qualidade de vida .......................... 5

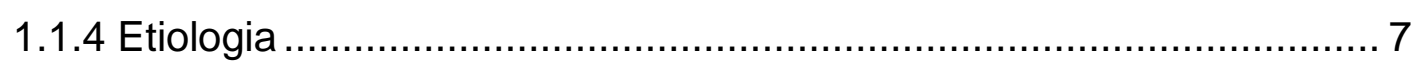

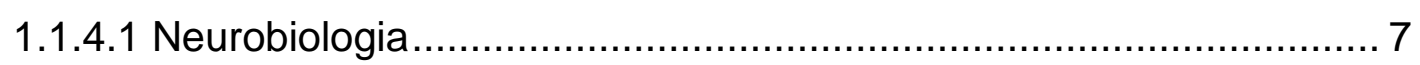

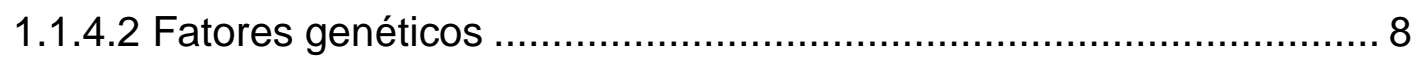

1.1.4.3 Neuro/somatoprogressão e teoria do envelhecimento acelerado .... 9

1.2 TELÔMERO E COMPRIMENTO TELOMÉRICO .............................. 11

1.2.1 Estudos epidemiológicos, genéticos e herdabilidade do comprimento

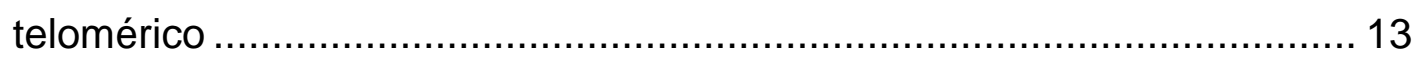

1.2.2 Telômero, envelhecimento celular e estresse oxidativo.................. 15

1.2.3 Comprimento telomérico e transtorno bipolar ........................... 15

1.2.4 Comprimento telomérico, idade paterna e transtorno bipolar ........... 16

2 JUSTIFICATIVA

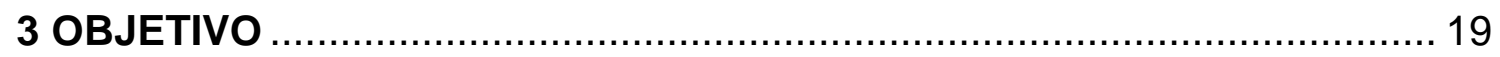

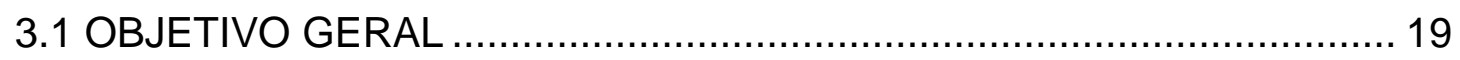

3.2 OBJETIVOS ESPECÍFICOS .......................................................... 19

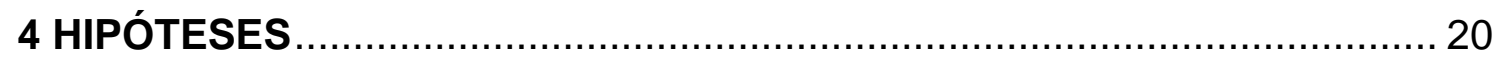

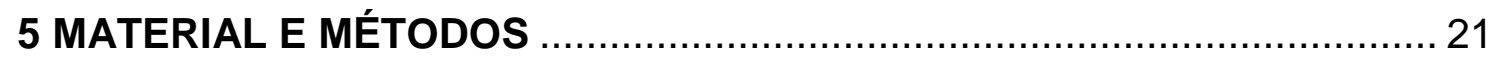

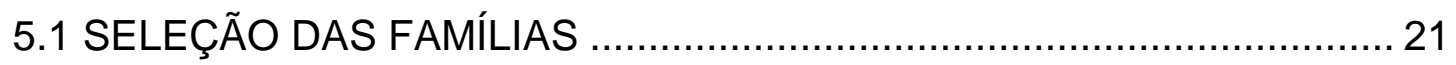

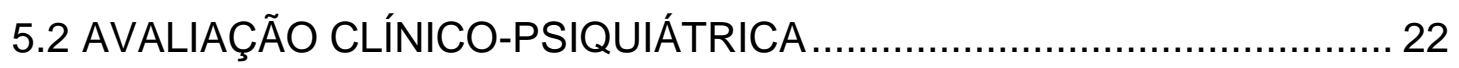

5.3 VARIÁVEIS CLÍNICAS - DIRETRIZES E CLASSIFICAÇÕES DO OPCRIT 


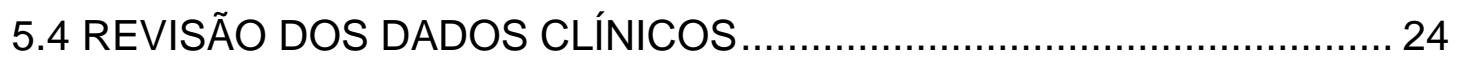

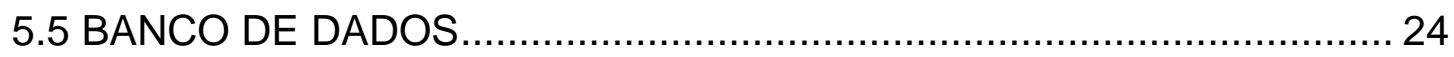

5.6 ANÁLISE DA INTEGRIDADE E QUALIDADE DO DNA.......................... 24

5.7 QUANTIFICAÇÃO RELATIVA DO COMPRIMENTO TELOMÉRICO VIA PCR EM TEMPO REAL QUANTITATIVO................................................ 25

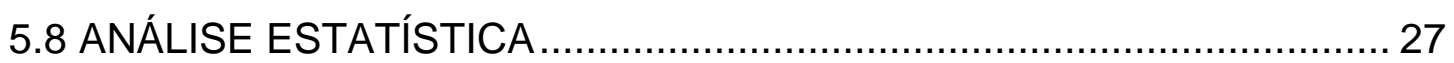

5.8.1 Modelo misto poligênico e cálculos de herdabilidade ...................... 27

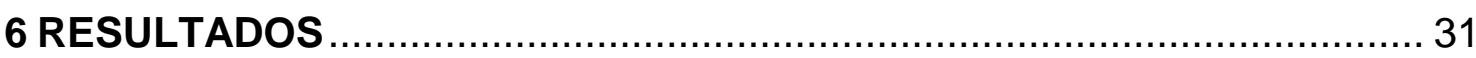

6.1 CARACTERIZAÇÃO DA POPULAÇÃO DE ESTUDO …........................... 31

6.2 ANÁLISE DESCRITIVA DA VARIÁVEL COMPRIMENTO TELOMÉRICO

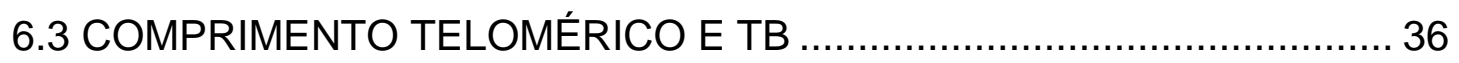

6.4 COMPRIMENTO TELOMÉRICO E GRUPO DOENÇA PSIQUIÁTRICA 37 6.5 COMPRIMENTO TELOMÉRICO E VARIÁVEIS CLÍNICAS ................... 38 6.6 COMPRIMENTO TELOMÉRICO - MODELO GERAL............................ 41

6.7 COMPRIMENTO TELOMÉRICO, IDADE PATERNA E MATERNA E TB42 6.8 HERDABILIDADE DO COMPRIMENTO TELOMÉRICO ....................... 46

6.9 ANÁLISE DESCRITIVA GLOBAL DO COMPRIMENTO TELOMÉRICO NAS FAMÍLIAS COM TB E OUTRAS DP …........................................ 47

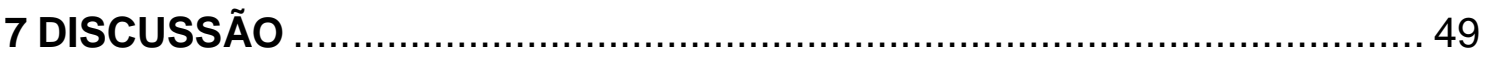

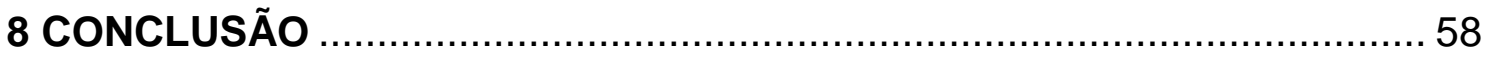

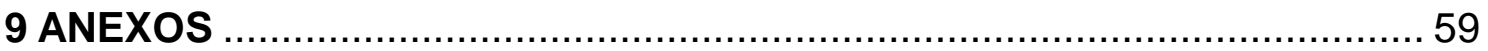

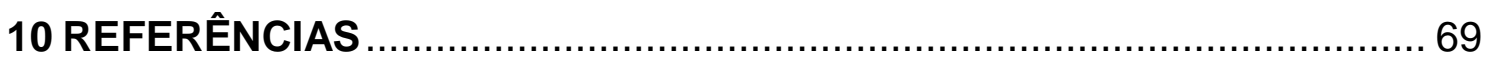

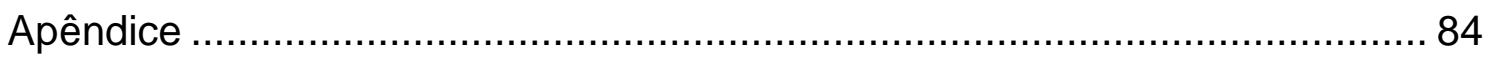




\section{INTRODUÇÃO}

\subsection{TRANSTORNO BIPOLAR}

\subsubsection{Aspectos clínicos}

O TB é um transtorno psiquiátrico crônico, caracterizado por alterações patológicas de humor, com episódios recorrentes de elação ou exaltação do humor e/ou episódios de humor depressivo. Denomina-se de mania as fases em que há elevação de humor e quando não muito intensas, chama-se de hipomania. Há também episódios patológicos do humor em que há a presença tanto de episódios com sintomas maníacos como depressivos denominados de episódios mistos (Sajatovic, 2005; Grande et al., 2016). Na Figura 1 são ilustrados os diferentes sintomas e estágios do TB.

Quadros clínicos semelhantes ao TB são relatados desde a antiguidade. O próprio Hipócrates ("pai da medicina") já havia descrito os quadros clínicos de depressão (melancolia) e mania (Goodwin, Jamison, 1990). Até o século XIX, acreditava-se que depressão e mania eram entidades clínicas distintas. Entretanto, um dos mais importantes psiquiatras do início do século $X X, 0$ alemão Emil Kraepelin, baseando-se na observação clínica e na evolução de portadores de disfunções mentais, chamou de psicose maníaco-depressiva a doença responsável pela alternância contínua ou recorrente de períodos em que o doente ficava prostrado, sem interesse ou iniciativa, com períodos em que o paciente apresentava elevação de humor. No início da segunda metade do século XX, outro psiquiatra alemão Karl Leonhard, baseando-se também em observações clínicas, sugeriu a separação entre os pacientes que apresentavam quadros puramente melancólicos (chamados por ele de depressões unipolares), dos pacientes com quadros em que ocorriam episódios de mania e em outros momentos episódios de depressão, denominado de TB (Goodwin, Jamison, 1990). Esses conceitos serviram de base para os sistemas de ordenação e classificação diagnóstica, iniciados também na segunda metade do século XX, sendo revisados a cada 10-20 anos. No momento, os critérios diagnósticos para o TB comumente utilizados 
são os descritos na Classificação Internacional das Doenças em sua 10 edição - CID-10 (OMS, 2010) e os critérios do Manual Diagnóstico e Estatístico dos Transtornos Mentais 5aㅡ edição, do inglês Diagnostic and Statistical Manual of Mental Disorders - DSM-V (APA, 2013).

Os manuais para diagnóstico em psiquiatria propõem critérios específicos para a caracterização de um episódio de alteração do humor e fornecem as diretrizes para considerar como patológica as alterações observadas. Cada qual estabelece e caracteriza sintomas necessários para que se diagnostique um quadro depressivo ou maníaco. A definição de um episódio depressivo ou maníaco não requer a presença de todos os sintomas associados a cada fase da doença. Os sintomas considerados para 0 diagnóstico são listados nos próprios manuais. Segundo estes, o TB pertence ao grupo de transtornos do humor - juntamente com a Depressão Maior (DM) e outros transtornos.

O episódio maníaco é caracterizado pela presença de humor anormal e persistentemente elevado, expansividade ou irritabilidade acompanhada de pelo menos três (quatro, se o humor é apenas irritável) sintomas adicionais por pelo menos uma semana (ou um tempo menor se resultar em hospitalização). O episódio hipomaníaco é similar ao maníaco, mas menos severo, não envolvendo hospitalização, psicose e prejuízo funcional importante. A duração de cada um desses episódios deve ser de pelo menos quatro dias. Os episódios depressivos maiores são caracterizados pela presença de tristeza, ou perda do interesse ou prazer acompanhado de sintomas adicionais, num total de ao menos cinco sintomas que ocorrem na maior parte do dia, quase todos os dias durante no mínimo duas semanas. A presença de episódios de DM prévios não são exigência para o diagnóstico de TB, apesar de ocorrerem na grande maioria dos pacientes. Além disso, tanto o quadro depressivo quanto - maníaco podem ser acompanhados por sintomas psicóticos. Entre fenômenos alucinatórios, as alucinações auditivas e visuais são as mais comuns. Contudo, é mais frequente observar a presença de delírios, notadamente de cunho persecutório e grandioso na mania, ou persecutório, de culpa e de ruína na depressão. Há momentos no curso da doença em que os sintomas depressivos e maníacos podem ocorrer simultaneamente, 
caracterizando o chamado estado misto. Os episódios mistos, portanto, são caracterizados por apresentarem simultaneamente os critérios para mania e DM. A presença desse estado no curso da doença torna a realização do diagnóstico mais difícil e o tratamento mais complexo (Grande et al., 2016; Cuomo et al., 2017; Muneer, 2017).

Desta forma, o TB se mostra heterogêneo, abrangendo um espectro de sintomas bastante amplo com um polo claramente depressivo, estados mistos e um polo intensamente maníaco. Observa-se também que o ritmo das oscilações do humor varia entre os indivíduos, caracterizando ainda diferentes subgrupos. Na Figura 1 são ilustrados todos os estágios da doença.

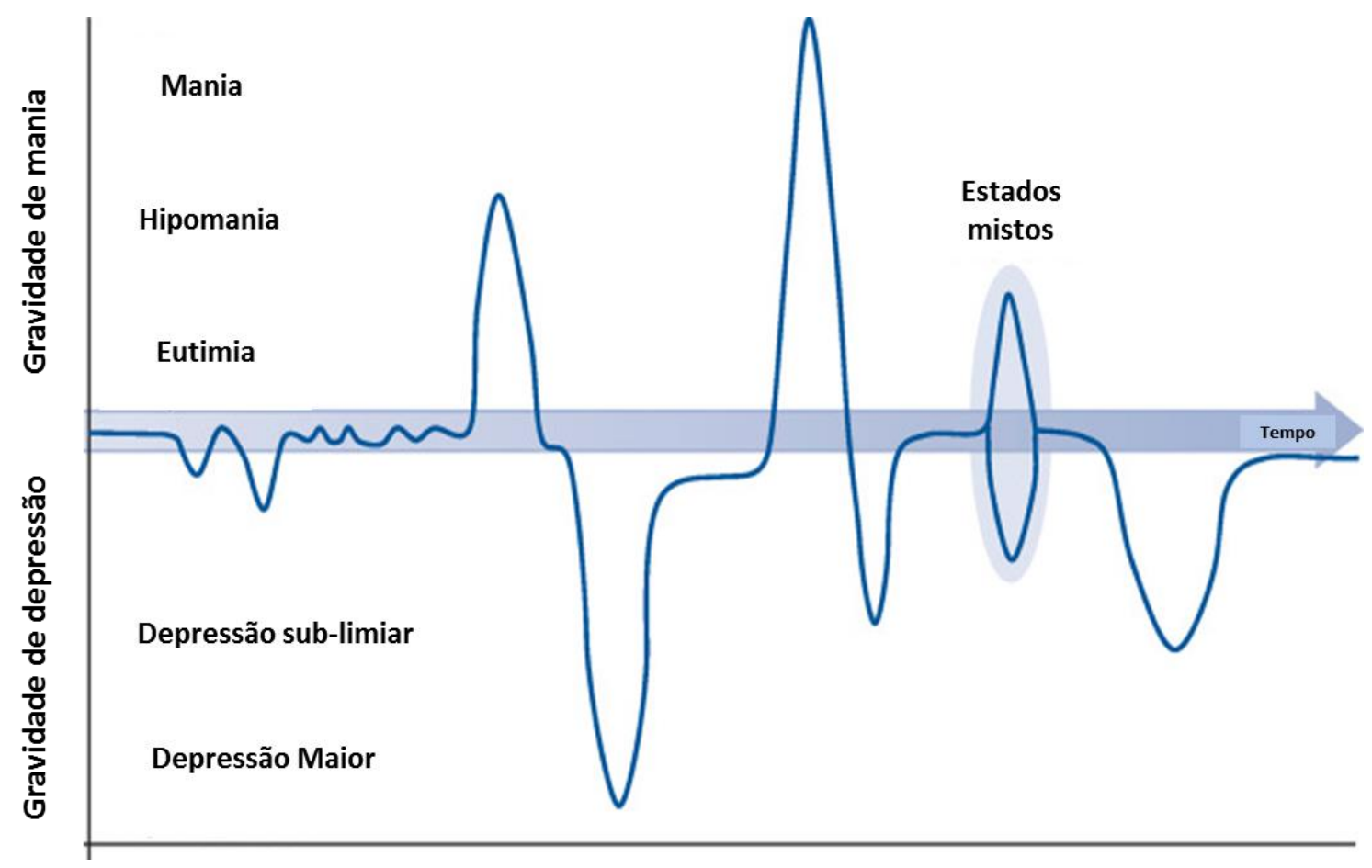

FONTE: Adaptado de Grande et al., 2016

Figura 1 - Progressão e diferentes estágios do TB

\subsubsection{Epidemiologia}

Os estudos epidemiológicos estimam a prevalência mundial do TB entre 1 e $2 \%$ independente da nacionalidade, origem étnica ou status socioeconômico (Sajatovic, 2005; Alonso et al., 2011; Grande et al., 2016). Um dos primeiros grandes estudos epidemiológicos realizado nos Estados Unidos 
na década de 80 - o Epidemiological Catchment Area Study (ECA) - avaliou 18 mil americanos e encontrou uma prevalência de 1,3\% para o TB, sem diferenças entre os sexos (Weissman et al., 1988). Na população brasileira, Andrade e colaboradores (2002) encontraram para a cidade de São Paulo (bairro de Pinheiros) uma prevalência de TB ao longo da vida de 1\%. Ainda, um estudo mais recente e a nível global da Iniciativa Mundial de Pesquisa em Saúde Mental da Organização Mundial da Saúde estimou a prevalência do TB em, aproximadamente, 2,4\% na população mundial (Merikangas et al., 2011). Quanto à incidência, uma pesquisa na população dinamarquesa observou uma taxa de 24,5 novos casos de TB por 100 mil pessoas-ano (Jensen, Steinhausen, 2016).

No que diz respeito ao sexo, os estudos mostram que homem e mulher não apresentam distinção na prevalência de TB, ou seja, a doença atinge igualmente os sexos (Weissman et al., 1996; Hendrick et al., 2000; Charlson et al., 2016), apesar de os episódios depressivos e os estados mistos serem mais predominantes em mulheres (Lish et al., 1994; Kessler et al., 1997; Perugi et al., 2001). Além disso, nem mesmo raça, estado civil, condições socioeconômicas e culturais parecem influenciar de modo significativo a ocorrência da doença (Szadoczky et al., 1998; Perugi et al., 2001; Suppes et al., 2001).

De um modo geral, o início da doença ocorre antes dos 30 anos de idade, sendo que o período de pico de acometimento costuma aparecer entre as idades de 15 e 19 anos. Alguns estudos também apontam para uma faixa maior entre os 13 e 30 anos, entre o período de adolescência e início da idade adulta (Bebbington, Ramana, 1995; Jensen, Steinhausen, 2016). Uma pesquisa da National Depressive and Manic-Depressive Association (DMDA) dos Estados Unidos encontrou que 59\% dos pacientes com TB experienciaram seus primeiros sintomas durante a infância ou adolescência (Lish et al., 1994); outros apontam que 20 a $30 \%$ dos pacientes experienciam um primeiro episódio afetivo antes dos 20 anos e, por isso, compreender os transtornos afetivos na infância e adolescência se faz necessário, pois o início precoce da doença tem sido relacionado a um pior quadro clínico e pior prognóstico (Kupfer et al., 2002). Por outro lado, o TB pode também se manifestar pela 
primeira vez em idades mais avançadas (Yassa et al., 1988; Sajatovic, 2005). O início tardio, após 60 anos, embora mais raro e associado a alterações orgânicas, também demonstra pior prognóstico (Shulman, Herrmann, 1999).

\subsubsection{Prognóstico, comorbidades e qualidade de vida}

Vários fatores podem interferir no prognóstico da doença e estarem associados com sua piora progressiva. Como visto no item acima, o início precoce e tardio está relacionado a um mau prognóstico. Além disso, Gitlin e colaboradores (1995) mostraram que a ocorrência de um maior número de episódios depressivos do que maníacos durante a vida também estão relacionados a um pior prognóstico.

Outro fator importante são as comorbidades. Comorbidade se refere de modo amplo à presença simultânea de duas ou mais enfermidades. No caso dos transtornos mentais, um mesmo indivíduo pode apresentar doenças clínicas concomitantes como, por exemplo, doenças cardiovasculares, diabetes, hipertensão (comorbidades clínicas), como também pode preencher critérios para outros transtornos psiquiátricos (comorbidades psiquiátricas). No TB é comum a presença de comorbidades com doenças psiquiátricas como, por exemplo, transtornos de ansiedade e uso e abuso de álcool e outras drogas (Nery et al., 2009; Issler et al., 2010). A prevalência de TB em comorbidade com dependência de substâncias é elevada. Estima-se que mais de $50 \%$ dos portadores de TB apresentem diagnóstico de abuso e/ou dependência a drogas durante a vida, incluindo o álcool (Sonne, Brady, 1999; Chengappa et al., 2000). Por outro lado, através dos dados do National Comorbidity Survey coordenado por Kessler e colaboradores (1994), observou-se que 92,9\% dos indivíduos com TB apresentaram critérios para algum subtipo de transtorno de ansiedade (fobias, transtorno de pânico, transtorno de estresse pós-traumático ou transtorno obsessivo-compulsivo) ao longo da vida, enquanto na população geral a prevalência é de $25 \%$. A associação dos quadros ansiosos com TB compromete de modo importante a recuperação dos pacientes, estando também associados com mau prognóstico (Perugi et al., 1999). Observa-se, então, uma correlação entre TB e outros transtornos psiquiátricos (ansiedade, 
dependência química e transtorno de personalidade), que dificulta 0 diagnóstico pela presença dos fenótipos distintos compartilhados. Com isso, é perceptível como a presença de comorbidade também determina um pior prognóstico da doença (Lecrubier, 2001).

A presença de comorbidades também indica fator de risco para o comportamento suicida (De Abreu et al., 2011) uma vez que está associada a um aumento importante no risco de suicídio (Lecrubier, 2001). Um estudo de coorte apontou que 32\% dos portadores de TB cometem suicídio (Angst, Preisig, 1995). Outro de base populacional avaliou mais de 15 mil pacientes suecos com TB e verificou que a taxa de suicídio foi 15 vezes maior do que o esperado na população normal (Osby et al., 2001).

O mesmo estudo sueco de Osby e colaboradores (2001) relatou que a taxa de mortalidade por causas não naturais foi oito vezes maior nos pacientes com TB, sendo os acidentes e o suicídio as maiores causas. Já a taxa de mortalidade por causas naturais foi aproximadamente duas vezes maior em TB. Dentre os fatores que mais contribuíram para mortalidade por causas naturais foram alterações endócrinas, demência, doenças cardiovasculares e cerebrovasculares (Osby et al., 2001). Assim, a somatória das causas naturais e não naturais de morte parecem exercer bastante influência no TB, reduzindo aproximadamente 10 anos a expectativa de vida dos pacientes (Chang et al., 2011). É evidente, portanto, que as taxas de mortalidade se mostram elevadas no TB (Osby et al., 2001; Charlson et al., 2016), impactando de forma expressiva a expectativa de vida desses indivíduos.

A redução na expectativa de vida também está associada ao prejuízo funcional que é uma consequência considerável nos pacientes com TB. A doença está associada a um alto grau de incapacidade quando comparada a outras doenças crônicas como diabetes, asma, osteoartrite e infecção pelo vírus da imunodeficiência humana (Murray, Lopez, 1997). A incapacitação em realizar funções parece estar relacionada aos períodos depressivos. Um estudo de Merikangas e colaboradores (2011) verificou que $74 \%$ dos pacientes já sofreram algum tipo de impedimento funcional grave ou muito grave nos episódios depressivos e $50 \%$ nos episódios de mania/hipomania.

Consequentemente, o TB está associado a taxas de desemprego, 
dificuldades relacionadas ao trabalho, estresse interpessoal e relações sociais prejudicadas. Percebe-se que o TB não só afeta as interações sociais, como favorece uma perda no controle social, estando relacionado também a uma autoconfiança elevada durante episódios de exaltação de humor (Owen et al., 2017). Além disso, dois grandes estudos revelaram taxas de desemprego de cerca de $60 \%$, mesmo entre pacientes com ensino superior completo (Kupfer et al., 2002; Hirschfeld et al., 2003). Numa das pesquisas, $88 \%$ dos entrevistados relataram dificuldades ocupacionais (Hirschfeld et al., 2003). A outra também mostrou que $65 \%$ dos entrevistados tiveram dificuldade em manter relações de longo prazo, e 64\% tinham dificuldade no relacionamento com os filhos (Kupfer et al., 2002).

Todos esses fatores contribuem grandemente para uma piora na qualidade de vida de um paciente com TB. É evidente, portanto, como o TB é um transtorno de grande impacto na vida do indivíduo e dos familiares e sua complexa evolução, associada à presença de quadros sintomáticos diversos, com diversas comorbidades, piora do prognóstico e alto grau de incapacitação impõem maior dificuldade no diagnóstico, na seleção de medicações preventivas e no tratamento adequado que ainda permanece aquém das necessidades dos pacientes.

\subsubsection{Etiologia}

\subsubsection{Neurobiologia}

As bases neurobiológicas do TB são ainda pouco conhecidas (Zivanovic, Nedic, 2012; Maletic, Raison, 2014), apesar dos importantes progressos nas pesquisas. Esses avanços se devem graças aos progressos tecnológicos em áreas do conhecimento, como os estudos de neuroimagem, o sequenciamento de última geração do genoma humano $\mathrm{e}$, consequentemente, um vasto desenvolvimento nos campos de biologia molecular e genética-molecular, que juntos contribuem para elucidar as causas e os muitos mecanismos envolvidos na neuroprogressão da doença.

A genética epidemiológica foi a primeira abordagem a demonstrar, 
através dos estudos em famílias, gêmeos e adotivos, um importante componente genético do TB, como será descrito a seguir:

\subsubsection{Fatores genéticos}

É bem provável que haja envolvimento de um conjunto de fatores genéticos e ambientais que interagem entre si durante as diferentes fases do neuro-desenvolvimento determinando diferentes graus de vulnerabilidade à doença (Brietzke et al., 2012). Estudos de família, gêmeos e de adoção reforçam o caráter não só familial como também um importante componente genético do TB, estimando-se a herdabilidade da doença entre 70 a $80 \%$ (Craddock, Jones, 1999; Taylor et al., 2002; Craddock, Sklar, 2013). Apesar desta alta herdabilidade e do grande número de estudos ao longo das últimas décadas, a tentativa na identificação de variantes genéticas que contribuíssem para a suscetibilidade do TB tem apresentado resultados limitados (Greenwood et al., 2013).

As estratégias de avaliação de genes candidatos têm identificado diversos polimorfismos de nucleotídeo único (SNP, do inglês single nucleotide polymorphism) associados ao aumento de risco, principalmente aqueles em genes relacionados à funcionalidade de monoaminas e glutamato, como os da enzima monoamina oxidase (MAO, do inglês L-monoamine oxidases), do transportador de dopamina (DAT, do inglês dopamine active transporter), do transportador de serotonina (5-HTT, do inglês 5-hydroxytryptamine), da enzima triptofano hidroxilase (TPH2, do inglês tryptophan hydroxylase), dos receptores 2 e 4 de dopamina (D2R e D4R), dos receptores 4 e 2A de serotonina (5-HT4R e 5-HT2AR), das subunidades 1, 2A e 2B do receptor ionotrópico NMDA ( $N$ methyl-D-aspartate receptor) de glutamato (GRIN1, do inglês glutamate ionotropic 6 receptor NMDA type subunit 1), entre outros. Além disso, foram identificados SNPs que conferem risco tanto para TB, DM e esquizofrenia, em genes como os codificadores da enzima catecol O-metiltransferase (COMT, do inglês catechol-O-methyltransferase), do fator neurotrófico derivado do cérebro (BDNF, do inglês brain-derived neurotrophic factor), da neuregulina-1 (NRG-1, do inglês neuregulina-1) e da proteína DISC-1 (disrupted in schizophrenia) 
(Maletic, Raison, 2014). Apesar de estudos com genes candidatos terem gerado alguns resultados positivos, eles raramente foram replicados por outros grupos em amostras independentes, o que torna seus resultados questionáveis, pois tratam-se de efeitos muito pequenos, raros ou até mesmo resultados falso-positivos.

Mais recentemente, estudos de associação utilizando o genoma completo (GWAS, do inglês genome-wide association studies) em TB e subsequentes estudos de metanálises envolvendo milhares de indivíduos evidenciaram associações significativas com novos genes candidatos, entretanto, acredita-se que esses loci encontrados explicam apenas 1-2\% da susceptibilidade genética total para o TB (Burton, 2007; Baum et al., 2008; Ferreira et al., 2008; Sklar et al., 2008; Scott et al., 2009; Smith et al., 2009; Sklar et al., 2011). Um desses maiores estudos investigou 7.841 indivíduos com TB e identificou 34 SNPs associados com o risco para desenvolver esse fenótipo. O estudo confirmou, por exemplo, importantes e já descritas associações com o gene CACNA1C (calcium voltage-gated channel subunit alpha1 $C$ ) e identificou também outros importantes genes associados ao TB como o gene ODZ4 (gene homólogo ao Drosophila pair-rule gene ODZ) (Sklar et al., 2011). De todo modo, esses estudos têm encontrado uma gama de variantes comuns com pequeno efeito (Purcell et al., 2009).

Apesar dos estudos de ligação (linkage) e estudos de associação sugerirem vários loci de vulnerabilidade para o fenótipo, as variantes associadas ao risco para TB ainda permaneceram elusivas (Serretti, Mandelli, 2008). Dessa forma, acredita-se que exista uma grande heterogeneidade no TB, e, portanto, que não exista um único gene afetado, mas numerosas regiões cromossômicas e genes candidatos com evidências significativas no envolvimento do TB, cada uma com pequeno efeito, e que suas relações com o ambiente sejam responsáveis pelo transtorno (Craddock, Sklar, 2013).

\subsubsection{Neuro/somatoprogressão e teoria do envelhecimento acelerado}

O que se têm visto mais recentemente são evidências apoiando a existência de anormalidades clínicas e neurobiológicas progressivas em 
indivíduos com TB, provavelmente associadas a um envelhecimento celular acelerado nesses pacientes (Vasconcelos-Moreno et al., 2017). Observou-se que há uma grande quantidade de integração e sobreposição entre os mecanismos neurobiológicos - incluindo alterações progressivas em nível molecular e celular, e na estrutura e função do sistema nervoso central presentes tanto no TB como nas doenças associadas ao envelhecimento (Rizzo et al., 2014; Lindqvist et al., 2015; Jacoby et al., 2016; VasconcelosMoreno et al., 2017).

As doenças clínicas que são mais frequentes no TB são aquelas mais comumente vistas em pessoas de idades avançadas, relacionadas com 0 envelhecimento, como, por exemplo, doenças cardiovasculares, osteoporose, câncer e demência que têm instigado alguns pesquisadores a caracterizarem o TB como um distúrbio do envelhecimento acelerado (Simon et al., 2006; Rizzo et al., 2014). Sugere-se, assim, que um envelhecimento patológico pode ser componente da doença, evidenciado pelas alterações neurobiológicas e neuroprogressivas similares tanto no TB como no envelhecimento, como: alterações a nível cerebral (diminuição do volume cerebral), bem como alterações a nível imunológico (aumento de citocinas inflamatórias e de células T $\mathrm{CD}^{+} \mathrm{CD}^{2} 8^{-}$circulantes, do inglês cluster of differentiation); alterações mitocondriais; estresse oxidativo (aumento de óxido nítrico, por exemplo) e também senescência celular (encurtamento dos telômeros) (Jacoby et al., 2016; Vasconcelos-Moreno et al., 2017).

Essas evidências, portanto, levantam a hipótese de que certas doenças psiquiátricas como o TB estão associadas ao envelhecimento biológico acelerado no organismo como um todo ou mesmo a nível celular. "Envelhecimento biológico acelerado" ocorre quando a idade biológica (definida fisiologicamente e associada aos processos patológicos) supera a idade cronológica. Assim, sugere-se que os indivíduos com TB estariam com a idade biológica acima da idade cronológica, dado pelos processos patológicos avançados na doença (Lindqvist et al., 2015).

O conhecimento dos processos de envelhecimento e senescência celular, portanto, podem contribuir para a busca de novos e promissores alvos moleculares, que ajudariam a explicar melhor a neuroprogressão em TB 
(Vasconcelos-Moreno et al., 2017). O comprimento telomérico, um parâmetro de senescência celular e alvo do presente estudo, será descrito a seguir:

\subsection{TELÔMERO E COMPRIMENTO TELOMÉRICO}

Telômeros são estruturas especializadas, localizadas no final de cada cromossomo, associadas a proteínas de proteção e constituídas por material genético não-codificante. São repetições (em tandem) da sequência de nucleotídeos 5'-TTAGGG-3', que podem variar de 2 a 15 mil pares de base (pb) (Engelhardt, Finke, 2001). Os telômeros têm como funções principais: manter a integridade e a estabilidade da estrutura cromossômica; mediar a replicação do cromossomo; proteger a porção final dos cromossomos de degradação e rearranjos cromossômicos deletérios (Blackburn, 2000); além de regular 0 processo de envelhecimento celular (Blasco, 2007).

Em células somáticas normais, cada divisão celular está associada à perda de nucleotídeos teloméricos, devido à dificuldade da enzima DNA polimerase em replicar a fita de DNA no sentido 3'-5' (Greider, Blackburn, 1996; Blackburn, 2001). Essa perda de DNA não codificante na porção terminal dos cromossomos resulta em redução do comprimento do telômero (ou telomérico). Quando esta região apresenta um comprimento crítico, ocorre uma sinalização que induz parada de crescimento e senescência celular (Autexier, Greider, 1996; Tollefsbol, Andrews, 2001). Uma das formas de compensar "o problema de replicação final" ou "o problema de replicação das extremidades" (do inglês "end replication problem") e evitar a perda deste material genético, mantendo o tamanho telomérico constante, é a adição de novas cópias 5'-TTAGGG-3'. Isso é realizado pela enzima telomerase - uma ribonucleoproteína que consiste de uma subunidade de RNA e de duas subunidades proteicas - que é expressa principalmente em células embrionárias e em menor quantidade em tecidos adultos (Guilleret, Benhattar, 2003). Porém, se a expressão de telomerase é baixa, os telômeros encurtarão a cada divisão celular devido à replicação incompleta do final de cromossomos lineares.

Dessa forma, o comprimento dos telômeros pode servir como um biomarcador da idade biológica de uma célula, constituindo um "relógio 
molecular" relacionado ao potencial de divisão da célula e ao envelhecimento celular (Epel et al., 2004). Logo, o comprimento telomérico é associado com senescência celular e longevidade, bem como com transtornos associados ao envelhecimento e câncer (Djojosubroto et al., 2003). Isto é, o telômero tende a diminuir progressivamente com a inflamação, o estresse oxidativo e, especialmente, com o envelhecimento (Harley et al., 1990; Svenson et al., 2011).

Diferentes tipos celulares têm taxas específicas de encurtamento telomérico, devido ao próprio tamanho distinto dos telômeros bem como à expressão e atividade da telomerase (Romano et al., 2013). Além disso, o comprimento dos telômeros é influenciado por diferentes fatores genéticos, epigenéticos e ambientais como, por exemplo, o fumo, a atividade física, o índice de massa corpórea, entre outros (Codd et al., 2013; Rode et al., 2014; Arsenis et al., 2017; Astuti et al., 2017) e a taxa de perda telomérica varia com a idade (Frenck et al., 1998) (Figura 2). Devido a essa variação do comprimento telomérico de acordo com a idade, ele pode ser considerado um marcador preditivo da idade biológica do indivíduo.

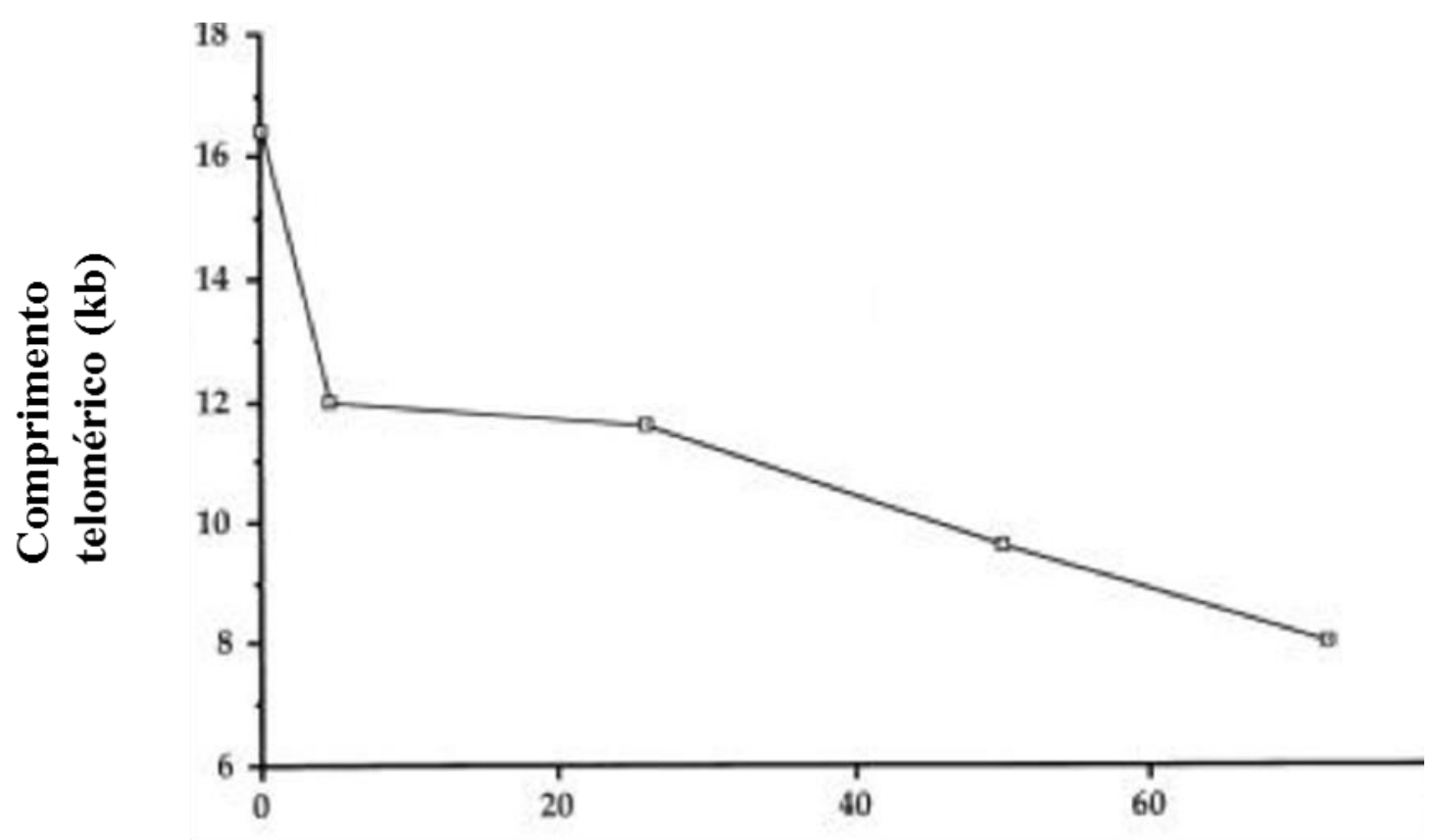

Idade (anos)

FONTE: Adaptado de Frenck et al., 1998

Figura 2 - Fases do encurtamento telomérico em leucócitos do sangue periférico 
Portanto, o encurtamento dos telômeros pode ser entendido como um índice para o estado de saúde dos indivíduos, uma vez que refletiria lesões celulares e tempo de vida (Aviv et al., 2006). O sistema de manutenção dos telômeros/telomerase parece, assim, desempenhar um papel central na biologia do crescimento do tecido normal, reparação e remoção, e a pesquisa nesse campo do envelhecimento celular cresce exponencialmente (Klapper et al., 2001; Xi et al., 2013; Opresko, Shay, 2017).

1.2.1 Estudos epidemiológicos, genéticos e herdabilidade do comprimento telomérico

A partir das evidências empíricas dos estudos epidemiológicos, o comprimento dos telômeros passou a ser associado à senescência celular e longevidade, bem como a distúrbios associados ao envelhecimento (Djojosubroto et al., 2003; Aubert, Lansdorp, 2008; Opresko, Shay, 2017). Estudos epidemiológicos evidenciam correlação entre o encurtamento de telômeros e o aumento da mortalidade por doenças cardiovasculares e infecciosas (Cawthon et al., 2003). Doenças neurodegenerativas severas como a doença de Alzheimer também tem apresentado associação negativa com o comprimento telomérico sendo este um possível fator de risco para o desenvolvimento da doença (Forero et al., 2016) bem como para o aparecimento da demência em adultos com síndrome de Down (Jenkins et al., 2016). Com relação ao câncer, a metanálise mais recente sugere associação de telômeros mais longos com risco para câncer de pulmão ou câncer em homens (Zhang et al., 2017).

Além de o comprimento telomérico estar relacionado à alta mortalidade $\mathrm{e}$ doenças associadas ao envelhecimento, é bem estabelecido na literatura que doenças hereditárias monogênicas como a disceratose congênita, a fibrose pulmonar idiopática e a cirrose hepática são enfermidades ocasionadas pelo encurtamento telomérico excessivo e, por isso, são denominadas de telomeropatias. Defeitos na maquinaria da manutenção telomérica e mutações em proteínas de reparo do DNA que contribuem para preservação dos telômeros estão entre as causas dessas doenças (Opresko, Shay, 2017). 
Estudos mostram a influência de fatores genéticos na biologia do telômero, como, por exemplo, estudos de associação genética que revelam associações entre o tamanho telomérico e SNPs nos genes associados a enzima telomerase: o gene da transcriptase reversa (TERT, do inglês telomerase reverse transcriptase) e o gene da RNA telomerase (TERC do inglês telomerase RNA component) (Atzmon et al., 2009). Outros estudos também identificaram SNPs nos genes associados às proteínas de proteção do telômero como, por exemplo, o POT1 (protection of telomeres 1), que também está associado com longevidade humana, sugerindo que os genes que regulam o comprimento telomérico podem influenciar a longevidade humana (Deelen et al., 2011; Soerensen et al., 2011).

Recentemente, estudos tem reportado a herdabilidade como a principal base para a variação do comprimento telomérico humano. Um estudo de longevidade em famílias estimou em 54\% a herdabilidade do comprimento telomérico de leucócitos em 3.037 indivíduos (Svenson et al., 2011). De acordo com a mais recente metanálise do comprimento telomérico, com 19.713 indivíduos, encontrou-se alta estimativa da herdabilidade para esse traço fenotípico (70\%), além de evidência para um componente de herança materna e uma associação positiva com a idade paterna (Broer et al., 2013). A herdabilidade do comprimento telomérico nos estudos apresentados na metanálise varia entre 34 e $82 \%$, mostrando diferentes e divergentes estimativas - seja pelas diferentes formas que o comprimento telomérico é medido ou pela composição da amostra - que precisam ser reconciliadas e melhor estabelecidas.

Até onde se sabe na literatura, encontrou-se apenas um estudo investigando a herdabilidade geral do comprimento telomérico (a partir da correlação mãe-prole/pai-prole) em transtornos psiquiátricos (Costa Dde et al., 2015). Os autores verificaram em trios com transtorno de déficit de atenção e hiperatividade (TDAH) que, a partir das diferenças interindividuais do telômero encontradas, a herdabilidade geral da doença se mostra como o possível principal mecanismo para explicar essa variação interindividual do comprimento telomérico no TDAH (Costa Dde et al., 2015). É fundamental, portanto, que os futuros estudos que investigam o comprimento telomérico em famílias, trios ou 
estudos de gêmeos, considerem também a forte determinação genética desse parâmetro, dada pela herdabilidade.

\subsubsection{Telômero, envelhecimento celular e estresse oxidativo}

Como foi visto, os telômeros são biomarcadores da idade biológica de um indivíduo, pois tendem a encurtar progressivamente com a idade, inflamação e estresse oxidativo (Aubert, Lansdorp, 2008; Svenson et al., 2011). Estudos apoiam o conceito de que o estresse oxidativo desempenha um papel importante no encurtamento telomérico, sendo um importante modulador da perda de telômeros (Von Zglinicki, 2002; Szebeni et al., 2014; Lindqvist et al., 2015). Além disso, estes sugerem que a defesa atenuada ao estresse oxidativo e a telomerase deficiente contribuem para o encurtamento de telômero em oligodendrócitos em DM (Szebeni et al., 2014). Outro estudo descobriu que o estresse comportamental levou a diminuição do comprimento telomérico em ratos que receberam injeção com corticosterona quando comparados aos controles (Cai et al., 2015), mostrando que também o estresse comportamental pode estar relacionado ao tamanho do telômero. Essas evidências dão suporte à importante associação do estresse oxidativo e comportamental na manutenção do telômero, que deve ser levada em consideração nos futuros estudos.

\subsubsection{Comprimento telomérico e transtorno bipolar}

Um estudo preliminar realizado por Simon e colaboradores (2006) encontrou redução do comprimento dos telômeros de leucócitos periféricos (660 pb) em indivíduos com transtornos do humor (DM e TB), em comparação com controles saudáveis. Dez anos mais tarde, em 2016, uma metanálise envolvendo 14.827 indivíduos demonstrou encurtamento telomérico em diferentes transtornos psiquiátricos estudados: transtornos de ansiedade, transtornos de humor - incluindo DM e TB - e psicoses (Darrow et al., 2016). No que diz respeito especificamente ao TB, tanto a redução de telômero (Lima et al., 2015; Barbe-Tuana et al., 2016; Vasconcelos-Moreno et al., 2017), 
quanto telômeros mais longos (Martinsson et al., 2013; Squassina et al., 2016) foram relatados. No entanto, o comprimento telomérico mais longo é interpretado como o efeito do lítio atuando como um medicamento neuroprotetor durante o tratamento de TB (Martinsson et al., 2013; Squassina et al., 2016).

Até que ponto o curso da doença e a gravidade do TB estão associados ao comprimento telomérico é uma questão pouco explorada, uma vez que estudos de comprimento telomérico em TB são mais raros do que em outras doenças psiquiátricas como, por exemplo, esquizofrenia e depressão. São necessários, dessa forma, mais estudos que elucidem a contribuição do comprimento telomérico na compreensão da recente teoria do TB como distúrbio do envelhecimento acelerado.

\subsubsection{Comprimento telomérico, idade paterna e transtorno bipolar}

Enquanto é bem estabelecido que o telômero encurta com a idade na maioria dos tecidos humanos, nos espermatozoides é uma exceção, pois homens mais velhos têm espermatozoides com telômeros mais longos (Kimura et al., 2008). Isso é explicado pelo fato da atividade da telomerase ser alta nos testículos e pela aparente perda seletiva de células progenitoras com telômero mais curto, representando um mecanismo de plasticidade adaptativa entre gerações ao longo do envelhecimento que permite uma extensão no tempo de vida das linhagens futuras para que se reproduzam em idades avançadas (Eisenberg et al., 2017). Por isso, estudos recentes têm visto que o efeito da idade paterna no telômero pode ser cumulativo ao longo das gerações (De Meyer et al., 2007; Eisenberg et al., 2012). Como dito anteriormente, um estudo de metanálise também encontrou uma associação positiva entre idade paterna no nascimento e comprimento telomérico da prole (Broer et al., 2013), ou seja, quanto maior a idade paterna no nascimento maior o comprimento telomérico da prole.

Por outro lado, há algumas evidências de que a idade paterna avançada parece conferir um maior risco para algumas doenças, entre elas, alguns transtornos psiquiátricos. Por exemplo, tem-se observado que a idade paterna 
avançada pode ser um fator de risco para o TB (Frans et al., 2008) e para a esquizofrenia (Sipos et al., 2004; Malaspina et al., 2014). Apesar disso, um estudo mais recente de Malaspina e colaboradores (2014) observou que na esquizofrenia, a idade paterna avançada e o histórico familiar - dois fatores de risco - estão significativamente associados com telômeros longos em homens com esquizofrenia. Entretanto, esses estudos são poucos e inconsistentes. Com relação ao $\mathrm{TB}$, pouco se sabe sobre a relação entre comprimento telomérico e idade paterna avançada em história familiar para TB, bem como a relação entre idade paterna e efeitos positivos ou negativos nos telômeros das futuras gerações não são bem esclarecidas. 


\section{JUSTIFICATIVA}

Até o momento, os estudos que procuram evidenciar um envelhecimento celular acelerado no TB através da associação com o tamanho dos telômeros são ainda em número limitado e geralmente inconclusivos. Estudos de famílias com vários membros afetados por TB envolvendo medidas dos telômeros não são encontrados na literatura científica até então. Portanto, a presente proposta de trabalho procurou contribuir nesse tema através da investigação do comprimento dos telômeros de leucócitos de indivíduos afetados e não afetados pelo TB em várias famílias brasileiras previamente selecionadas. Procurou-se também correlacionar esses dados com a gravidade da doença dos indivíduos afetados e com outras variáveis. Acredita-se que a abordagem recente de avaliar o comprimento telomérico em famílias com TB apresenta grande potencial para esclarecer melhor se, de fato, a hipótese do envelhecimento acelerado nessa doença é plausível e mediada pela biologia do telômero, podendo elucidar uma maior compreensão da patologia e neuroprogressão da doença. 


\section{OBJETIVO}

\subsection{OBJETIVO GERAL}

O objetivo geral do presente estudo foi investigar o comprimento telomérico, um dos parâmetros do processo de envelhecimento celular, em famílias com vários membros com o diagnóstico de TB.

\subsection{OBJETIVOS ESPECÍFICOS}

a) Investigou-se a diferença no comprimento telomérico entre os membros das famílias, com e sem o diagnóstico para TB, em células brancas do sangue periférico (leucócitos);

b) Associou-se o comprimento telomérico com informações clínicas dos indivíduos que indicam gravidade da doença, como, por exemplo: curso da doença, tempo de hospitalização total, ideação suicida, entre outros;

c) Procurou-se obter um modelo geral final que melhor explicasse a variação do comprimento telomérico entre as diferentes famílias, de acordo com as variáveis do estudo;

d) Verificou-se a associação entre idade paterna no nascimento dos filhos com o comprimento telomérico da prole;

e) Capturou-se a variabilidade genética existente do comprimento telomérico entre as famílias pela estimativa da herdabilidade na amostra de estudo. 


\section{HIPÓTESES}

As hipóteses do presente estudo foram:

a) Existe diferença no comprimento telomérico entre membros com TB membros saudáveis;

b) O comprimento telomérico dos membros com TB é menor do que os dos indivíduos normais;

c) Quanto maior a gravidade da doença, evidenciada pelos parâmetros clínicos, menor o comprimento telomérico dos indivíduos com a doença;

d) Idade paterna avançada está associada positivamente ao comprimento telomérico da prole;

e) O comprimento telomérico apresenta alta herdabilidade nas famílias do estudo. 


\section{MATERIAL E MÉTODOS}

\subsection{SELEÇÃO DAS FAMÍLIAS}

O desenho do estudo foi de corte transversal, de uma população composta por 22 famílias com vários indivíduos com TB, oriundas do biorrepositório de amostras do Programa de Genética e Farmacogenética (ProGene) do Instituto de Psiquiatria do Hospital das Clínicas da Faculdade de Medicina da Universidade de São Paulo (IPq-HC-FMUSP).

A amostra utilizada faz parte de um estudo iniciado entre os anos de 1993 e 1997, chamado "Genética das Psicoses" e com apoio financeiro da Comunidade Econômica Europeia ("London-São Paulo Collaborative Project on the Molecular Genetics of the Major Psychoses" - Contract Number: Cl1-CT920010). O objetivo do projeto consistiu em selecionar famílias com vários membros com diagnóstico de esquizofrenia e de TB e em coletar dados clínicos, bem como amostra biológica (sangue) dos indivíduos, para futuros estudos genético-epidemiológicos e genético-moleculares.

As famílias foram submetidas à uma triagem inicial e os critérios para inclusão no estudo foram:

a) Pelo menos dois indivíduos de cada família deveriam ter o diagnóstico, segundo os critérios do Research Diagnostic Criteria (RDC), para DM, transtorno esquizoafetivo e TB;

b) Os indivíduos avaliados deveriam ter idade superior a 18 anos (aspectos éticos);

c) Ausência de bilinealidade, para evitar o viés de quadros de transtornos combinados e para melhor diagnóstico da expressão dos transtornos; assim, a doença deveria ter ou linhagem paterna ou linhagem materna.

Para o presente estudo, foram selecionados 143 indivíduos de 22 famílias para análise do comprimento telomérico, dos quais 60 indivíduos apresentavam TB (foram excluídas as famílias que não continham ou continham apenas uma amostra de sangue presentes no biorrepositório). Os heredogramas que representam a estrutura das 22 famílias estão no ANEXO A. 


\subsection{AVALIAÇÃO CLÍNICO-PSIQUIÁTRICA}

As famílias contendo múltiplos afetados pelo TB foram inicialmente identificadas pelo método "Estudo de Famílias", em inglês: Family History (Tsuang et al., 1977; Leckman et al., 1987), que colhe informações através de entrevistas com cada participante da pesquisa, reunindo os potenciais indivíduos.

Após a seleção, foram utilizadas duas entrevistas para a avaliação de cada indivíduo: Schedule for Affective Disorders and Schizophrenia - Lifetime (SADS-L), em sua versão em português (Roteiro para Distúrbios Afetivos e Esquizofrenia - versão para a vida toda), sob responsabilidade do Prof. Valentim Gentil Filho (Spitzer et al., 1975); e Operational Criteria - OPCRIT (versão 3.3), um programa computacional utilizado para coleta de dados e para verificar a presença de sinais e sintomas psiquiátricos (Mcguffin et al., 1991).

O SADS-L fornece, além do diagnóstico atual e pregresso, informações diretas pelo RDC, tais como sexo, idade, estado civil, grau de escolaridade, idade de início do quadro psicopatológico, presença de sintomas associados, comorbidades e histórico de tratamento ambulatorial ou hospitalar (Spitzer et al., 1975; Endicott, Spitzer, 1978). Além disso, o SADS é organizado como uma entrevista diagnóstica semi-estruturada que permite mais flexibilidade do que entrevistas completamente estruturadas, pois os entrevistadores podem usar suas próprias palavras, reformular perguntas e julgamentos clínicos, eliminando muitas vezes os vieses de averiguação. Esse questionário foi aplicado por um psiquiatra e conferido por outro profissional da mesma área. Quando houve divergência na avaliação dos resultados, um terceiro avaliador, também psiquiatra, determinou a decisão final do diagnóstico.

O OPCRIT 3.3 é um sistema eletrônico confiável e fácil de aplicar que consta com 90 questões e utiliza 12 sistemas classificatórios para diagnóstico psiquiátrico: DSM-III, DSM-III-R, CID-10, Critério de St. Louis, RDC, Critérios de Taylor e Abrams, Critério de Carpenter para esquizofrenia, Sintomas de Primeira Ordem de Schneider, subtipos de esquizofrenia segundo Tsuang, Winokur, Crow e Farmer, como também conceitos franceses de psicoses não afetivas segundo Pichot e Pull (Mcguffin et al., 1991). 
Informações sobre tipo de abordagem terapêutica utilizada e melhora do tratamento também foram coletadas e, quando possível, medicações e doses utilizadas no passado e/ou no momento da entrevista. É importante relatar que nem todos os membros das famílias selecionadas passaram por avaliações clínico-psiquiátricas ou tiveram amostra de sangue coletadas (os membros que passaram por avaliações clínico-psiquiátricas e tiveram coleta de material biológico estão identificados nos heredogramas).

\subsection{VARIÁVEIS CLÍNICAS - DIRETRIZES E CLASSIFICAÇÕES DO OPCRIT}

As variáveis clínicas incluídas no presente estudo foram extraídas do OPCRIT (e algumas também do SADS-L) para todos os indivíduos afetados por algum transtorno psiquiátrico, não apenas para TB. Um total de oito variáveis clínicas foi incluído na análise: status da doença (que na análise estatística foram subdivididos em grupos bipolares $x$ saudáveis e doentes $x$ saudáveis), idade de início da doença, tempo de hospitalização total, tempo de doença, interação social, ideação suicida, curso da doença e comorbidades (Tabela 2). Para melhor entendimento dos resultados e gráficos, é importante relatar a seguir uma breve descrição de algumas dessas variáveis de acordo com as Diretrizes e Classificações do OPCRIT:

A ideação suicida é classificada como "preocupação com pensamentos de morte" (não necessariamente de si próprio) acompanhados dos seguintes sintomas: pensamentos suicidas, desejo de morte, tentativa de matar a si próprio. O score "0" significa ausência de ideação suicida; "1", quando há duração de pelo menos uma semana ou tentativa de suicídio; "2", duração de pelo menos duas semanas e "3", quando os sintomas perduram por pelo menos um mês (Mcguffin et al., 1991).

O curso da doença apresenta a gravidade da doença do indivíduo no momento da avaliação, sendo, portanto, pontuado de forma hierárquica: score "1", para quem apresentou um único episódio com boa recuperação; "2", para múltiplos episódios com boa recuperação; "3", para múltiplos episódios com recuperação parcial; "4", para doença crônica contínua (DCC) e "5", para DCC com deterioração (Mcguffin et al., 1991). 


\subsection{REVISÃO DOS DADOS CLÍNICOS}

Os dados coletados e descritos nos itens anteriores foram realizados na década de 90 por diferentes psiquiatras. Por isso, antes de iniciar a parte experimental de avaliação do comprimento telomérico, foi necessário realizar uma completa revisão e reorganização dos dados clínicos de cada indivíduo das 22 famílias do estudo. Para cada família foram então organizadas pastas contendo as informações das entrevistas clínico-psiquiátricas de cada membro, com dados do SADS-L e do OPCRIT. Também nessas pastas contém os dados das vinhetas de cada indivíduo pertencente à sua respectiva família.

\subsection{BANCO DE DADOS}

Depois de organizar as pastas contendo todas as informações dos indivíduos foi construído ao longo do projeto um banco de dados com todas as variáveis do estudo que incluiu as variáveis clínicas, citadas nos itens acima; as demográficas e não-clínicas como sexo, idade, escolaridade, idade materna e paterna; as informações das famílias com identificações do próprio indivíduo e do pai e da mãe de cada integrante do estudo (necessárias para a construção das matrizes de relacionamento, que serão melhor explicitadas na subseção da análise estatística), além dos dados da variável resposta do comprimento telomérico, obtidos após os experimentos de PCR (Polymerase Chain Reaction) em tempo real.

\subsection{ANÁLISE DA INTEGRIDADE E QUALIDADE DO DNA}

O sangue periférico dos indivíduos do estudo foi coletado em tubo contendo anticoagulante EDTA (ethylenediamine tetraacetic acid) e a extração de DNA genômico de leucócitos foi realizada com fenol tamponado, que provoca a desnaturação das proteínas de maneira eficiente. O clorofórmio também foi usado como agente desnaturante das proteínas contidas na amostra. As amostras foram mantidas a $-20^{\circ} \mathrm{C}$ até o presente momento, e, como foram armazenadas há mais de 20 anos em biorrepositório, foi feita uma 
reavaliação da qualidade do material.

Para o presente projeto todas as 143 amostras de DNA do estudo foram quantificadas novamente através do aparelho NanoDrop (Thermo Scientific, Waltham, Massachusetts, USA) e, para averiguar a qualidade do material extraído, também foram verificadas as razões entre os comprimentos de onda 260/230nm (relação ácidos nucleicos/compostos químicos) e 260/280nm (relação ácidos nucleicos/proteína). É importante ressaltar que para os (poucos) tubos de armazenamento das amostras de DNA que se encontravam vazios devido ao tempo, foram acrescentados água destilada e deixados overnight em banho-maria para ressuspensão do DNA.

Já a integridade do DNA foi avaliada por eletroforese em gel de agarose $1,5 \%$. Tanto a quantificação quanto a eletroforese em gel demonstraram ótima qualidade e integridade do DNA leucocitário dos indivíduos do estudo, permitindo então a avaliação do comprimento telomérico com a técnica de PCR em tempo real.

\subsection{QUANTIFICAÇÃO RELATIVA DO COMPRIMENTO TELOMÉRICO VIA PCR EM TEMPO REAL QUANTITATIVO}

A quantificação do comprimento da região telomérica foi mensurada via técnica de PCR em tempo real quantitativo, padronizada e adaptada através do método descrito anteriormente por Cawthon (2002; 2009). A técnica consiste em determinar, através do método da curva-padrão relativa, a razão relativa (razão $T / S$ ) entre o número de cópias da região telomérica $(T)$ e o número de cópias de um gene de cópia única (S). Essa razão representa a medida relativa do comprimento telomérico de cada indivíduo. Nesse método, as reações de amplificação de $T$ e $S$ foram realizadas em singleplex, mas para diminuir os vieses bem como o efeito dos erros de pipetagem, foi utilizada uma ponteira multicanal.

Antes de realizar os experimentos de PCR para a avaliação do comprimento telomérico, as amostras foram todas diluídas para $1 \mathrm{ng} / \mu \mathrm{l}$, segundo a padronização realizada no laboratório. A curva-padrão, para a região telomérica e para o gene de cópia única, foi composta de cinco pontos 
em uma diluição seriada (1:5), utilizando como DNA padrão um pool de DNA de 10 amostras controles (concentração inicial a $10 \mathrm{ng} / \mu \mathrm{l}$ ). O gene de cópia única escolhido foi o da $\beta$-globina, já que é um gene constitutivo, presente em todos os tecidos e em todas as fases do desenvolvimento.

Foi utilizado o fluoróforo $S Y B R^{\mathrm{TM}}$ Green (2 $\mu$ por reação) como repórter (Power SYBR® Green PCR Master Mix, Applied Biosystems, Foster City, California, USA). Os primers utilizados (Invitrogen, Thermo Scientific) para a região telomérica (Tel) e para o gene da $\beta$-globina (HBG) se encontram na Tabela 1. A concentração final dos primers (forward + reverse) para Tel e HBG, utilizadas nas reações, foi de $5 \mu \mathrm{M}$, a partir da diluição de primer feita na escala de 1:20 da solução estoque à $100 \mu \mathrm{M}$.

As reações de PCR foram realizadas em placas de 384 poços com o equipamento QuantStudio ${ }^{\mathrm{TM}} 7$ Flex Real-Time PCR System (Applied Biosystems). As condições de temperatura da PCR para os primers de Tel e HBG foram 95 $\mathrm{C}$ por 2 minutos, seguido de 40 ciclos de 95 $\mathrm{C}$ por 15 segundos e $62^{\circ} \mathrm{C}$ por 1 minuto. É importante ressaltar que em cada placa de PCR foram colocadas três diferentes amostras calibradoras ("interplate calibrators") para eliminar o viés de possíveis variações entre uma placa e outra. Ao término de cada reação, foi também realizada a curva de dissociação (curva de melting) para verificar a especificidade da reação.

Tabela 1 - Sequência dos primers utilizados na reação de PCR em tempo real

\begin{tabular}{llc}
\hline Alvo & & \multicolumn{1}{c}{ Sequência do Primer } \\
\hline \multirow{2}{*}{ Tel } & Forward & 5'-CGGTTTGTTTGGGTTTGGGTTTGGGTTTGGGTTTGGGTT-3' \\
& Reverse & 5'-GGCTTGCCTTACCCTTACCCTTACCCTTACCCTTACCCT-3' \\
\hline \multirow{2}{*}{ HBG } & Forward & 5'-GCTTCTGACACAACTGTGTTCACTAGC-3' \\
& Reverse & 5'-CACCAACTTCATCCACGTTCACC-3' \\
\hline
\end{tabular}

NOTA: Os primers para a região telomérica utilizados nesse estudo não apresentam sequência idêntica aos do artigo de referência; são primers mais otimizados e menos instáveis do que os referidos no artigo.

Após a amplificação de cada fragmento, o aparelho gerou duas curvaspadrão, uma curva padrão para T e outra para S. Nessas curvas, o aparelho 
interpolou o valor do Cycle Threshold $(\mathrm{Ct})$ - a intersecção entre a curva de amplificação e a linha de threshold - de cada amostra de interesse (processadas em triplicata) para encontrar a quantidade de DNA correspondente (em ng). O aparelho gerou não só o valor do $\mathrm{Ct}$ e da quantidade em ng, como também a média (do Ct e da quantidade em ng) e o desvio-padrão entre as triplicatas.

Por fim, a razão T/S foi calculada para cada amostra segundo a fórmula:

$$
\text { razão } \frac{T}{S}=\frac{\text { média da quantidade de } T(n g)}{\text { média da quantidade de } S(n g)}
$$

Após a obtenção de todos os cálculos da razão T/S que representam o comprimento telomérico relativo dos indivíduos, essa variável foi, então, acrescentada no banco de dados para as futuras análises estatísticas.

\subsection{ANÁLISE ESTATÍSTICA}

Para a análise descritiva do comprimento telomérico, foram calculadas medidas-resumo (média, desvio-padrão, quartis, entre outros) para a razão $\mathrm{T} / \mathrm{S}$, como também para as variáveis coletadas no estudo e, para melhor visualização da distribuição da variável resposta, foram gerados histogramas e boxplots (diagrama de caixa). Para o teste da normalidade dos dados, foi utilizado o teste estatístico de Kolmogorov-Smirnov (D). A análise estatística foi realizada com o auxílio do software $R$, versão 3.2.0. O nível de significância ( $\alpha$ ) adotado, em todos os testes estatísticos, foi $<0,05$.

\subsubsection{Modelo misto poligênico e cálculos de herdabilidade}

Todas as análises que associaram o comprimento telomérico com as diferentes covariáveis, bem como o cálculo estimado de herdabilidade do comprimento telomérico, foram realizados no software $R$, versão 3.2.0, através do pacote Coxme, utilizando a função Imekin. Alguns cálculos também foram confirmados no programa SOLAR (Sequential Oligogenic Linkage Analysis 
Routines), versão 6.6.2. Por ser uma amostra não independente e com o intuito de levar em consideração a estrutura familiar dos dados do presente estudo na análise estatística foi ajustado o modelo misto poligênico (Lange, 2002). Esse modelo é baseado na decomposição genética do fenótipo $y_{i}$, sendo descrito como uma função linear de traço quantitativo e é dado por:

$$
y_{i}=\mu+\beta_{j} X_{i j}+g_{i}+e_{i}
$$

\section{Em que:}

a) $y_{i}$ é o vetor que representa a variável resposta, ou seja, o fenótipo de interesse (no caso, o comprimento telomérico representado pela razão $\mathrm{T} / \mathrm{S})$;

b) $\mu$ é o intercepto, isto é, a média global (valor basal constante) da resposta $y_{i}$;

c) $X_{i j}$ representa a matriz de delineamento fixa, ou seja, a matriz de covariáveis (variáveis explicativas) relevantes na explicação da resposta $y_{i}$

d) $\beta_{j}$ é o vetor de parâmetros (coeficientes) associados às covariáveis (efeitos fixos ambientais);

e) $g_{i}$ representa a matriz de relacionamento (matriz $\phi$ ), ou seja, o vetor dos efeitos aleatórios poligênicos associados à estrutura de famílias (também chamado de componente herdável ou genético);

f) $e_{i}$ é o vetor de erros associado ao modelo, também chamado de efeito aleatório residual (é a parte que o modelo proposto não conseguiu explicar, seja por "falta" de covariáveis importantes, seja pela natureza puramente aleatória do fenótipo).

A estimativa dos efeitos de cada covariável incluída $\left(\beta_{j}\right)$, e sua respectiva significância estatística, é realizada pelo modelo por meio do teste de Wald. É importante ressaltar também que a estrutura de relacionamento e correlação familiar, obtidas através dos heredogramas das famílias estudadas, é incorporada ao modelo em seu termo aleatório pela matriz de relacionamento 
(matriz kinship: $\phi$ ), composta por valores que indicam o grau de parentesco de cada indivíduo estudado com os demais e que no modelo está relacionada ao efeito aleatório poligênico (Almasy, Blangero, 1998). Como apenas indivíduos de uma mesma família são correlacionados devido ao parentesco consanguíneo, a matriz $\phi$ assume a conformação bloco-diagonal, isto é, composta de blocos (submatrizes) contendo os valores de correlação intrafamiliar e nula entre famílias. Assim, a matriz de relacionamento leva em consideração o componente genético compartilhado entre indivíduos da mesma família, por exemplo: o componente genético compartilhado entre pai e filho é igual a meio; entre irmãos, meio; entre avô e neto, um quarto; e entre esposo e esposa, zero (Weir et al., 2006). A inclusão dessa matriz no modelo de associação é muito relevante, pois reduz a variabilidade para cada uma das covariáveis acrescentadas e aumenta a chance de obtenção de valores de $p$ significativos, ou seja, da detecção do que, de fato, interfere na variabilidade do comprimento telomérico.

O uso desta classe de modelos possibilita o cálculo de diversas medidas para o entendimento da relação do fenótipo com componentes herdáveis e ambientais. A principal na área de genética é, sem dúvida, o cálculo de herdabilidade. Por definição, a herdabilidade de um traço "é a proporção da variação total fenotípica que é devido às diferenças genéticas dos indivíduos" (Cummings, 2010). No contexto dos modelos poligênicos mistos, a estimativa da herdabilidade é análoga ao cálculo do coeficiente de correlação intra-classe (Koch, 2006), que objetiva exprimir em termos matemáticos a contribuição relativa da variabilidade genética dentro das famílias (componente herdável) sobre a variabilidade total do fenótipo.

Matematicamente, a variância fenotípica total $\left(\sigma_{g}^{2}+\sigma_{e}^{2}\right)$ é o resultado da somatória da variância poligênica $\left(\sigma_{g}^{2}\right)$, atribuída ao efeito genético, mais a variância ambiental $\left(\sigma_{e}^{2}\right)$, atribuída ao efeito residual (De Andrade et al., 1999). Assim, a herdabilidade $\left(h^{2}\right)$ é calculada como a proporção da variabilidade fenotípica total que é atribuída ao efeito genético e é dada pela fórmula: 


$$
h^{2}=\frac{\sigma_{g}^{2}}{\sigma_{g}^{2}+\sigma_{e}^{2}}
$$

Por fim, com esta formulação matemática definida, podem-se estudar os efeitos dos componentes genéticos (herdabilidade) no desenho de estrutura familiar. 


\section{RESULTADOS}

\subsection{CARACTERIZAÇÃO DA POPULAÇÃO DE ESTUDO}

A população de estudo foi composta de 22 famílias $(N=143)$, com vários membros afetados por transtornos psiquiátricos, sendo que a doença psiquiátrica mais prevalente foi o TB, correspondendo a $42 \%$ da população total (Tabela 2). Homens e mulheres não diferiram expressivamente quanto à média de idade, apresentando ambos os grupos uma média total relativamente alta ( 45 anos), indicando que a população de estudo foi em sua maioria composta por adultos.

Tabela 2 - Caracterização da população de estudo

\begin{tabular}{cccc}
\hline Variáveis & Homens & Mulheres & TOTAL, N (\%) \\
\hline Idade (anos) & 46,9 & 43,5 & 45 \\
Média & 43 & 40 & 40 \\
Mediana & 17,9 & 13,6 & 15,7 \\
Desvio-padrão & & & \\
Escolaridade (anos) & 3 & 1 & $4(2,8)$ \\
17 ou mais & 0 & 6 & $6(4,2)$ \\
15 & 3 & 3 & $6(4,2)$ \\
14 & 10 & 7 & $17(11,9)$ \\
11 & 2 & 6 & $8(5,6)$ \\
9 a 10 & 13 & 18 & $31(21,7)$ \\
7 a 8 & 31 & 40 & $71(49,7)$ \\
Abaixo de 7 & & & \\
Status da doença & 26 & 22 & $48(33,6)$ \\
Saudável & 26 & 34 & $60(42)$ \\
Transtorno Bipolar & 4 & 13 & $17(11,9)$ \\
Depressão Maior & 2 & 3 & $5(3,5)$ \\
Depressão Menor & 2 & 3 & $5(3,5)$ \\
Transtorno Esquizoafetivo & 0 & 4 & $4(2,8)$ \\
Depressão Intermitente & 1 & 1 & $2(1,4)$ \\
Alcoolismo & 0 & 1 & $1(0,7)$ \\
Hipomania & 1 & & $1(0,7)$ \\
Demência & & & $c 0 n t i n u a$
\end{tabular}


Tabela 2 (cont.) - Caracterização da população de estudo

\begin{tabular}{|c|c|c|c|}
\hline Variáveis & Homens & Mulheres & TOTAL, N (\%) \\
\hline \multicolumn{4}{|l|}{ Comorbidades $^{a}$} \\
\hline Não & 18 & 34 & $52(52,5)$ \\
\hline Sim & 19 & 28 & $47(47,5)$ \\
\hline \multicolumn{4}{|l|}{ Ideação Suicida } \\
\hline Não & 29 & 42 & $71(64)$ \\
\hline Pelo menos 1 semana & 9 & 15 & $24(21,6)$ \\
\hline Pelo menos 2 semanas & 1 & 2 & $3(2,7)$ \\
\hline Pelo menos 1 mês & 4 & 9 & $13(11,7)$ \\
\hline \multicolumn{4}{|l|}{ Curso da doença } \\
\hline Único episódio & 6 & 6 & $12(13,3)$ \\
\hline Muitos episódios c/ boa recuperação & 12 & 26 & $38(42,2)$ \\
\hline Muitos episódios c/ recuperação parcial & 8 & 15 & $23(25,6)$ \\
\hline Doença crônica contínua & 4 & 9 & $13(14,4)$ \\
\hline Doença crônica contínua com & 4 & 0 & $4(4,4)$ \\
\hline \multicolumn{4}{|l|}{ Tempo de hospitalização total (anos) } \\
\hline Média & 3 & 3,4 & 3,3 \\
\hline Mediana & 3 & 3 & 3 \\
\hline Desvio-padrão & 1,8 & 2,3 & 2,1 \\
\hline \multicolumn{4}{|l|}{ Idade de início da doença (anos) } \\
\hline Média & 24,7 & 22,8 & 23,5 \\
\hline Mediana & 20,5 & 20 & 20 \\
\hline Desvio-padrão & 11,7 & 9,1 & 10,2 \\
\hline \multicolumn{4}{|l|}{ Tempo de doença (anos) } \\
\hline Média & 16,9 & 18 & 17,6 \\
\hline Mediana & 17 & 17 & 17 \\
\hline Desvio-padrão & 10,5 & 11,7 & 11,2 \\
\hline \multicolumn{4}{|l|}{ Idade materna no nascimento (anos) ${ }^{\mathrm{b}}$} \\
\hline Média & 27,8 & 29,5 & 28,8 \\
\hline Mediana & 28 & 29 & 28,5 \\
\hline Desvio-padrão & 6,2 & 6 & 6,1 \\
\hline \multicolumn{4}{|l|}{ Idade paterna no nascimento (anos) ${ }^{c}$} \\
\hline Média & 33,1 & 35,3 & 34,4 \\
\hline Mediana & 31,5 & 34 & 33 \\
\hline Desvio-padrão & 7,2 & 9 & 8,3 \\
\hline \multicolumn{4}{|l|}{ Interação social $^{a}$} \\
\hline Sim & 45 & 44 & $89(76,1)$ \\
\hline Não & 7 & 21 & $28(23,9)$ \\
\hline
\end{tabular}


Tabela 2 (cont.) - Caracterização da população de estudo

\begin{tabular}{cccc}
\hline Variáveis & Homens & Mulheres & TOTAL, N (\%) \\
\hline Razão T/S & & & \\
Média & 1,4 & 1,4 & 1,4 \\
Mediana & 1,4 & 1,4 & 1,4 \\
Desvio-padrão & 0,3 & 0,3 & 0,3 \\
\hline TOTAL, N (\%) & $62(43,4)$ & $81(56,6)$ & $143(100)$ \\
\hline
\end{tabular}

Legenda: ${ }^{a}$ As comorbidades psiquiátricas mais frequentes apresentadas foram: DM, alcoolismo e transtornos de ansiedade (principalmente fobias). ${ }^{b} n$ total de indivíduos que apresentavam idade materna no nascimento $=86 .{ }^{\circ} n$ total de indivíduos que apresentavam idade paterna no nascimento $=66 .{ }^{d}$ Interação social $=$ a sociabilidade foi medida pela presença ou ausência de participação em atividade em grupo. ${ }^{e}$ Razão $T / S=$ quantificação relativa do comprimento telomérico

\subsection{ANÁLISE DESCRITIVA DA VARIÁVEL COMPRIMENTO TELOMÉRICO}

O teste de normalidade de Kolmogorov-Smirnov realizado para a variável dependente (razão T/S) revelou normalidade da resposta, ou seja, a variável apresenta distribuição normal $(D=0,052, p$ valor $=0,834)$. Para a razão $\mathrm{T} / \mathrm{S}$, o gráfico quantil-quantil da probabilidade normal está representado na Figura 3. O gráfico mostra um único indivíduo fora do envelope de confiança, que não interferiu nas suposições das modelagens realizadas.

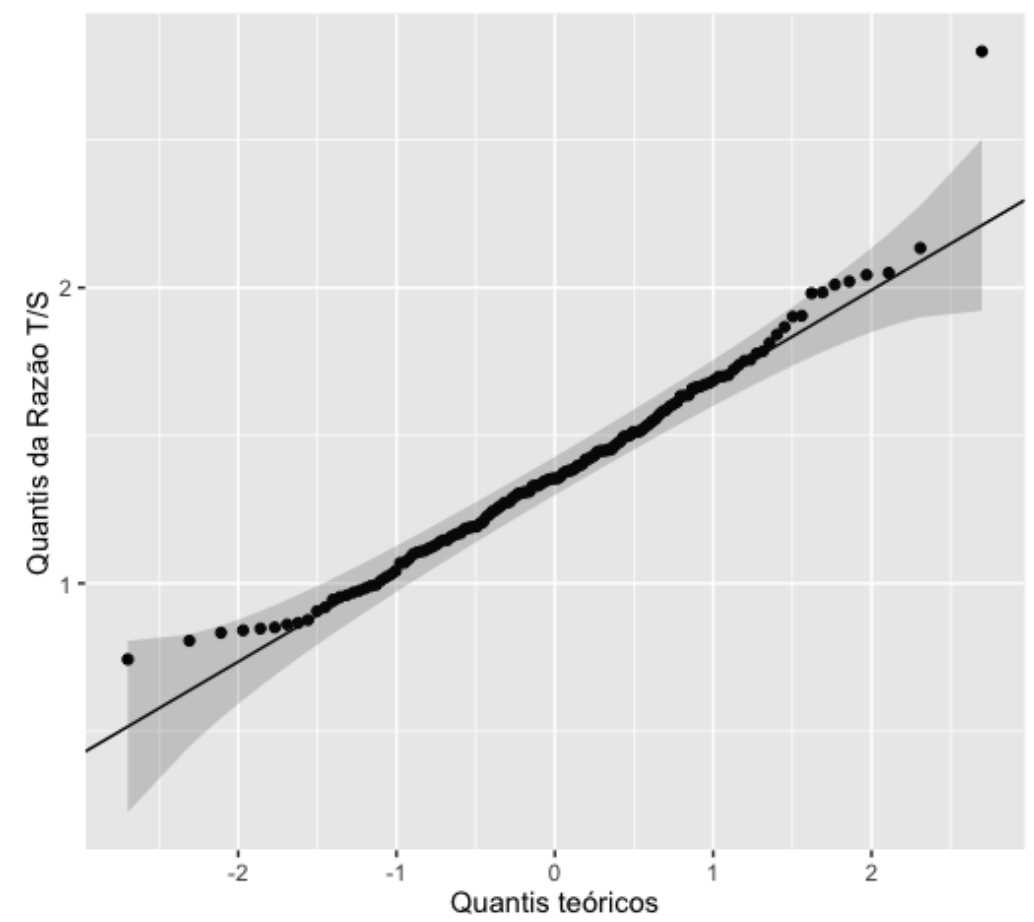

Figura 3 - Gráfico quantil-quantil da razão T/S. Os dados apresentam distribuição normal para a variável resposta razão $T / S(D=0,052, p$ valor $=0,834)$. $O$ indivíduo fora do intervalo de confiança não interferiu nas futuras análises 
A covariável sexo não diferiu significativamente quanto ao comprimento telomérico ( $p=0,412$, no modelo poligênico final). $O$ resumo de informações da variável razão T/S entre os sexos está apresentado na Tabela 3.

Tabela 3 - Comparação da razão T/S entre homens e mulheres

\begin{tabular}{|c|c|c|}
\hline & Homens $(n=62)$ & Mulheres $(n=81)$ \\
\hline Média & 1,4 & 1,4 \\
\hline Mediana & 1,4 & 1,4 \\
\hline Desvio-padrão & 0,3 & 0,3 \\
\hline CV (\%) ${ }^{a}$ & 24,1 & 23,5 \\
\hline Mínimo & 0,7 & 0,9 \\
\hline Máximo & 2 & 2,8 \\
\hline
\end{tabular}

Legenda: ${ }^{a} \mathrm{CV}=$ Coeficiente de variação. Não houve diferença estatisticamente significante na média do comprimento telomérico (razão T/S) entre homens e mulheres $(p=0,412)$

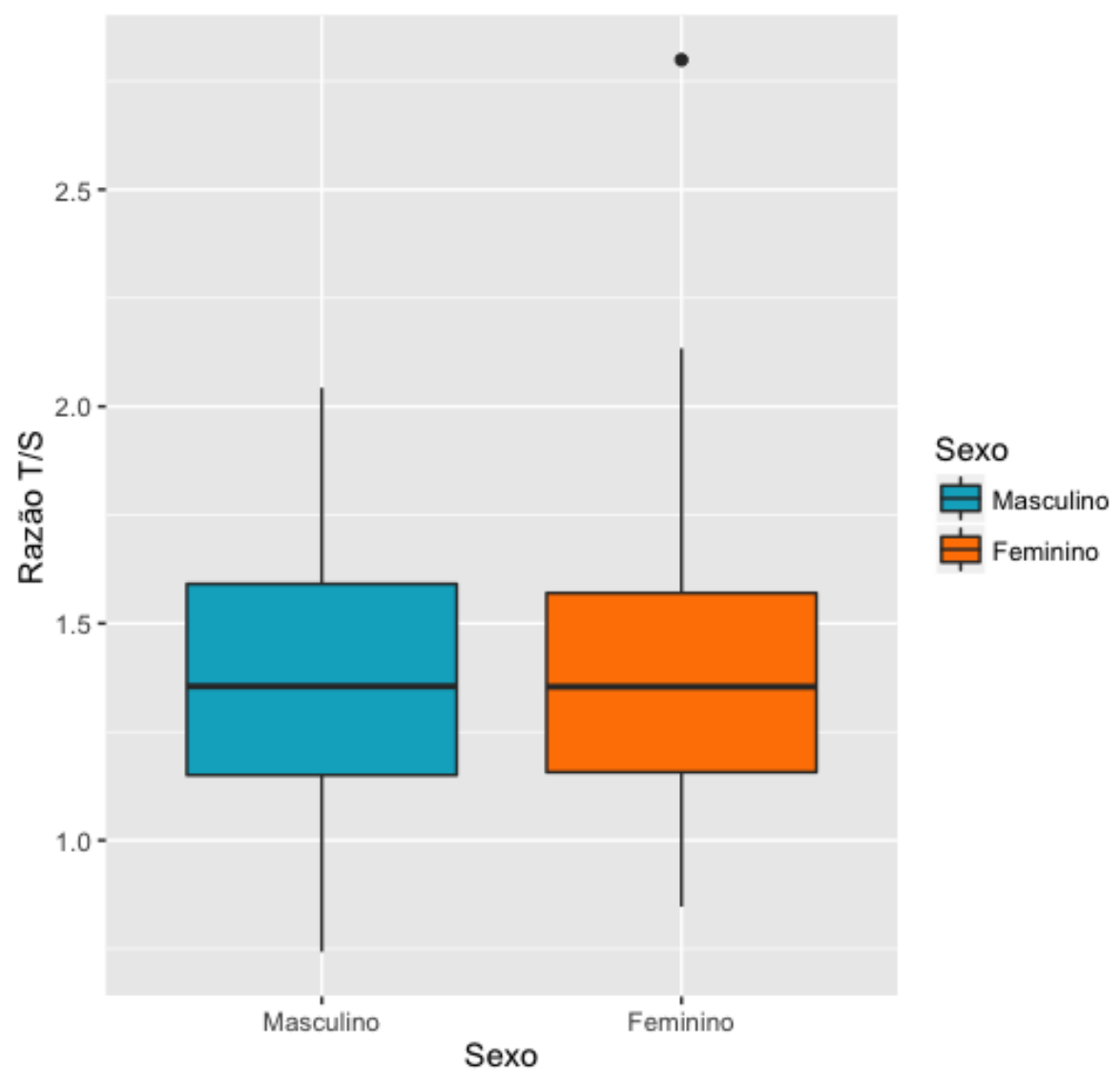

Figura 4 - Comparação da razão T/S entre homens e mulheres. Boxplot da razão T/S entre homens e mulheres. Não houve diferença estatisticamente significante ( $p=$ $0,412)$ entre homens $(n=62)$ e mulheres $(n=81)$ 
A distribuição da razão T/S por sexo também pode ser observada através do boxplot na Figura 4. Percebe-se que a variação da característica é semelhante entre os sexos.

Quando se verificou a dispersão da idade em relação à variável dependente, notou-se que houve uma linha de tendência (calculada via regressão não-paramétrica loess), indicando que o comprimento telomérico decresce com a idade (Figura 5). Percebeu-se também que a curva mais acentuada ocorre nos primeiros anos de vida; dos 30 aos 50 anos parece estabilizar e, a partir dos 50 anos, decresce novamente com maior acentuação a partir dos 70 anos.

De fato, a associação entre idade e comprimento telomérico no modelo poligênico mostrou que houve associação estatisticamente significante com efeito negativo entre as duas variáveis $(\beta=-0,003 ; p=0,009)$, o que era esperado, já que o comprimento telomérico reduz com a idade (por isso, valor de $\beta$ também negativo). Por fim, não houve associação significativa entre comprimento telomérico e grau de escolaridade $(\beta=0,003 ; p=0,842)$.

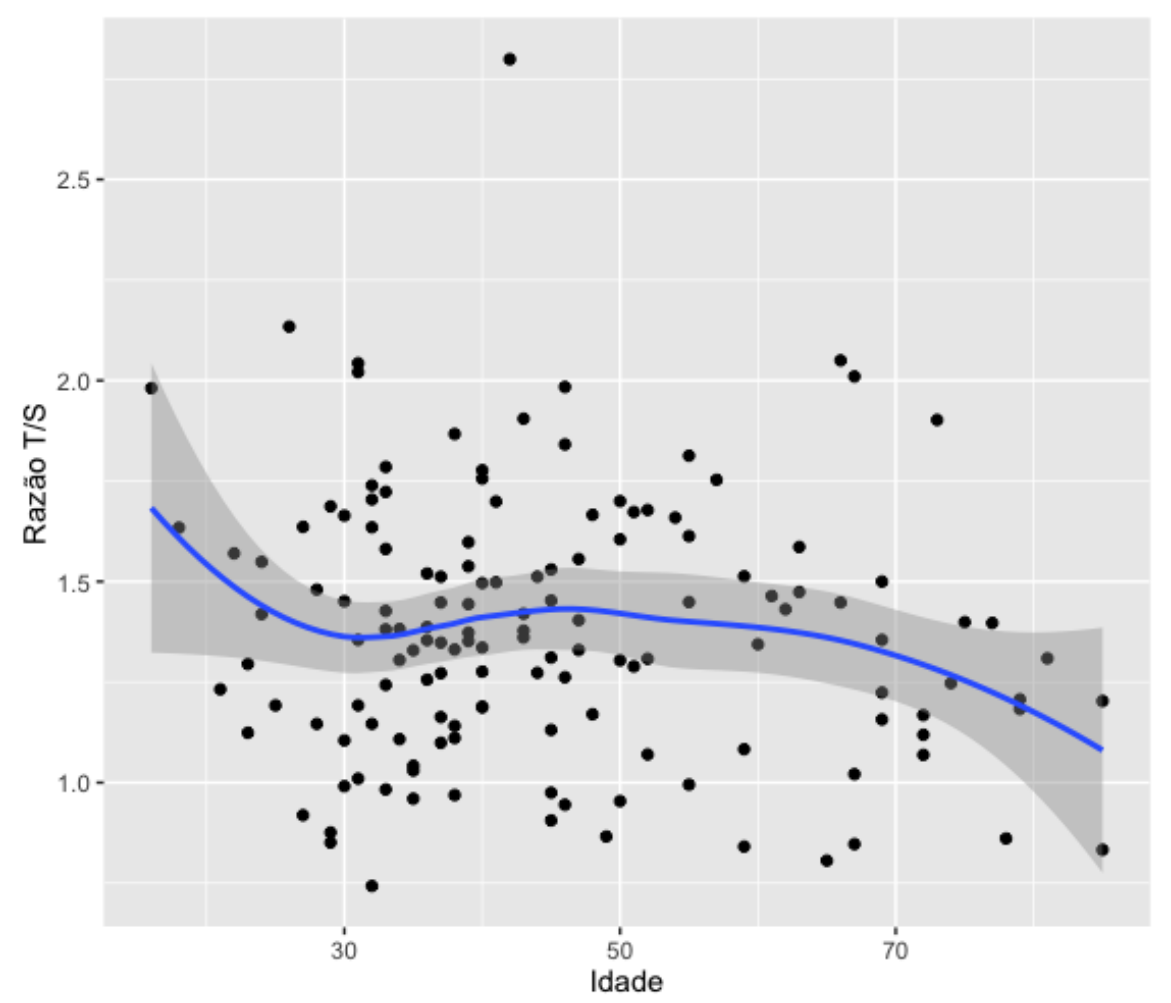

Figura 5 - Gráfico de dispersão do comprimento telomérico de acordo com a idade (com linha de tendência). Houve associação negativa estatisticamente significante entre as duas variáveis $(\beta=-0,003 ; p=0,009)$, ou seja, a razão T/S diminuiu de acordo com a idade dos indivíduos do estudo 


\subsection{COMPRIMENTO TELOMÉRICO E TB}

Através do modelo misto poligênico, observou-se o comportamento da covariável dicotômica bipolar (ausência/presença de TB) em relação a variável resposta comprimento telomérico, sempre ajustado para sexo e idade. Não houve associação estatisticamente significante entre as duas variáveis ( $\beta=$ $0,001 ; p=0,696)$. Pode-se observar melhor, com o boxplot, a associação não significativa entre TB e razão T/S (Figura 6). Apesar de não ter sido encontrada associação significante entre as duas covariáveis, observou-se uma pequena tendência de encurtamento telomérico para os bipolares em comparação com os indivíduos saudáveis.

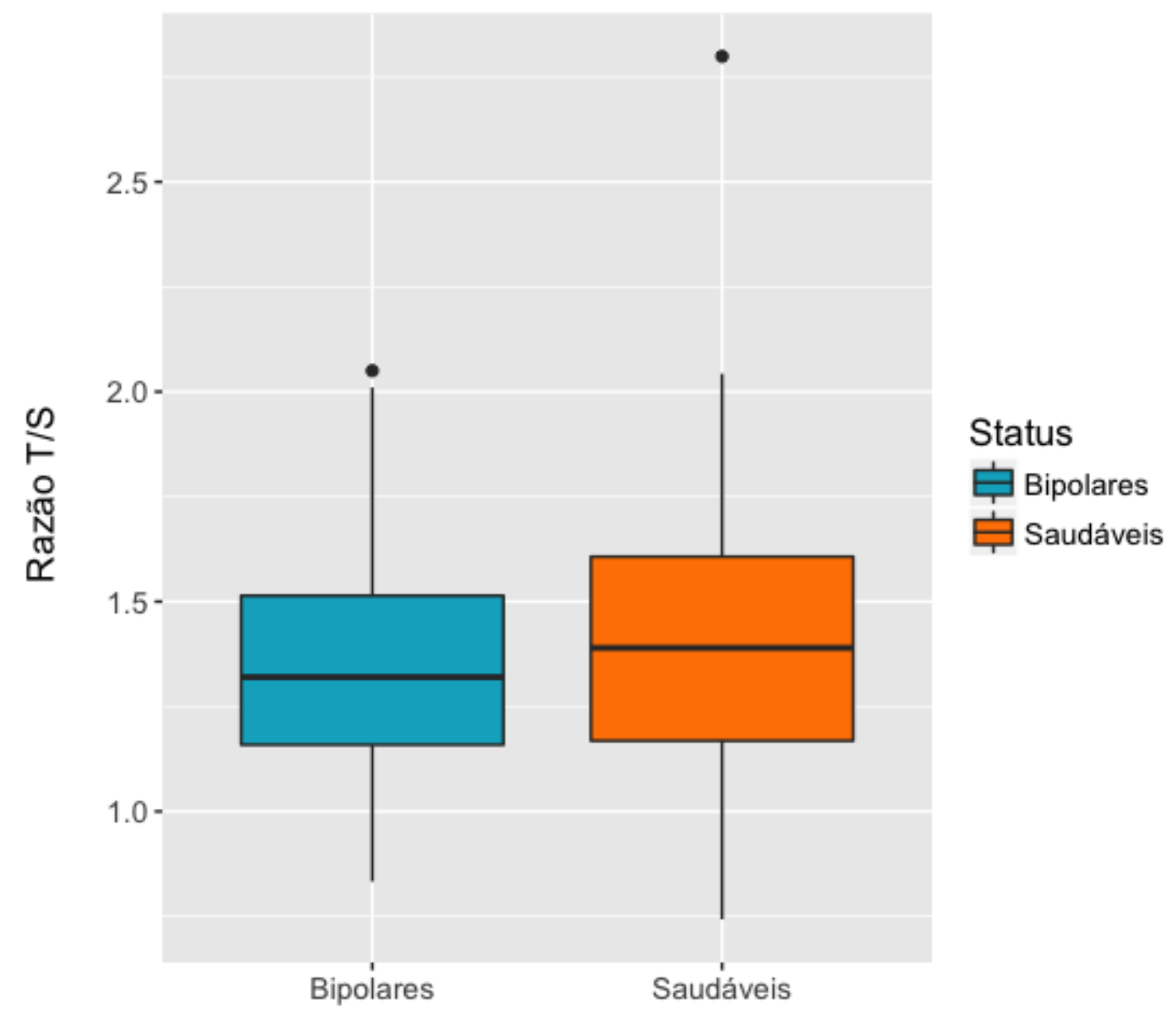

Figura 6 - Comparação da razão T/S entre bipolares e saudáveis. Boxplot da razão $T / S$ entre TB e saudáveis. Não houve diferença estatisticamente significante ( $p=$ $0,696)$ entre bipolares $(n=60)$ e saudáveis $(n=48)$ 


\subsection{COMPRIMENTO TELOMÉRICO E GRUPO DOENÇA PSIQUIÁTRICA}

Comparou-se também o comprimento telomérico entre os indivíduos saudáveis e todos os indivíduos com doenças psiquiátricas (incluindo o TB). Não houve associação estatisticamente significante do comprimento telomérico entre os dois grupos doentes versus saudáveis $(\beta=-0,000 ; p=0,998)$. $\mathrm{Na}$ Figura 7, pode-se observar melhor essa comparação, e na Figura 8 foi possível ainda observar separadamente a média da razão T/S nos três grupos: saudáveis versus TB versus indivíduos com outras doenças psiquiátricas. Notou-se que a média da razão T/S entre os indivíduos com TB e outras doenças foi menor do que a média dos saudáveis, porém não houve diferença estatisticamente significativa entre elas $(\beta=-0,001 ; p=0,834)$.

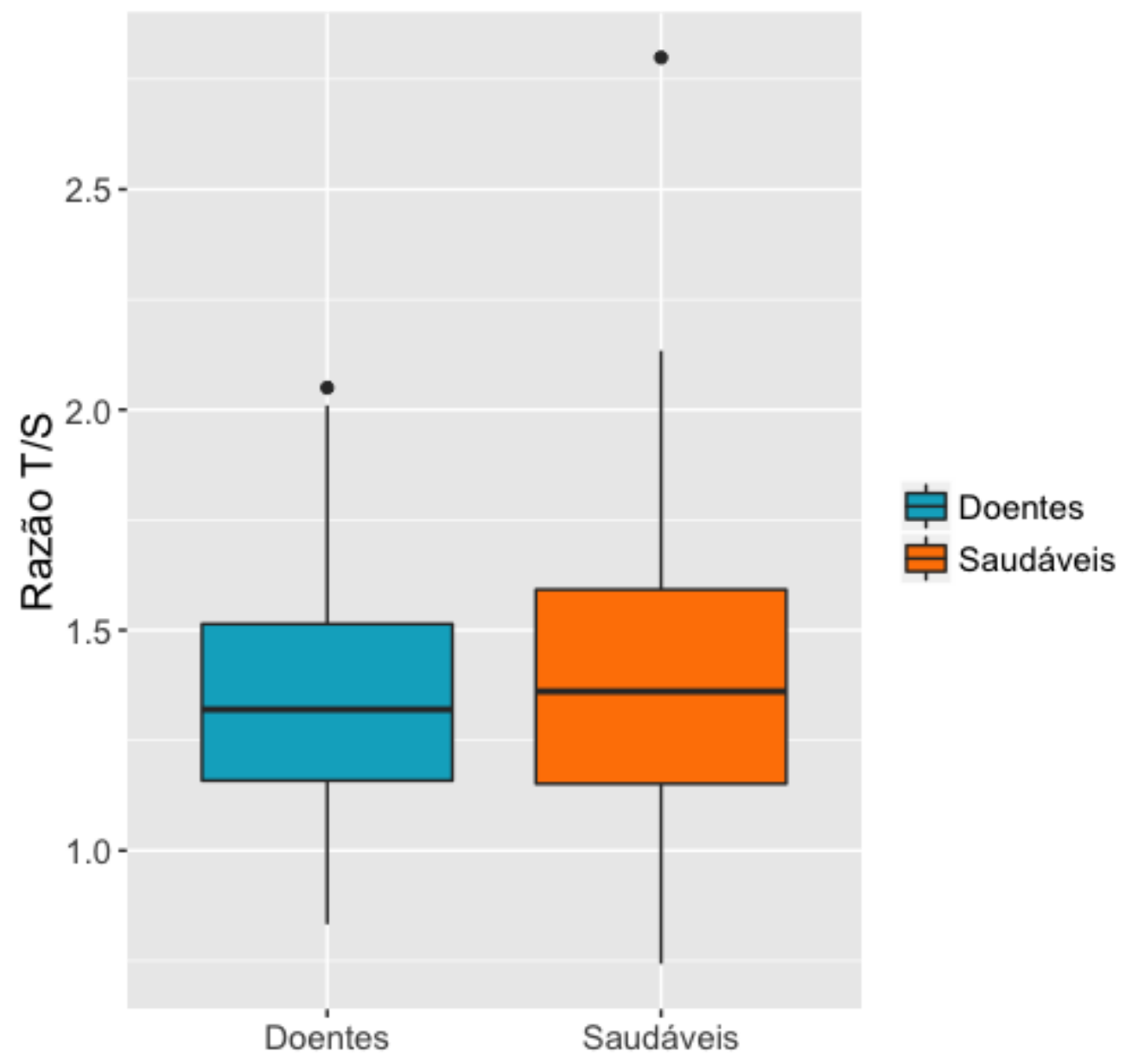

Figura 7 - Comparação da razão T/S entre todos os indivíduos com doença psiquiátrica (doentes) e saudáveis. Boxplot da razão T/S entre doentes e saudáveis. Não houve diferença estatisticamente significante $(p=0,998)$ entre doentes $(n=95)$ e saudáveis $(n=48)$ 


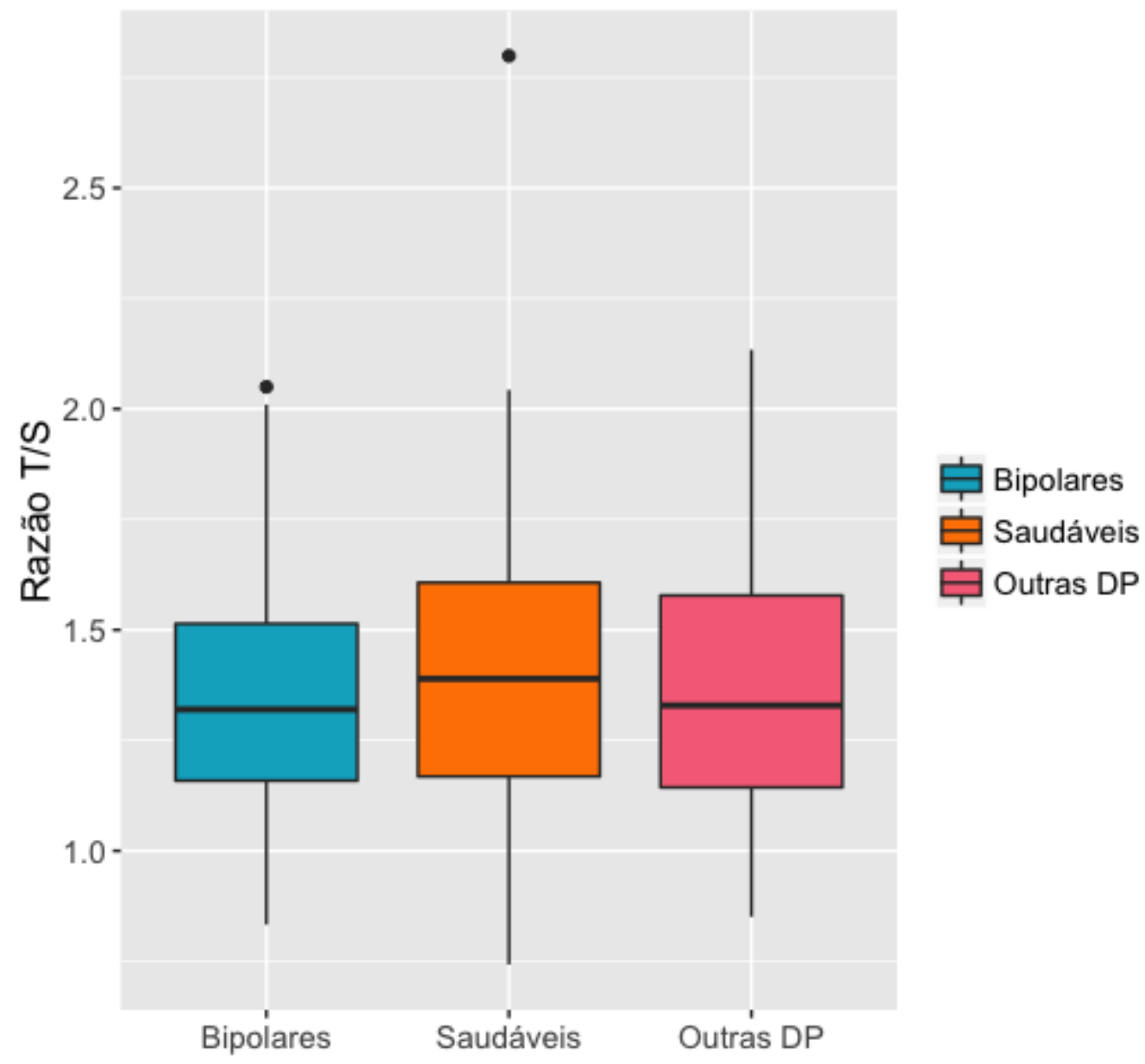

Figura 8 - Comparação da razão T/S entre bipolares, saudáveis e indivíduos com outras doenças psiquiátricas. Boxplot da razão T/S entre grupo TB, saudáveis e indivíduos com outras doenças psiquiátricas. Não houve diferença estatisticamente significativa $(p=0,834)$ entre bipolares $(n=60)$, saudáveis $(n=48)$ e indivíduos com outras doenças psiquiátricas $(n=35)$. Outras $D P=$ Outras doenças psiquiátricas (descritas na Tabela 2)

\subsection{COMPRIMENTO TELOMÉRICO E VARIÁVEIS CLÍNICAS}

Através do ajuste do modelo misto poligênico também se observou o comportamento das outras variáveis clínicas em relação à variável resposta comprimento telomérico. Inicialmente, foram testadas associações univariadas da resposta com todas as variáveis clínicas do indivíduo (ou seja, uma por uma, isoladamente) e apenas algumas delas mostraram associações significantes positivas ou negativas com o comprimento telomérico, como: a covariável ideação suicida $(\beta=-0,061 ; p=0,028)$ e a interação entre ideação suicida e curso da doença $(\beta=-0,033 ; p=0,025)$. É importante ressaltar que 
nessas análises com as variáveis clínicas foram considerados todos os status psiquiátricos, não apenas o grupo com TB. Na Figura 9, o boxplot representa melhor a associação negativa existente entre ideação suicida e razão T/S. Observou-se que quanto maior o grau (duração) de ideação suicida, menor o comprimento telomérico (evidenciado pelo valor de $\beta$ negativo).

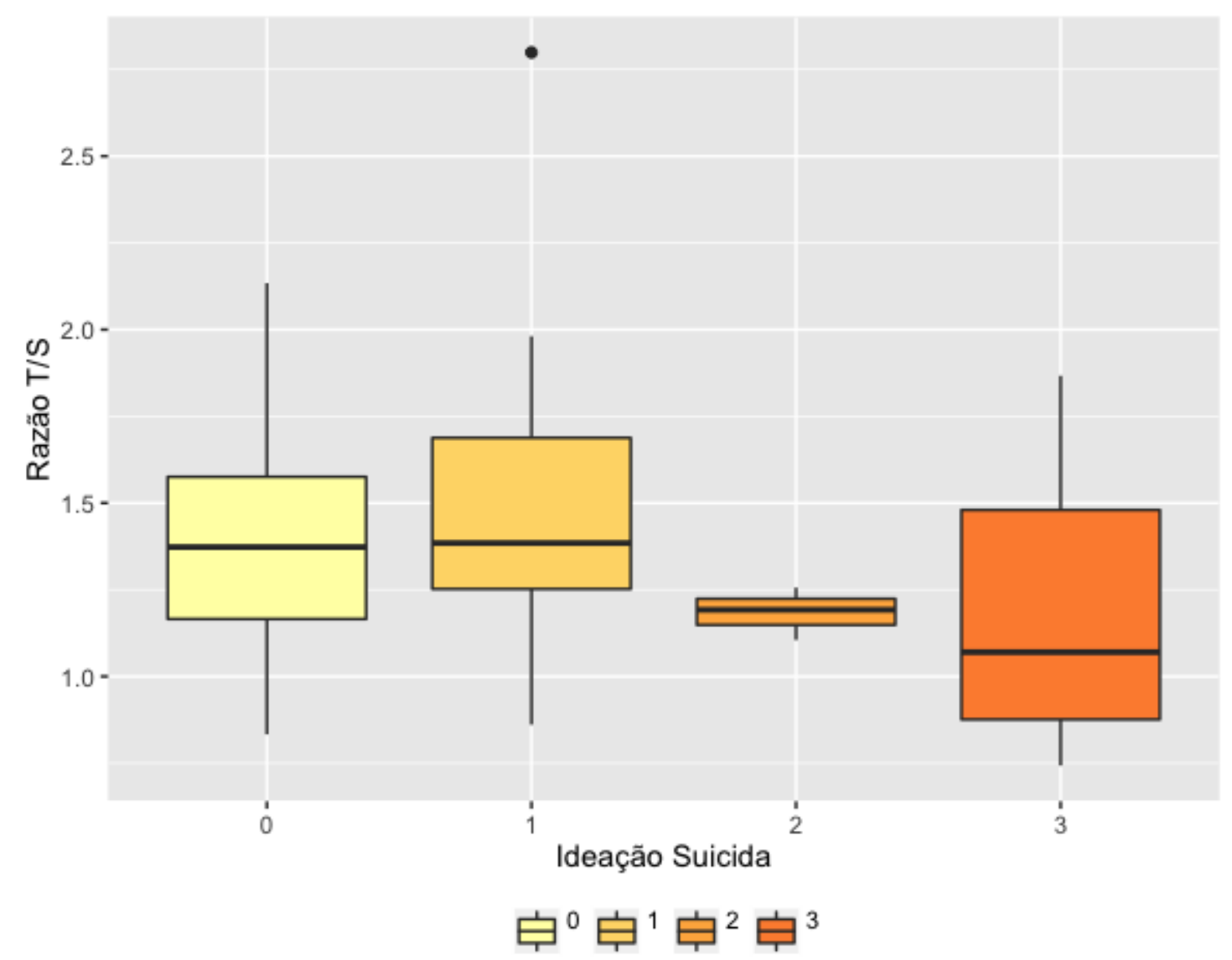

Figura 9 - Comparação da razão T/S e ideação suicida. Boxplot da razão T/S e ideação suicida. Houve associação negativa estatisticamente significante $(\beta=-0,061$; $p=0,028)$ entre os grupos. 0 = ausência de ideação suicida $(n=71) ; 1$ = duração de pelo menos uma semana ou tentativa de suicídio $(n=24) ; 2$ = duração de pelo menos duas semanas $(n=3) ; 3=$ duração de pelo menos um mês $(n=13)$

Apesar da covariável curso da doença não ter apresentado associação estatisticamente significativa com a razão $T / S(p=0,342)$ no modelo univariado, percebeu-se uma tendência à diminuição da razão $T / S$ com $o$ aumento da gravidade do curso da doença $(\beta=-0,030)$, ou seja, os indivíduos com graus mais avançados da doença também apresentaram menor comprimento telomérico (Figura 10). 


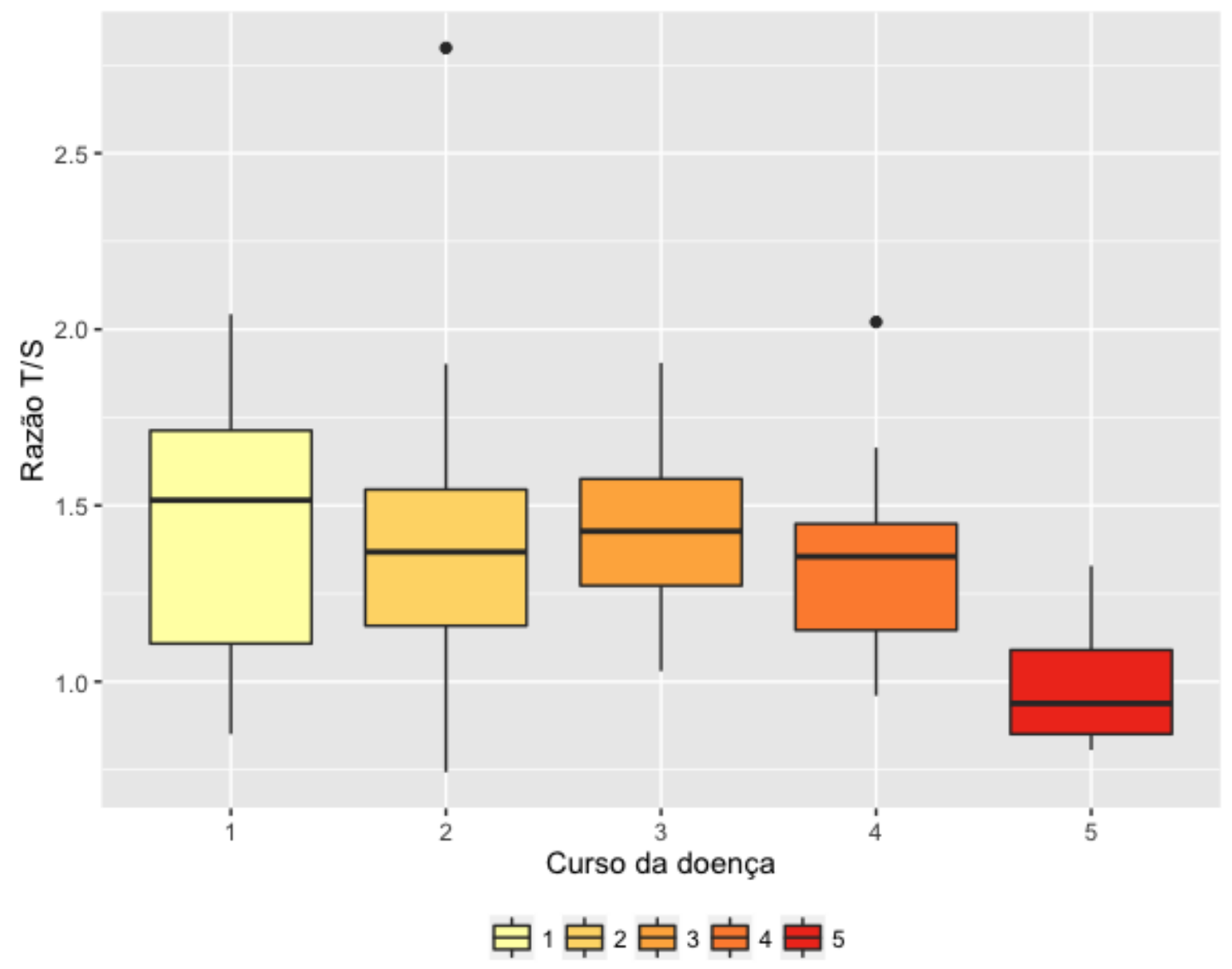

Figura 10 - Comparação da razão T/S e curso da doença. Boxplot da razão T/S e curso da doença. Não houve associação estatisticamente significante $(p=0,342)$ entre os grupos, porém percebe-se pelo valor negativo de $\beta(\beta=-0,030)$ uma tendência a um encurtamento telomérico em graus mais avançados do curso da doença. $1=$ Único episódio $\mathrm{c} /$ boa recuperação $(\mathrm{n}=12) ; 2$ = Muitos episódios $\mathrm{c}$ / boa recuperação $(\mathrm{n}=$ 38); 3 = Muitos episódios c/ recuperação parcial $(n=23) ; 4$ = Doença crônica contínua (DCC) $(n=13) ; 5=$ DCC com deterioração $(n=4)$

Na Figura 11, foi possível observar graficamente a interação significativa entre ideação suicida e curso da doença. Isto é, quanto maior a duração de ideação suicida e pior o curso da doença, mais claramente foi possível observar uma queda acentuada do comprimento telomérico (correlação negativa) e os indivíduos com as menores médias de razão T/S.

É importante ressaltar que em todos os modelos de associação criados foram feitos ajustes para as covariáveis "sexo" e "idade", as quais foram incluídas em todas as análises. 


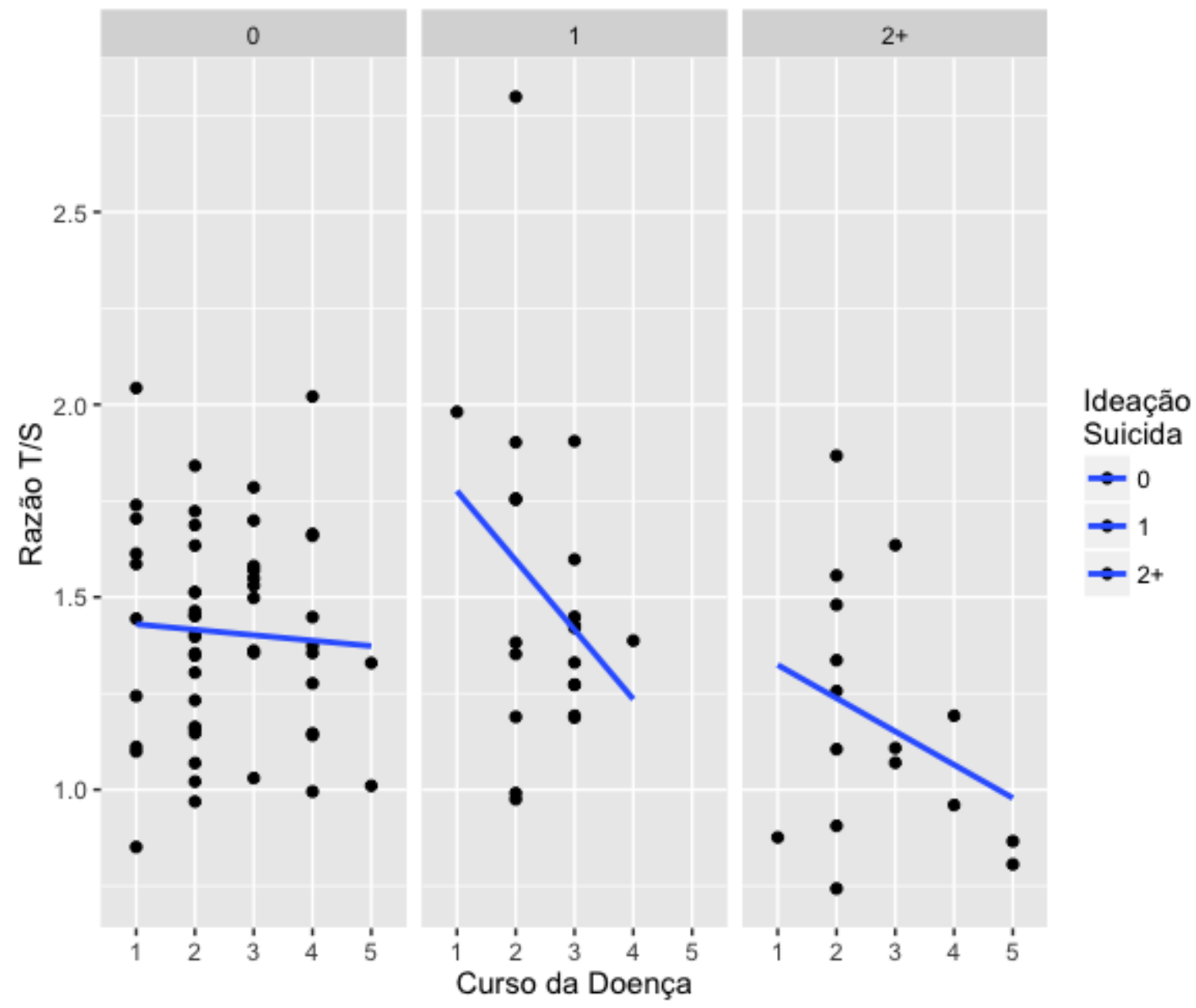

Figura 11 - Gráfico da associação entre razão T/S e interação entre ideação suicida e curso da doença. Houve associação negativa significante $(\beta=-0,033 ; p=0,025)$ entre a razão T/S e a interação entre ideação suicida e curso da doença

\subsection{COMPRIMENTO TELOMÉRICO - MODELO GERAL}

Com o propósito de encontrar um modelo geral que explicasse melhor a variação do comprimento telomérico entre as famílias, buscou-se incluir um número selecionado de covariáveis no modelo misto poligênico. Assim, foram analisados diversos modelos gerais, cada um com um número diverso de covariáveis que melhor explicariam a variação do telômero, de modo que o critério para se escolher o modelo final foi aquele parcimonioso entre o número de covariáveis e a significância destes, levando-se também em consideração a interpretação e relevância biológica e médica/clínica das covariáveis. Dessa forma, foi escolhido como modelo geral final aquele que incluiu sete 
covariáveis, sendo que idade materna, ideação suicida, curso da doença e interação entre curso da doença e ideação suicida apresentaram associação estatisticamente significativa com o comprimento telomérico (Tabela 4).

Tabela 4 - Modelo Geral Final do comprimento telomérico (razão T/S)

\begin{tabular}{|c|c|c|}
\hline Modelo Geral Final & Valores de $\beta$ & Valores de $p$ \\
\hline Idade materna & 0,012 & 0,008 \\
\hline Bipolar $^{\mathrm{a}}$ & 0,010 & 1 \\
\hline Idade de início da doença & 0,001 & 0,962 \\
\hline Status da doença & $-0,007$ & 0,924 \\
\hline Ideação suicida & 0,065 & 0,031 \\
\hline Curso da doença & 0,042 & 0,012 \\
\hline Tempo de hospitalização total & $-0,001$ & 0,970 \\
\hline Ideação suicida:Curso da doença ${ }^{\mathrm{b}}$ & $-0,046$ & 0,004 \\
\hline Ideação suicida:Tempo de hospitalização total ${ }^{c}$ & 0,006 & 1 \\
\hline
\end{tabular}

Legenda: Tabela do Modelo Geral Final do comprimento telomérico nas 22 famílias do estudo com todas as covariáveis utilizadas no modelo poligênico final e com os respectivos valores de $p$ e $\beta$ (efeito positivo ou negativo no comprimento telomérico). ${ }^{a}$ Bipolar = ausência/presença de TB. ${ }^{b}$ Interação entre ideação suicida e curso da doença; ${ }^{\circ}$ Interação entre ideação suicida e tempo de hospitalização total. Em negrito estão as covariáveis que apresentaram associação estatisticamente significativa com a razão $T / S$

É importante ressaltar que a interação entre ideação suicida e curso da doença apresentou associação com o comprimento telomérico em quase todos os modelos gerais analisados $(p<0,05)$, como também no modelo univariado, indicando que essas duas covariáveis apresentaram de fato importante e significante associação com o comprimento telomérico dos indivíduos do estudo.

\subsection{COMPRIMENTO TELOMÉRICO, IDADE PATERNA E MATERNA E TB}

Assim como as variáveis clínicas, as variáveis idade paterna e materna no momento do nascimento da prole também foram testadas no modelo poligênico univariado (um a um), a fim de verificar associação com o comprimento telomérico dos indivíduos do estudo. Porém nenhuma associação estatisticamente significante foi encontrada nem para idade paterna $(\beta=0,007$; 
$p=0,083)$ nem para idade materna $(\beta=0,007 ; p=0,152)$.

Contudo, durante o processo de construção do modelo geral, observouse que a covariável idade materna, juntamente com as covariáveis ideação suicida e curso da doença, também apresentou evidência de associação significante com o comprimento telomérico em quase todos os modelos que foram testados, inclusive no modelo geral final $(p=0,008)$. Por outro lado, não se observou qualquer associação estatisticamente significante entre comprimento telomérico e idade paterna (nem na associação univariada, nem nos diferentes modelos gerais utilizando as combinações de covariáveis).

Esta evidência encontrada para a idade materna levantou o questionamento: haveria alguma diferença dessa associação entre indivíduos bipolares e saudáveis? Desta forma, procurou-se associar no modelo poligênico a interação entre a covariável idade materna e o grupo bipolar (presença/ausência de TB) que, de fato, apresentou associação positiva estatisticamente significante com o comprimento telomérico $(\beta=0,022 ; p=$ 0,029) (Tabela 5). Com relação à idade paterna, nenhuma associação significativa foi encontrada quanto à interação com TB $(\beta=0,009 ; p=0,223)$ (Tabela 6).

Pode-se observar melhor o comportamento da interação entre idade materna, paterna e TB e sua associação com o comprimento telomérico nas Figuras 12 e 13. Observou-se na Figura 12 que quanto maior a idade materna no nascimento maior o comprimento telomérico dos filhos (as) apenas com TB. $\mathrm{Na}$ Figura 13, apesar de se ter observado efeito positivo da interação da idade paterna, não só com o grupo dos bipolares como também com o grupo de outras doenças psiquiátricas, não houve associação significativa com a razão $\mathrm{T} / \mathrm{S}$. 
Tabela 5 - Modelo Idade Materna: Associação da razão T/S e interação entre idade materna no nascimento e TB

\begin{tabular}{|c|c|c|}
\hline Modelo Idade Materna & Valores de $\beta$ & Valores de $p$ \\
\hline Idade materna & $-0,009$ & 0,283 \\
\hline Bipolar $^{a}$ & $-0,579$ & 0,047 \\
\hline Outras DP & $-0,300$ & 0,334 \\
\hline Sexo & 0,015 & 0,735 \\
\hline Idade materna:Bipolar ${ }^{b}$ & 0,022 & 0,029 \\
\hline Idade materna:Outras $\mathrm{DP}^{\mathrm{c}, \mathrm{d}}$ & 0,010 & 0,330 \\
\hline
\end{tabular}

Legenda: Tabela do Modelo Idade Materna que mostra a associação positiva do comprimento telomérico com a interação entre idade materna e TB $(\beta=0,022 ; p=0,029)$. ${ }^{a}$ Bipolar $=$ ausência/presença de TB. ${ }^{b}$ Interação entre idade materna e TB; ${ }^{c}$ Interação entre idade materna e outras doenças psiquiátricas. ${ }^{d}$ Outras $D P=$ Outras doenças psiquiátricas (descritas na Tabela 2). Em negrito estão as covariáveis que apresentaram associação estatisticamente significante com a razão $T / S$

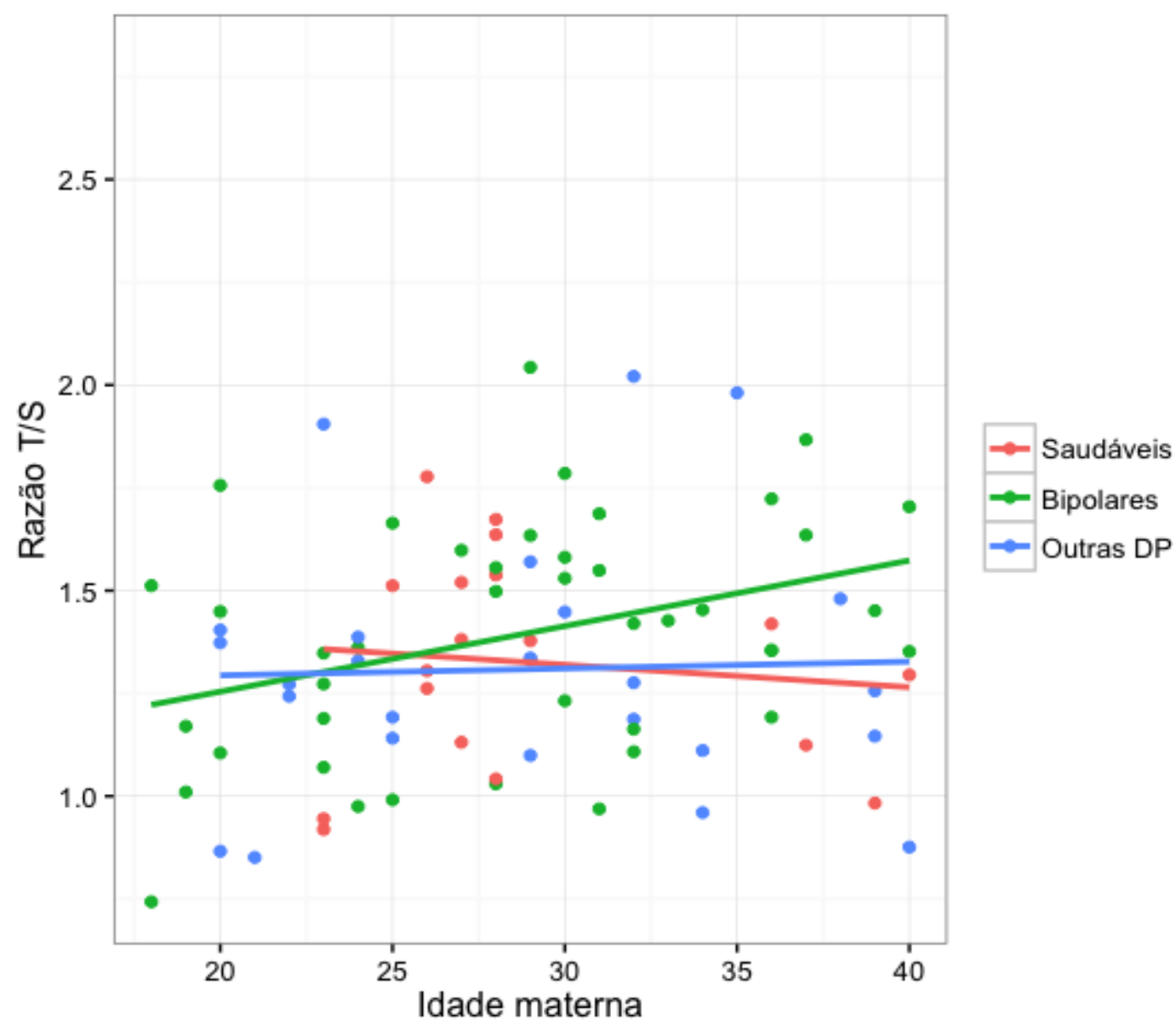

Figura 12 - Gráfico de dispersão da interação entre idade materna e TB e a associação com a razão T/S. Houve associação positiva do comprimento telomérico com a interação entre idade materna e TB $(\beta=0,022 ; p=0,029)$, ou seja, quanto maior a idade materna no nascimento, maior o comprimento telomérico da prole com TB 
Tabela 6 - Modelo Idade Paterna: Razão T/S e interação entre idade paterna no nascimento e TB

\begin{tabular}{ccc}
\hline Modelo Idade Paterna & Valores de $\boldsymbol{\beta}$ & Valores de $\mathbf{p}$ \\
\hline Idade paterna $^{\text {Bipolar }}{ }^{\mathrm{a}}$ & $-0,001$ & 0,811 \\
Outras DP $_{\text {Sexo }}$ & $-0,215$ & 0,394 \\
$-0,223$ & 0,382 \\
Idade paterna:Bipolar & $-0,069$ & 0,177 \\
Idade paterna:Outras DP $^{\mathrm{b}}$ & 0,009 & 0,223 \\
\hline
\end{tabular}

Legenda: Tabela do Modelo Idade Paterna. Não houve associação significante do comprimento telomérico com a interação entre idade paterna e TB $(\beta=0,009 ; p=0,223)$, apesar de o efeito ter sido positivo. ${ }^{a}$ Bipolar $=$ ausência/presença de TB. ${ }^{b}$ Outras $D P=$ Outras doenças psiquiátricas (descritas na Tabela 2). Interação entre idade paterna e outras doenças psiquiátricas

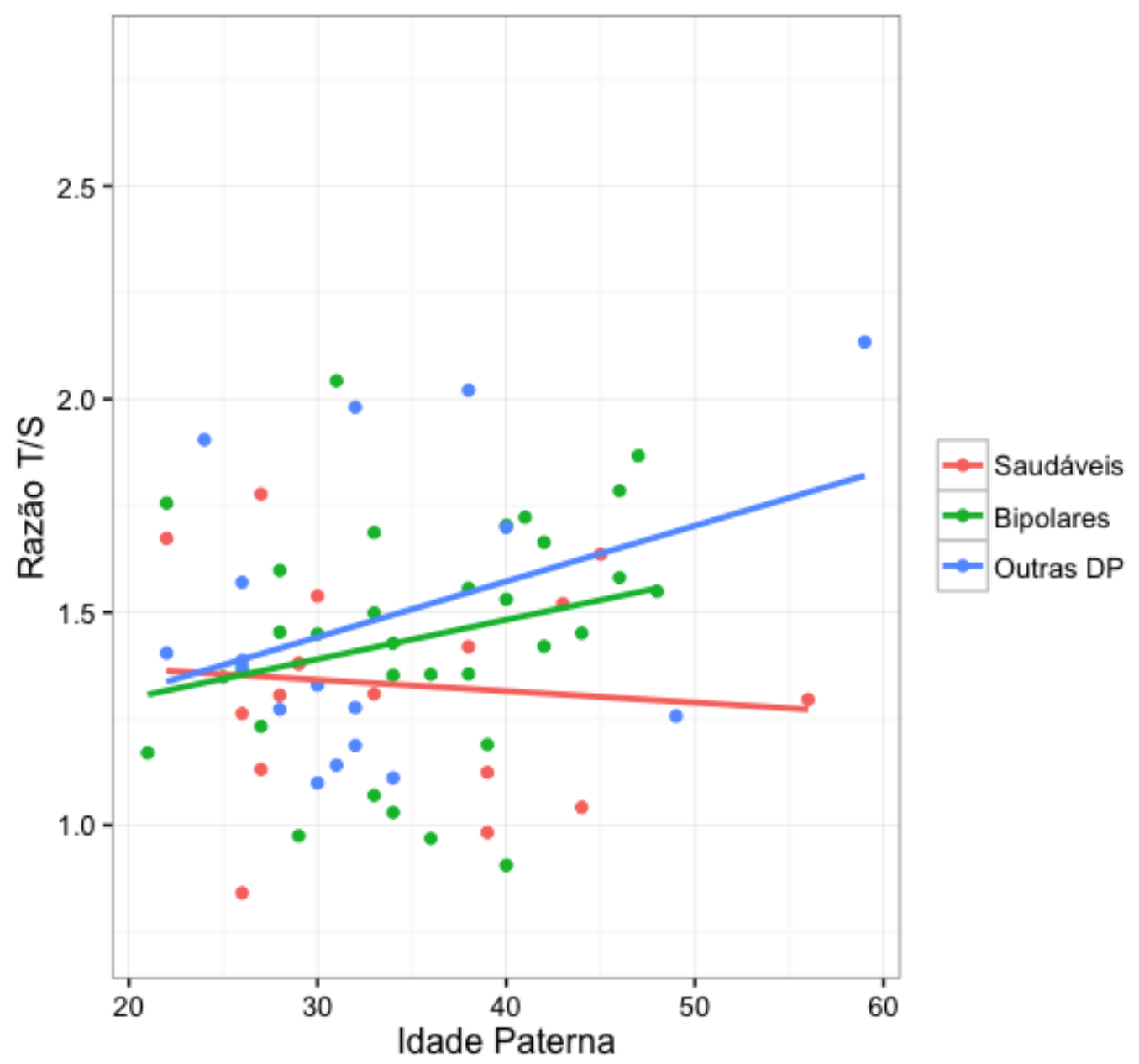

Figura 13 - Gráfico de dispersão da interação entre idade paterna e TB e a associação com a razão T/S. Não houve associação significante do comprimento telomérico com a interação entre idade paterna e TB $(\beta=0,009 ; p=0,223)$, apesar de se observar tendenciosamente que quanto maior a idade paterna no nascimento maior o comprimento telomérico da prole com TB e outras doenças psiquiátricas 


\subsection{HERDABILIDADE DO COMPRIMENTO TELOMÉRICO}

A fim de analisar a variabilidade genética do comprimento telomérico nessas famílias, calculou-se a herdabilidade dessa variável na presente amostra. A estimativa geral da herdabilidade do comprimento telomérico, ajustada para sexo e idade (modelo Sexo + Idade), tanto pelo software $\mathrm{R}$ como pelo SOLAR, foi de 0,68 (Tabela 7). Quando a covariável dicotômica TB foi acrescentada ao modelo esta não alterou a herdabilidade de modo significativo, mostrando que o efeito dessa covariável não impactou a herdabilidade do comprimento telomérico.

Tabela 7 - Herdabilidade do comprimento telomérico

\begin{tabular}{|c|c|c|c|}
\hline Modelos & Valores de $\beta$ & Valores de $p$ & $h^{2}$ \\
\hline Nulo $^{a}$ & & & 0,58 \\
\hline Sexo & $\beta$ sexo $=0,04$ & sexo $=0,43$ & 0,58 \\
\hline Idade & Bidade $=0,00$ & idade $=0,01$ & 0,68 \\
\hline Sexo + Idade & $\beta$ sexo $=0,02 / \beta$ Bidade $=0,00$ & sexo $=0,63 /$ idade $=0,01$ & 0,68 \\
\hline $\begin{array}{c}\text { Sexo + Idade + } \\
\text { Bipolar }^{\mathrm{b}}\end{array}$ & $\beta$ sexo $=-0,02 /$ Bidade $=0,00 / \beta$ bipolar $=0,02$ & sexo/idade/bipolar $>0,05$ & 0,64 \\
\hline
\end{tabular}

Legenda: Estimativa da herdabilidade do comprimento telomérico em cinco diferentes modelos que variam de acordo com as covariáveis adicionadas (nulo; sexo; idade; sexo + idade e sexo + idade + TB). ${ }^{a}$ Nulo = modelo da herdabilidade basal do comprimento telomérico sem nenhuma covariável associada ao modelo. ${ }^{b}$ Bipolar = ausência/presença de TB. Em negrito a herdabilidade de 0,68 do comprimento telomérico que foi levada em consideração com as covariáveis sexo e idade associadas ao modelo

Também se estimou a herdabilidade do comprimento telomérico no modelo geral final: $h^{2}=0,51$. (Tabela 8). Percebeu-se que a herdabilidade diminuiu quando se acrescentaram no modelo as covariáveis significativas do estudo. 
Tabela 8 - Herdabilidade do comprimento telomérico no modelo final

\begin{tabular}{ccc}
\hline Modelo Final & Valores de $\boldsymbol{\beta}$ & Valores de $\mathbf{p}$ \\
\hline Idade materna $^{\text {Bipolar }}{ }^{a}$ & 0,012 & 0,008 \\
Idade de início da doença $_{\text {Status da doença }}$ & 0,010 & 1 \\
Ideação suicida & 0,001 & 0,962 \\
Curso da doença & $-0,007$ & 0,924 \\
Tempo de hospitalização total & 0,065 & 0,031 \\
Ideação suicida:Curso da doença & 0,042 & 0,012 \\
Ideação suicida:Tempo de hospitalização total & $-0,001$ & 0,970 \\
\hline $\boldsymbol{h}^{\mathbf{2}}=\mathbf{0 , 5 1}$ & $-0,046$ & 0,004 \\
\hline
\end{tabular}

Legenda: Tabela da herdabilidade do comprimento telomérico no modelo final com todas as covariáveis incluídas. ${ }^{a}$ Bipolar = ausência/presença de TB. Em negrito a herdabilidade de 0,51 do comprimento telomérico no modelo geral final

\subsection{ANÁLISE DESCRITIVA GLOBAL DO COMPRIMENTO TELOMÉRICO NAS FAMÍLIAS COM TB E OUTRAS DP}

Por fim, numa análise descritiva global, verificou-se a média do comprimento telomérico por família (Figura 14) e também a porcentagem de indivíduos afetados por algum transtorno psiquiátrico (incluindo DM e todas as outras doenças psiquiátricas) por família (linha laranja). As famílias com maior porcentagem de indivíduos afetados tenderam a apresentar comprimento telomérico abaixo da média, ou seja, a média global da razão T/S foi menor, quanto maior a quantidade de membros com transtornos psiquiátricos, em especial, o TB e vice-versa. Esta interpretação também pode ser relacionada aos valores de herdabilidade encontrados na modelagem descrita neste trabalho. 

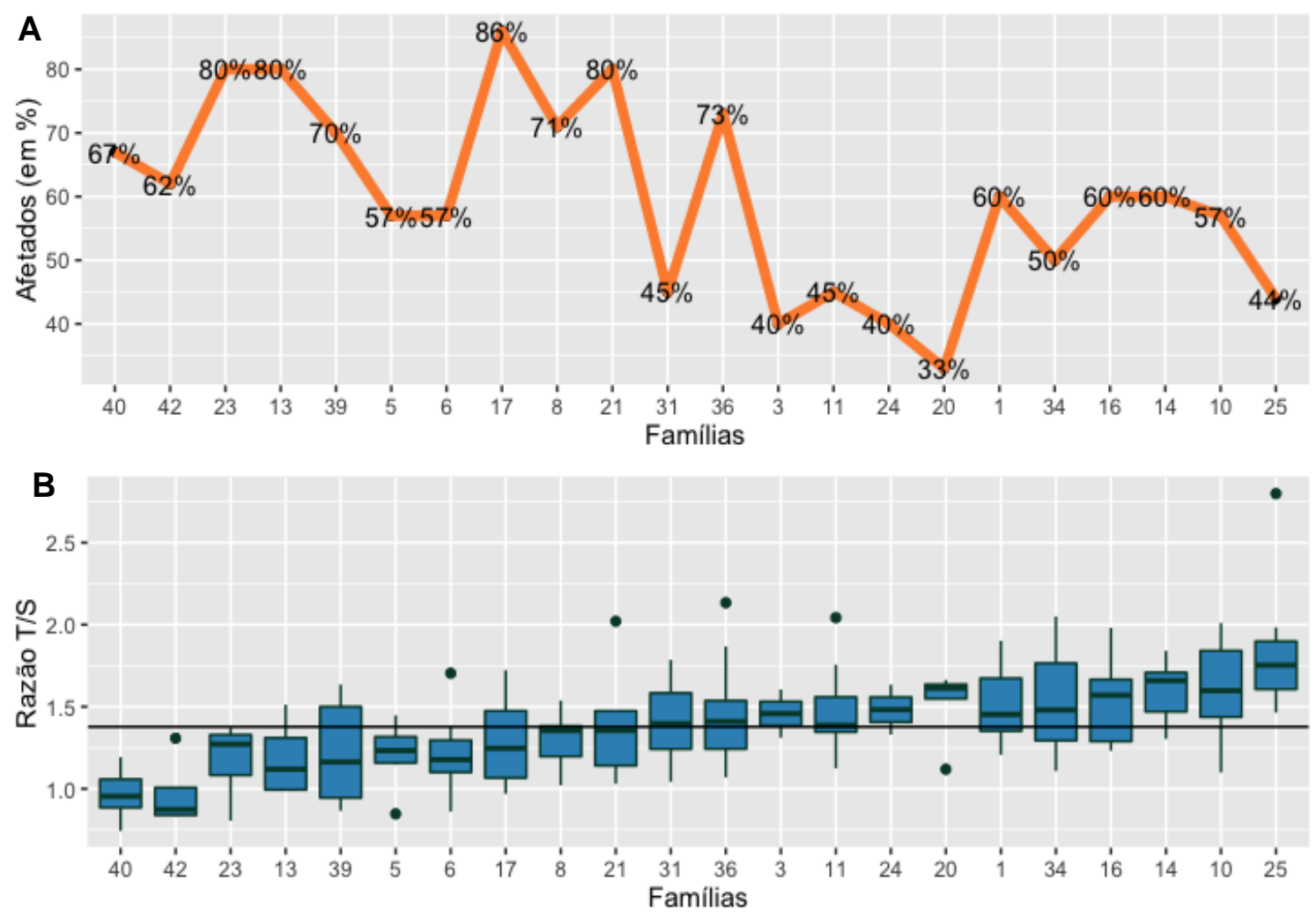

Figura 14 - Comparação da média do comprimento telomérico com a porcentagem de indivíduos afetados por família. Para análise global do comprimento telomérico nas famílias do estudo foi realizada uma comparação puramente descritiva da média do comprimento telomérico. Nota-se que as famílias com maior porcentagem de indivíduos afetados tendem a apresentar comprimento telomérico abaixo da média e vice-versa. A: Porcentagem de indivíduos afetados por família (linha laranja); B: Boxplots que representam a média da razão T/S por família. A linha horizontal no boxplot indica a média geral da razão T/S

NOTA: Os números nas abcissas (coordenada horizontal) representam a identificação de cada família nominada no período de coleta. 


\section{DISCUSSÃO}

O presente estudo avaliou o comprimento telomérico em famílias com vários membros afetados pelo TB. Primeiramente, para testar a hipótese inicial, foi investigado se havia diferença no comprimento telomérico entre membros saudáveis e afetados pelo TB. Depois, analisou-se o comprimento dos telômeros de acordo com a sintomatologia clínica e o curso da doença dos indivíduos com algum transtorno psiquiátrico (que não apenas o TB). Este estudo procurou também obter um modelo geral final para explicar a variabilidade do comprimento telomérico, bem como estimar o componente genético (herdabilidade) dessa variável nas famílias.

Observou-se que o fenótipo TB apresenta um efeito leve, porém não significativo, sobre o comprimento telomérico, ou seja, não houve diferença estatisticamente significante entre TB e tamanho de telômero, apesar da média geral dos indivíduos bipolares ser menor do que a dos indivíduos saudáveis nas 22 famílias estudadas. Quando se incluiu todos os indivíduos doentes no mesmo grupo (grupo de casos) e comparou com os indivíduos saudáveis (grupo controle), também não se verificou diferença no comprimento telomérico, apesar de se notar uma tendência a um encurtamento telomérico no grupo dos doentes. Todavia, quando se associaram as covariáveis clínicas (uma a uma) correspondentes à sintomatologia e curso das doenças psiquiátricas com a variável dependente, apenas ideação suicida e interação entre ideação suicida e curso da doença identificaram associação significativa com o comprimento telomérico.

Durante a obtenção do modelo poligênico final para o comprimento telomérico, notou-se também associação positiva da idade materna ao nascimento com o comprimento dos telômeros da prole. Ao investigar se havia alguma relação com 0 TB, também foi observada associação entre 0 comprimento telomérico da prole e a interação entre TB e idade materna, evidenciando que quanto maior a idade materna no nascimento, maior 0 comprimento telomérico do filho (ou filha) com TB. Este estudo mostrou também uma herdabilidade de $68 \%$ do comprimento do telômero nas 22 famílias com TB. 
Já existe na literatura uma variedade de estudos que relatam associação entre comprimento telomérico e diferentes fenótipos psiquiátricos, quando comparados a um grupo controle. Um desses primeiros estudos observou uma associação entre comprimento telomérico e estresse psicológico (Epel et al., 2004), relatando encurtamento telomérico nos casos de estresse. Estudos com transtornos de humor começaram em $2006 \mathrm{com}$ a publicação de Simon e colaboradores (2006), indicando a possibilidade de que a manutenção do comprimento dos telômeros pudesse estar de fato prejudicada nesses transtornos. A maioria dos estudos que investigou o fenótipo TB sugeriu uma associação negativa da doença com o comprimento telomérico (Simon et al., 2006; Rizzo et al., 2013; Rizzo et al., 2014; Lima et al., 2015; Powell et al., 2017; Vasconcelos-Moreno et al., 2017).

No presente estudo, todavia, não se encontrou diferença entre o comprimento dos telômeros afetados e não afetados por TB (variável dicotômica) nos membros das famílias do presente estudo, não corroborando a hipótese inicial em que se esperava encontrar diferença e associação negativa entre as duas variáveis. Um estudo de 2010 que investigou associação de comprimento telomérico com TB e outros transtornos psiquiátricos (como DM e esquizofrenia) em amostras de matéria cinzenta cerebelar, também não identificou diferença estatisticamente significante no comprimento telomérico entre casos e controles (Zhang et al., 2010), corroborando os dados do presente estudo. Resultado similar foi confirmado em uma metanálise recente de estudos de comprimento telomérico, em que esse parâmetro não diferiu entre os pacientes com TB versus controles saudáveis (Colpo et al., 2015). A falta de importantes covariáveis nas análises e a heterogeneidade intrínseca ao fenótipo de TB explicariam em parte os resultados negativos encontrados. É importante ressaltar que existem diferentes tipos de trajetórias e estágios de $T B$, sendo que os cursos evolutivos da doença podem apresentar diferentes graus de ativação do sistema imune e estresse oxidativo (Birmaher et al., 2014; Colpo et al., 2015). Esses fatores podem em maior ou menor grau contribuir para o encurtamento telomérico e necessitam ser avaliados nesses estudos.

Interessantemente, estudos recentes têm relatado também uma associação positiva do comprimento telomérico nos pacientes com TB que 
tomam ou não lítio. Os resultados têm mostrado um comprimento telomérico mais longo associado aos pacientes com TB que tomaram lítio em comparação com os controles saudáveis (Martinsson et al., 2013; Powell et al., 2017). A explicação dada é que o lítio, que tem um efeito neuroprotetor já comprovado, poderia também atuar sobre a fisiologia (ou maquinaria) dos telômeros, diminuindo ou evitando a taxa de encurtamento telomérico (Squassina et al., 2015). Assim, o tratamento com lítio também pode ser uma fonte potencial de heterogeneidade que deve ser avaliado nos estudos que associam comprimento telomérico e TB. Todavia, em todas as 22 famílias do presente estudo, apenas alguns indivíduos com TB tomaram lítio, não sendo possível, dessa forma, fazer uma análise de associação com o comprimento do telômero devido ao tamanho amostral pequeno.

Apesar de não ter sido encontrada diferença entre comprimento telomérico e a variável dicotômica TB, o presente estudo identificou associação de duas covariáveis clínicas, que indicam gravidade da doença, com o comprimento telomérico. Tanto a ideação suicida como a interação entre ideação suicida e curso da doença foram associadas à telômeros mais curtos, ou seja, quanto mais episódios de ideação suicida e/ou pior o curso da doença mais curto o telômero dos indivíduos que apresentam TB ou outra doença psiquiátrica. Isso sugere que a gravidade da doença é um fenótipo relevante e bem explicativo, importante a ser considerado nas associações com 0 comprimento telomérico, não só em TB, como também em outros transtornos psiquiátricos. Um estudo mais recente também corroborou esses dados, mostrando que pacientes em estágios avançados (fase tardia) de TB apresentam menor comprimento telomérico do que os pacientes em estágio inicial da doença e controles. Além disso, verificaram telômeros encurtados em pacientes com mania não medicados em comparação com os controles (Kose Cinar, 2017).

Estudos com TB também notaram que telômeros mais curtos estão associados com o número de episódios depressivos durante a vida (Elvsashagen et al., 2011). Também na DM se observou associação negativa entre encurtamento telomérico e o número de episódios depressivos (Hartmann et al., 2010; Wolkowitz et al., 2011). Todavia, nenhum desses estudos havia 
ainda observado associação direta entre comprimento telomérico e ideação suicida ou curso/gravidade da doença. O presente estudo parece ser o primeiro a ter observado em TB familial associação significativa dessas variáveis clínicas com encurtamento telomérico.

Notoriamente, um estudo recente em pessoas que cometeram suicídio relatou a primeira associação com telômeros mais curtos e alterações no número de cópias do DNA mitocondrial no córtex pré-frontal dorsolateral postmortem (DLPFC, do inglês Dorsolateral Prefrontal Cortex) desses indivíduos (Otsuka et al., 2017). Os autores sugeriram que a duração da exposição a um estressor psicológico, que foi maior em pacientes que se suicidaram, acarretou em maior encurtamento telomérico.

Outros estudos adotaram o conceito de que também o estresse oxidativo desempenharia um importante papel no encurtamento telomérico, sendo um importante modulador no controle da taxa de perda telomérica (Von Zglinicki, 2002; Szebeni et al., 2014). Além disso, os autores sugeriram que a defesa atenuada ao estresse oxidativo e à telomerase deficiente contribuiriam para o encurtamento de telômero em oligodendrócitos em pacientes com DM (Szebeni et al., 2014). Um estudo em ratos expôs também que o estresse comportamental induzido por injeção com corticosterona levou à diminuição do comprimento telomérico, ou seja, os animais que foram administrados com glicocorticoide (que reproduz o efeito do estresse) apresentaram telômeros encurtados, quando comparados aos controles (Cai et al., 2015).

Os resultados desses estudos envolvendo estresse psicológico e oxidativo dão suporte aos achados do presente estudo que evidenciou associação entre ideação suicida e comprimento telomérico. Todavia novas pesquisas envolvendo esses dois parâmetros são necessárias para corroborar e melhor elucidar o mecanismo subjacente dessa associação.

Com relação à idade paterna no nascimento, nenhuma associação foi encontrada com o comprimento telomérico (tanto no modelo univariado, como no modelo geral). Tal resultado não corroborou a hipótese inicial desse estudo - em que se esperava encontrar associação positiva do comprimento telomérico com a idade paterna - e com os primeiros estudos que colocaram em evidência a idade paterna no nascimento como um importante determinante 
no comprimento telomérico da prole, ao mostrarem que quanto maior a idade do pai no nascimento, maior o telômero dos filhos (De Meyer et al., 2007; Prescott et al., 2012). A princípio, qualquer associação positiva de comprimento telomérico com a idade parece ser contra intuitivo, no entanto, como explicado na introdução, o telômero é conhecidamente alongado no espermatozoide ao longo da vida. Nos seres humanos, há um ganho de, aproximadamente, 71 pares de bases no telômero de espermatozoides por ano e o efeito positivo da idade paterna avançada no telômero da prole parece ser cumulativo ao longo das gerações (Allsopp et al., 1992; Eisenberg et al., 2012; Broer et al., 2013).

Contudo, um resultado instigante e não esperado obtido foi a associação positiva encontrada entre idade materna no nascimento do filho e o comprimento telomérico da prole. Como descrito previamente, essa associação foi encontrada na grande maioria dos testes realizados para encontrar o modelo geral que melhor explicasse a variação do comprimento telomérico nas diferentes famílias, levando em consideração as diferentes variáveis do estudo. Notavelmente, apesar do comprimento telomérico de ovócitos serem estáveis com a idade, não aparentando haver efeito de idade materna sobre o telômero da prole, a metanálise com 19.713 indivíduos evidenciou um importante componente de herança materno para o comprimento telomérico com correlação mãe-prole significantemente maior do que pai-prole (Broer et al., 2013). Os autores atribuem esse fato a um possível mecanismo ligado ao cromossomo $X$ na determinação do tamanho telomérico (Nawrot et al., 2004). O principal gene candidato envolvido nesse mecanismo seria o gene $D K C 1$, importante para a função da telomerase e responsável pela disceratose congênita (telomeropatia). Outras possíveis explicações para a alta correlação mãe-prole incluem alterações no DNA mitocondrial ou mesmo outros mecanismos de imprinting específicos durante a gestação (Broer et al., 2013).

Alguns estudos têm encontrado também uma relação entre idade materna e comprimento telomérico da mãe, ou seja, maior comprimento telomérico em mulheres com idade materna avançada (Fagan et al., 2017; Pru, 2017). Os autores sugerem que a idade materna avançada no nascimento do último filho pode ser um marcador de longevidade nas mães. Esses resultados corroboram em partes os resultados do presente estudo, que determinou 
telômeros mais longos nos filhos que apresentavam idade materna avançada durante o nascimento da prole. Até onde se sabe, apenas um estudo em aves mostrou que a idade materna no nascimento, e não paterna, está positivamente correlacionada com o tamanho do telômero da prole (Asghar et al., 2015). Possíveis explicações para tal associação seriam uma maior atividade da telomerase nos ovários das fêmeas, como também o fato de fêmeas mais velhas apresentarem menos estresse social, temporal e territorial comparado às fêmeas mais jovens (que passam por condições extremamente estressantes como, por exemplo: chegam mais tarde na primavera, ocupam piores territórios de reprodução e não obtém ajuda dos machos para alimentação dos filhotes) (Asghar et al., 2015). Contudo, os resultados desse último estudo são especulativos e precisam ser melhor investigados. $O$ presente estudo, portanto, parece ser o primeiro a observar associação entre idade materna ao nascimento e comprimento telomérico da prole em humanos sugerindo a idade materna como um marcador de longevidade para os filhos, mas são necessários mais estudos para confirmarem esses resultados preliminares.

A fim de saber se essa associação estava presente igualmente acrescentando o grupo bipolar (ausência/presença de TB) no modelo, observou-se que a interação entre idade materna e TB também esteve associada positivamente ao comprimento telomérico da prole. Isso sugere, que a idade materna avançada não só pode ser um marcador de longevidade, como também o fenótipo bipolar parece reforçar essa condição, sugerindo uma correlação com TB, pois o que se observou foi que os filhos com TB apresentaram telômeros maiores, quanto maior a idade materna. Apesar de haver relatos de que a idade materna avançada está associada com depressão, ansiedade e sintomas de estresse nas filhas quando atingem a idade adulto-jovem (Tearne et al., 2016), nenhum estudo observou se essa interação está associada com o comprimento telomérico. Contudo, na esquizofrenia, a idade paterna avançada, não materna, e o histórico familiar dois fatores de risco - foram significativamente associados com telômeros longos em homens com esquizofrenia (Malaspina et al., 2014). Para explicar essa associação apenas nos casos, os autores apontam para um possível 
efeito compensatório, ou seja, telômeros maiores nos casos de esquizofrenia compensariam os riscos ocasionados pela doença. Porém, quanto à idade paterna no presente estudo, novamente essa associação não é relatada.

Uma explicação para não se ter encontrado associação em nenhum modelo entre idade paterna no nascimento e comprimento telomérico, e sim idade materna, pode ser devido ao número considerável de dados perdidos para essa variável (idade do pai). $\mathrm{O} n$ amostral de indivíduos com idade paterna no nascimento foi menor do que o $\mathrm{n}$ para idade materna, o que pode ter influenciado nos resultados obtidos. Além disso, é importante frisar que foi observada correlação moderada, altamente significativa, entre idade paterna e materna no nascimento da prole $\left(r^{2}=62 \% ; p=0,8 \times 10^{-8}\right.$; ver ANEXO B). A correlação existente entre as duas idades pode ter sido um confundidor para não se ter encontrado associação para a idade paterna (falso-negativo). Tal fato pode apontar também para influências conjuntas das idades dos pais sobre a dinâmica do tamanho telomérico da prole, sugerindo a idade parental, não apenas a materna ou apenas a paterna, como uma importante variável a ser investigada nos futuros estudos. Alguns estudos têm indicado que, de fato, a idade parental avançada pode apresentar uma contribuição relativa para determinar o comprimento telomérico de espermatozoides da prole (Ferlin et al., 2013) e ambos os componentes maternos e paternos podem ser fatores determinantes para o telômero dos filhos (Broer et al., 2013; De Meyer, Eisenberg, 2015).

O presente estudo também foi o primeiro a explorar a herdabilidade do comprimento telomérico em famílias com múltiplos membros com TB e a evidenciar uma alta herdabilidade do comprimento do telômero $(0,68)$, o que era esperado a partir das evidências de estudos anteriores. Slagboom et al. (1994) estimaram a herdabilidade do comprimento dos telômeros pela primeira vez em um estudo de gêmeos. Os autores encontraram uma alta herdabilidade $(0,78)$ em 115 pares de gêmeos (entre 2-63 anos) do comprimento médio do fragmento de restrição terminal (do inglês terminal restriction fragment - TRF). Desde então, estudos subsequentes também confirmaram a herdabilidade deste parâmetro em estudos de família (Lin et al., 2003; Njajou et al., 2007; AlAttas et al., 2012; Zhu et al., 2013; Honig et al., 2015) e gêmeos e trigêmeos 
(Andrew et al., 2006; Costa Dde et al., 2015), mas a metanálise já citada anteriormente na introdução mostra que há uma discrepância nas estimativas, que variam entre 0,34 e 0,82 (Broer et al., 2013). Estes dados mostram estimativas com grande variabilidade entre elas que precisam ser reavaliadas e melhor compreendidas. Outros estudos também mostraram que o comprimento do telômero varia amplamente entre os indivíduos de uma determinada faixa etária e alguns o sugeriram como um marcador de envelhecimento biológico (Aubert, Lansdorp, 2008; Honig et al., 2015).

Quanto à herdabilidade do comprimento dos telômeros em indivíduos com transtornos psiquiátricos, apenas um estudo foi identificado na literatura até o momento. Costa e colaboradores (2015) examinaram em trios de TDAH altos efeitos do comprimento telomérico materno e paterno no telômero das crianças afetadas, sugerindo que a maior parte da variabilidade do comprimento telomérico das crianças com TDAH pode ser explicada por aspectos genéticos relacionados à herdabilidade (Costa Dde et al., 2015). O presente estudo corrobora os dados no TB, sugerindo alta herdabilidade do comprimento telomérico, o qual pode ser um subfenótipo hereditário da doença e estar relacionado aos mecanismos envolvidos na patogênese do TB como também de outros distúrbios psiquiátricos.

É importante notar também que a estimativa da herdabilidade do comprimento telomérico no modelo geral final foi de $51 \%\left(h^{2}=0,51\right)$. Percebeu-se que a herdabilidade diminuiu levemente, quando se acrescentaram no modelo as covariáveis significativas do estudo, estando dentro do intervalo identificado no estudo de metanálise da herdabilidade do comprimento telomérico. Isso evidencia também que outras covariáveis associadas à gravidade da doença, ideação suicida, idade materna, entre outras, podem apresentar parcela significativa e explicativa na herdabilidade do comprimento telomérico. Porém, mais estudos devem levar em conta esses e outros diferentes fenótipos na análise da herdabilidade, pois podem eliminar a subjetividade das covariáveis e os efeitos de household (similaridade comportamental entre moradores que compartilham uma mesma residência), bem como ajudar ainda mais na identificação de subfenótipos hereditários. 
A análise descritiva final do comprimento telomérico permitiu identificar as famílias que apresentavam as maiores e menores médias relativas de razão T/S e comparar com a porcentagem de indivíduos afetados por família. Numa análise puramente descritiva e visual, foi identificado que as famílias com maior porcentagem de indivíduos afetados tenderam a apresentar comprimento telomérico abaixo da média, ou seja, a média global da razão T/S foi menor, quanto maior a quantidade de membros com transtornos psiquiátricos, em especial, o TB. Essa análise, apesar de ser descritiva, parece corroborar os dados de herdabilidade e a possível associação do comprimento telomérico com TB.

Por fim, é importante ressaltar que, como toda investigação científica, o presente estudo apresenta algumas limitações metodológicas, que incluem: um tamanho relativamente pequeno da amostra, a confiabilidade da informação clínica coletada (viés de averiguação) e a falta de outras informações relevantes para a análise do estudo como medicação, índice de massa corpórea, uso de cigarro, atividade física, tipo de dieta, entre outros. Apesar dessas limitações, os dados analisados foram robustos o suficiente para apresentar resultados significativos. 


\section{CONCLUSÃO}

O presente estudo não corroborou a hipótese de envelhecimento acelerado no TB, uma vez que não foi encontrada diferença no comprimento telomérico entre membros com e sem TB das 22 famílias. Entretanto, outros parâmetros que indicam gravidade da doença, como ideação suicida e curso da doença, apresentaram associação significativa com o comprimento telomérico. A associação com ideação suicida é uma potencial evidência de que esse sintoma, presente em outras doenças psiquiátricas e muito relevante em TB, é um fenótipo importante a ser avaliado nos futuros estudos com comprimento telomérico. Associar o comprimento telomérico dessas famílias com outros marcadores de estresse e envelhecimento, como, por exemplo, alterações no número de cópias do DNA mitocondrial desses indivíduos podem evidenciar ainda mais os mecanismos moleculares envolvidos na biologia do telômero nas condições de alta presença de estresse, como nos casos de ideação suicida e tentativa de suicídio. Da mesma forma, a interação entre idade materna avançada e TB associada positivamente com comprimento telomérico da prole é um resultado instigante, pois aparenta ser um marcador de longevidade, mas que merece ser investigado mais a fundo em futuros estudos. Por fim, a alta herdabilidade do comprimento telomérico evidenciada nessa população, sugere uma importante variabilidade genética do telômero, e estudos genéticos posteriores, que incluam o máximo de fenótipos possíveis, poderão facilitar ainda mais o entendimento de como essa medida é passada entre gerações, bem como sua relação com a etiologia e neuroprogressão do TB. 


\section{ANEXOS}

ANEXO A - Heredogramas das 22 famílias do estudo

\section{Família PB 001}

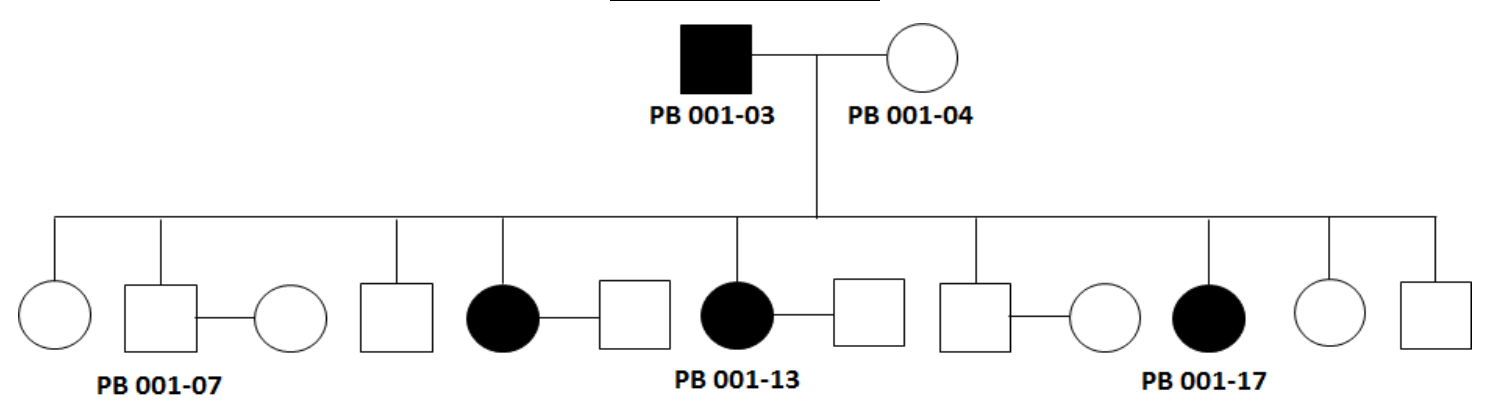

Família PB 003

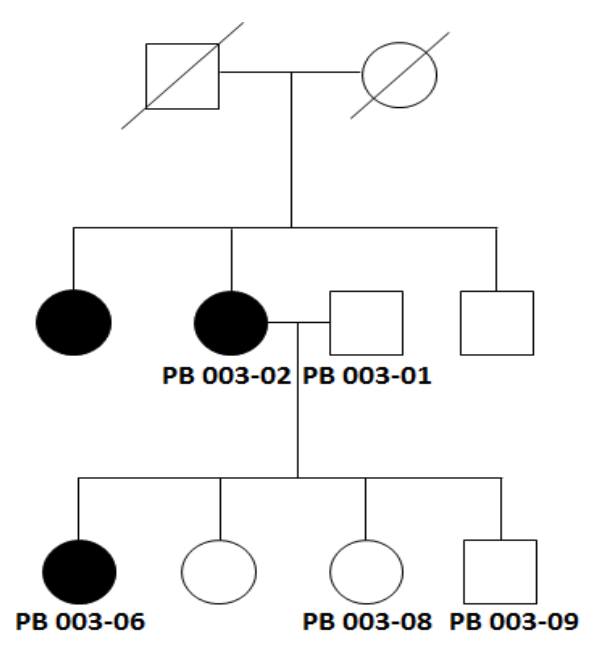

\section{Família PB 005}

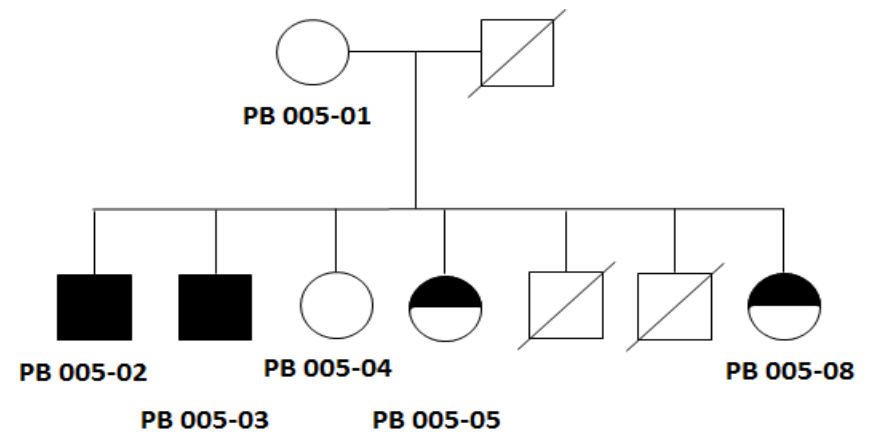




\section{Família PB 006}

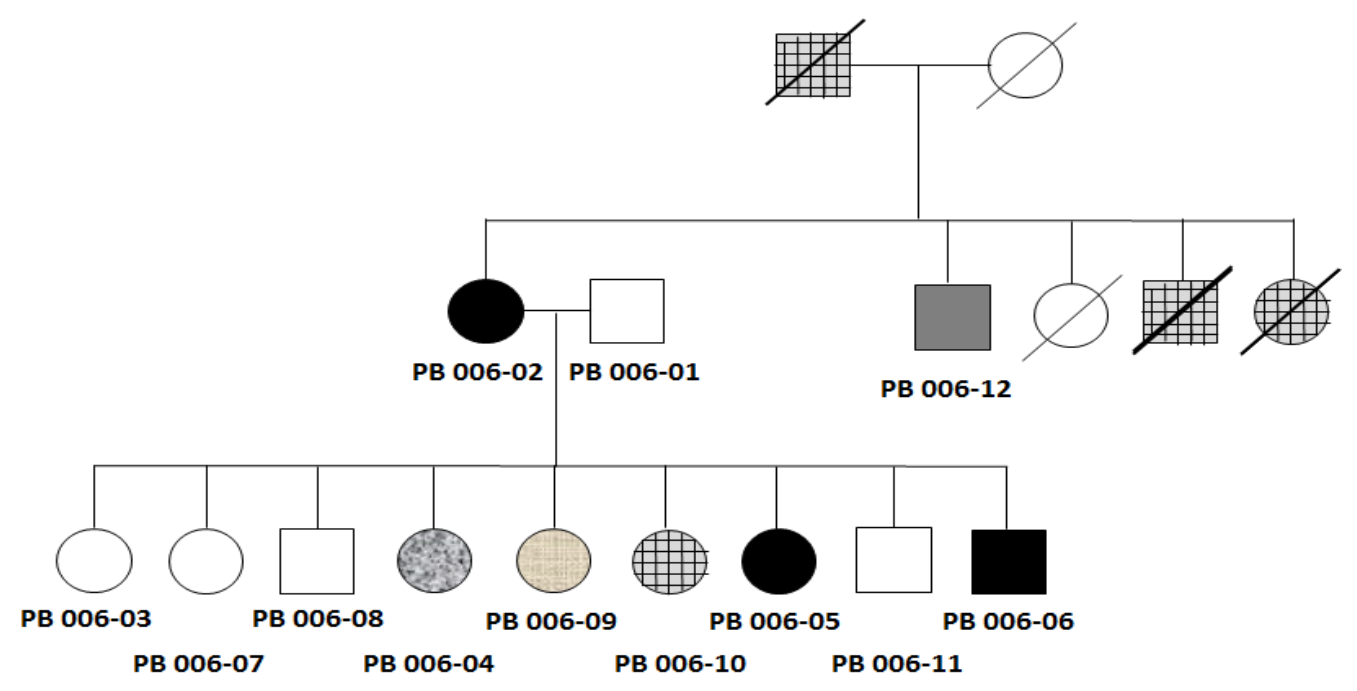

\section{Família PB 008}

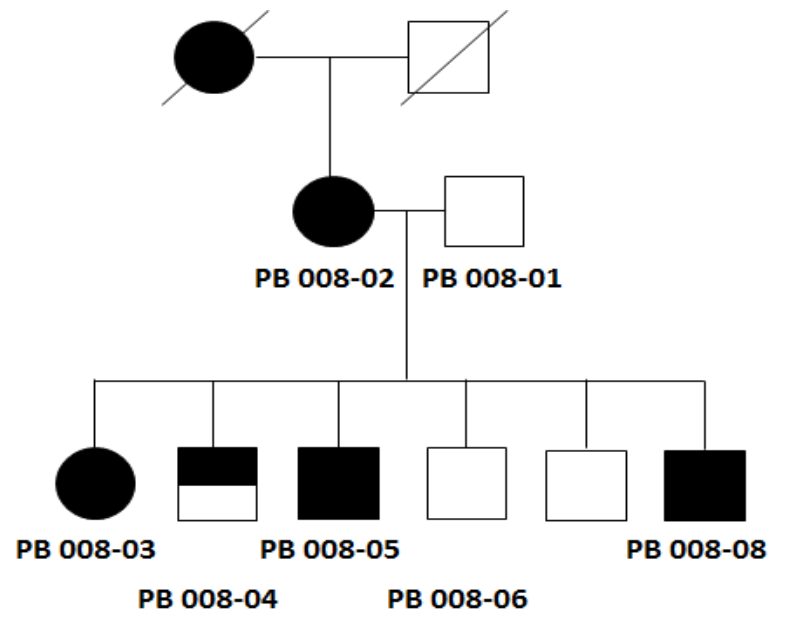

Família PB 010

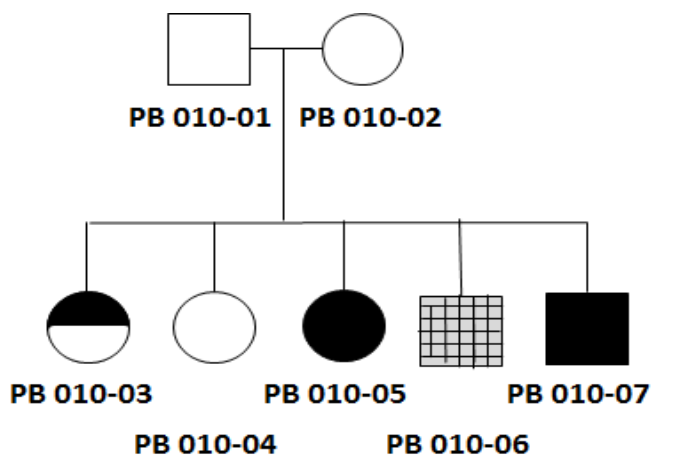




\section{Família PB 011}

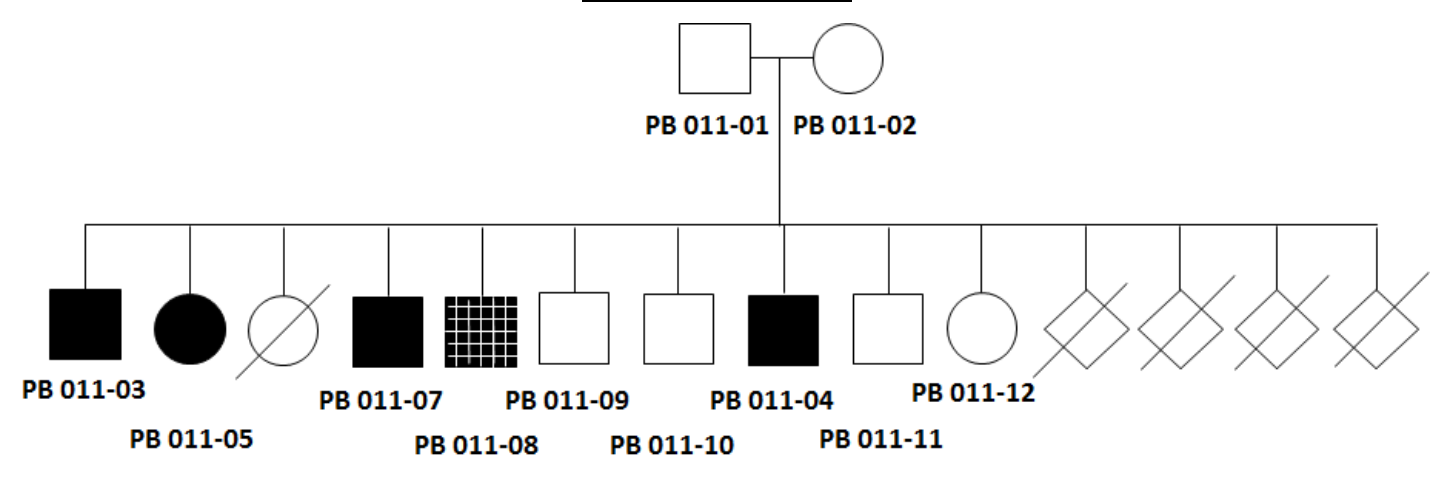

\section{Família PB 013}

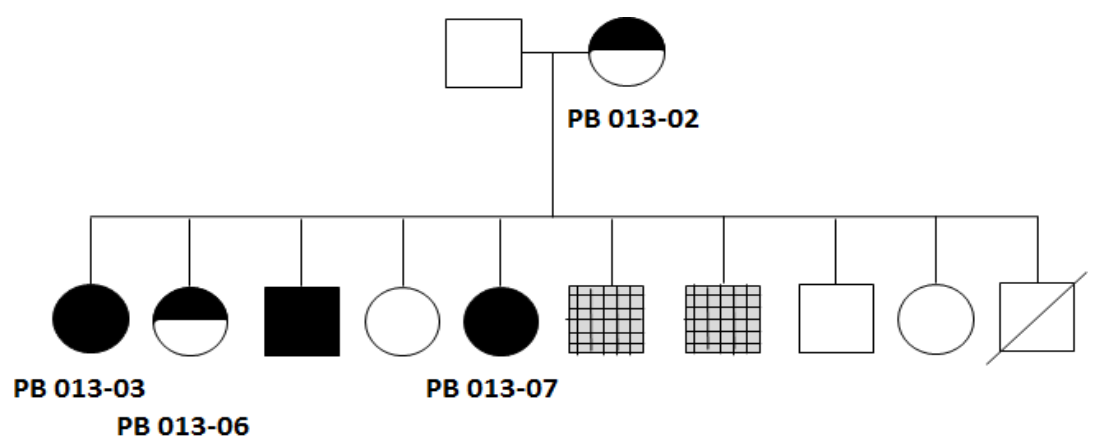

Família PB 014

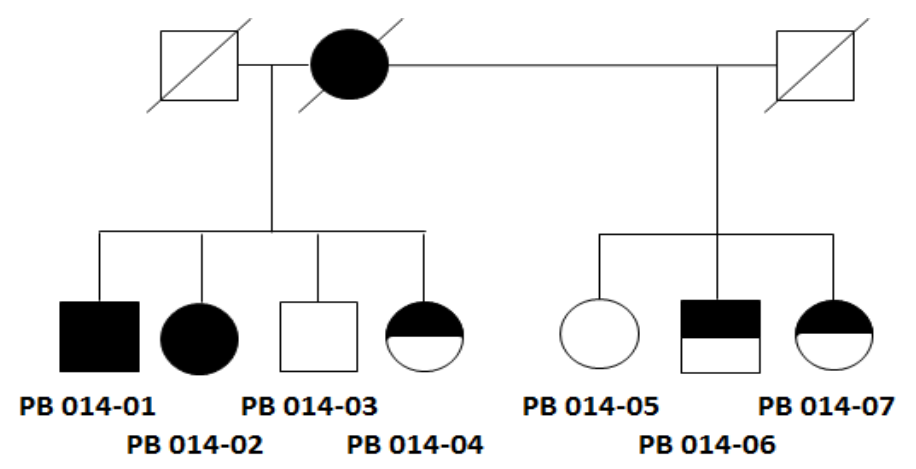

\section{Família PB 016}

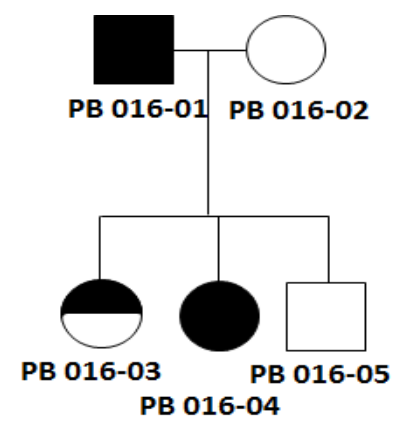




\section{Família PB 017}

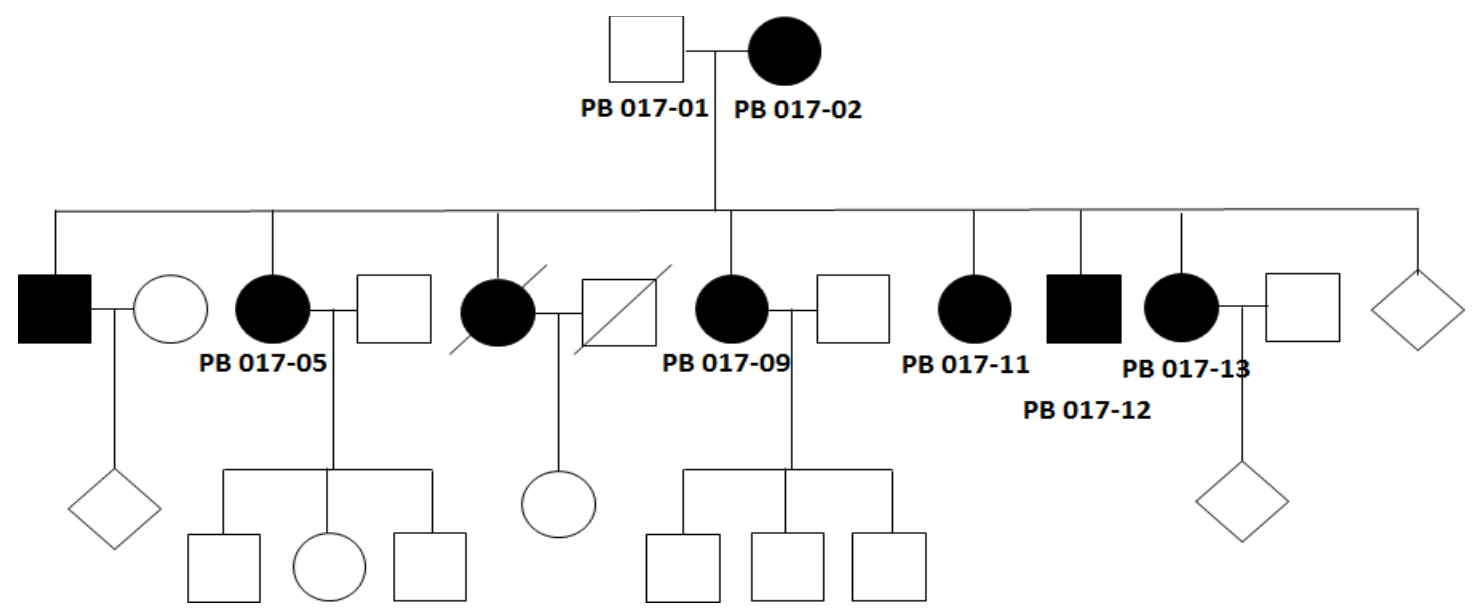

Família PB 020

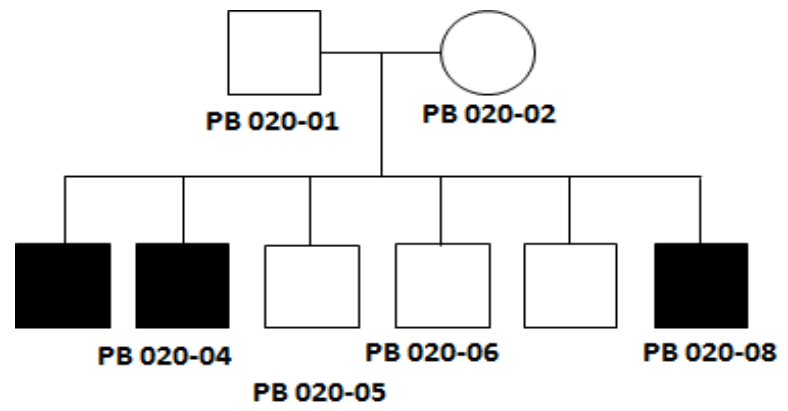

Família PB 021

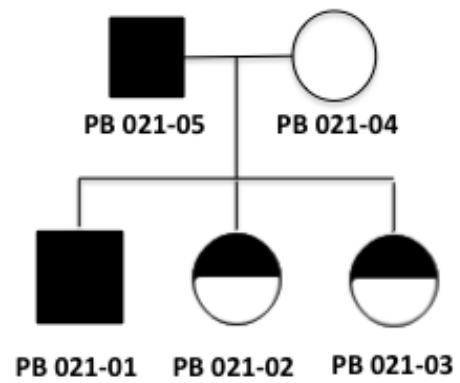


Família PS 023

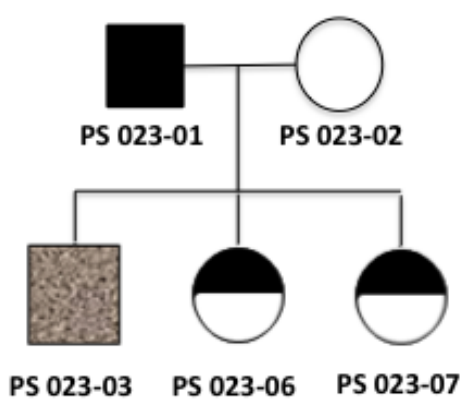

Família PB 024

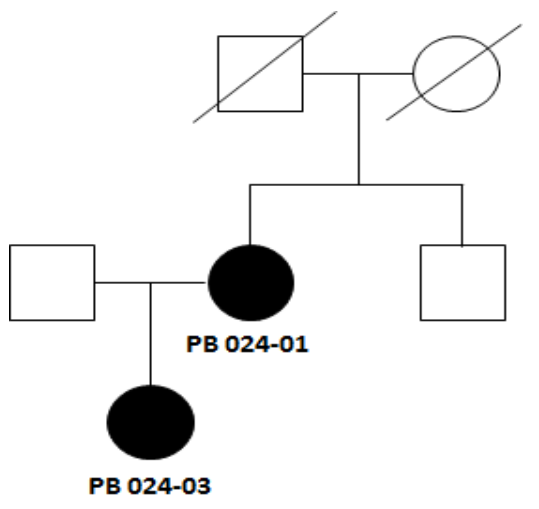

Família PB 025

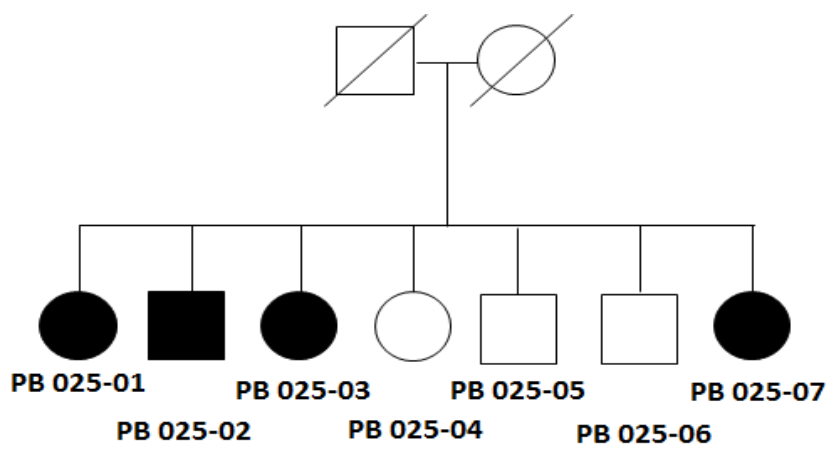




\section{Família PB 031}

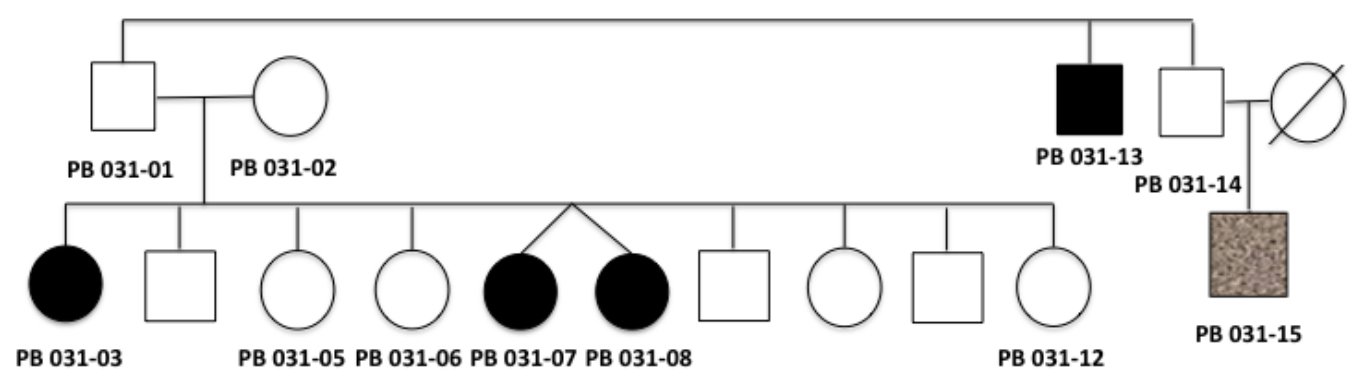

\section{Família PB 034}

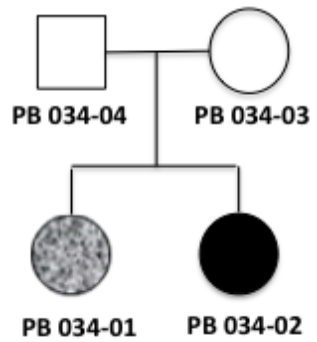

\section{Família PB 036}

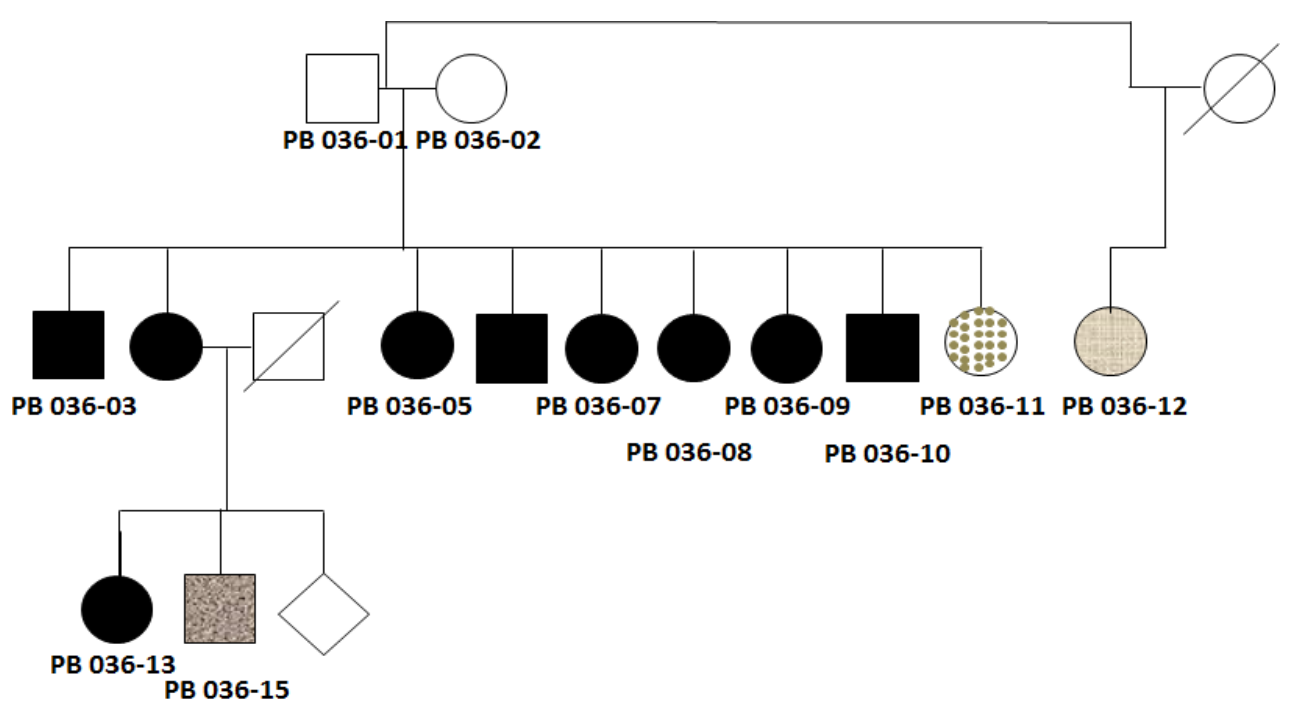




\section{Família PB 039}

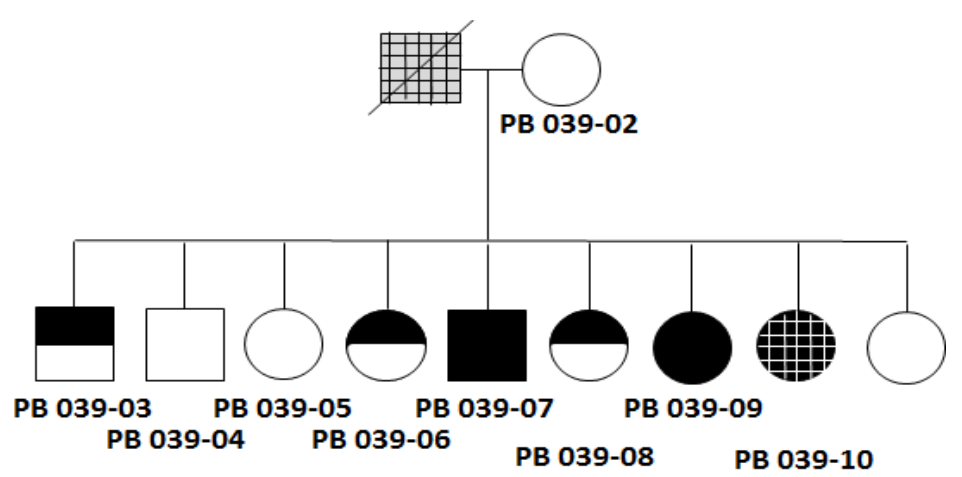

\section{Família PB 040}

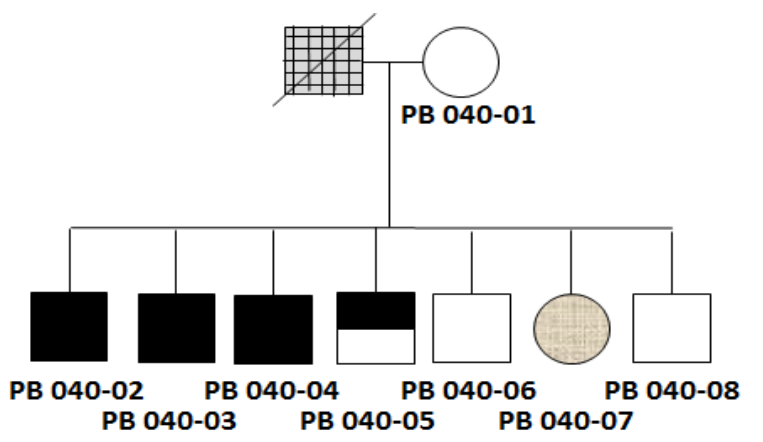

Família PB 042

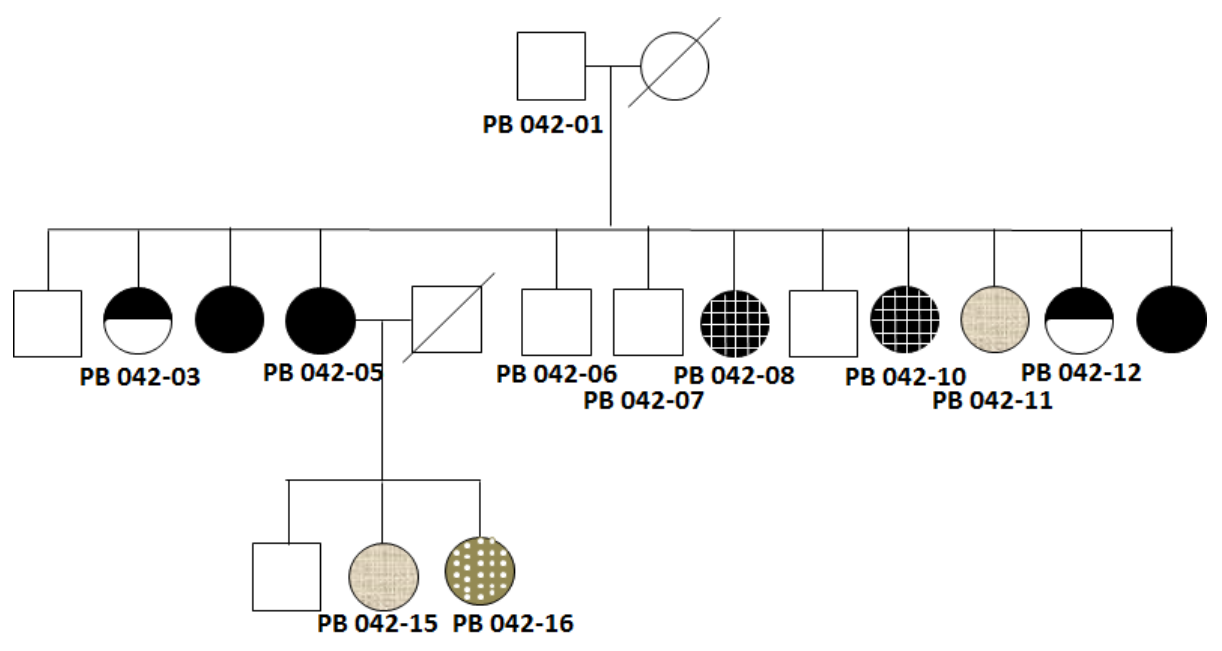




\section{Legenda}

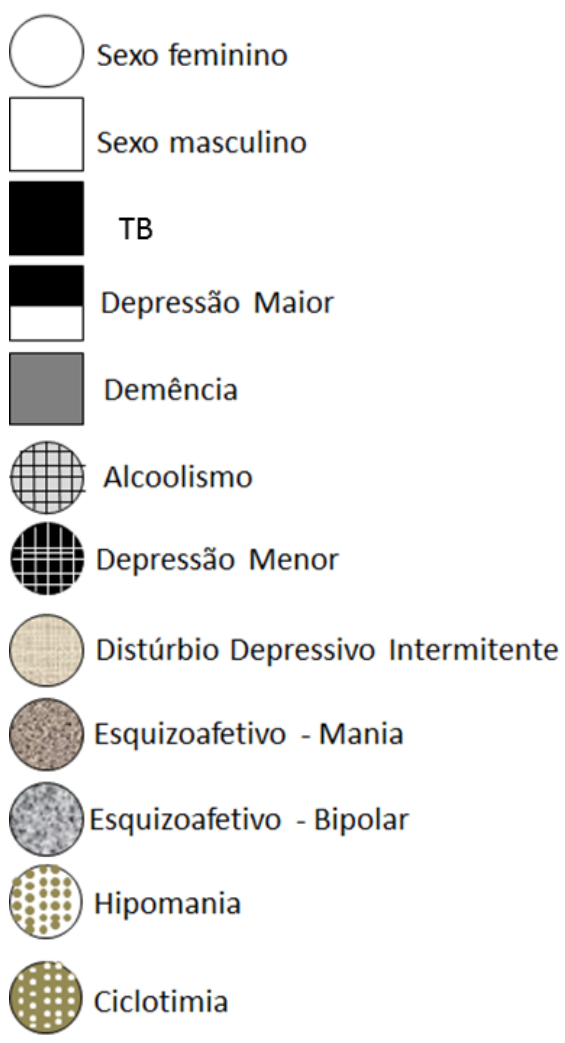


ANEXO B - Gráfico da correlação entre idade paterna e materna no nascimento da prole

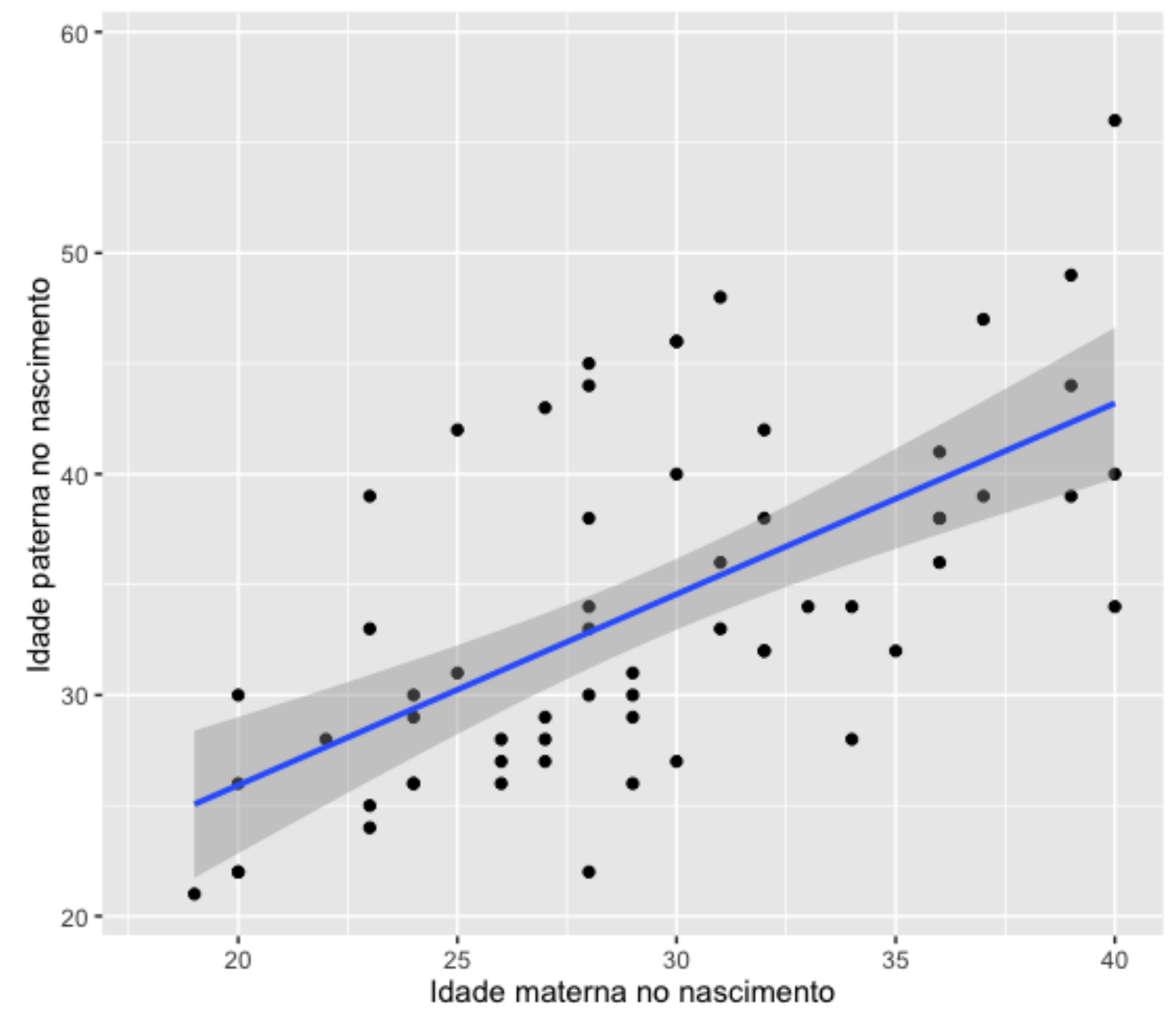

Figura 15 - Gráfico da correlação entre idade paterna e materna no nascimento da prole. Percebe-se uma alta correlação entre as idades do pai e da mãe no momento do nascimento dos filhos $\left(r^{2}=62 \% ; p=0,8 \times 10^{-8}\right)$ 
ANEXO C - Aprovação do comitê de ética em pesquisa - CEP

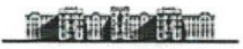 \\ MEDICINA \\ TSP \\ COMITÊ DE ÉTICA EM PESQUISA
}

\title{
APROVAÇÃO
}

O Comitê de Ética em Pesquisa da Faculdade de Medicina da Universidade de São Paulo, em sessão de 10/06/2015, APROVOU o Protocolo de Pesquisa no 215/15 intitulado: "AVALIAÇÃO DO COMPRIMENTO DE TELÔMEROS EM FAMÍlIAS COM VÁRIOS AFETADOS PELO TRANSTORNO BIPOLAR" apresentado pelo Departamento de PSIQUIATRIA

Cabe ao pesquisador elaborar e apresentar ao CEPFMUSP, os relatórios parciais e final sobre a pesquisa (Resolução do Conselho Nacional de Saúde no 466/12, inciso IX.2, letra "c").

Pesquisador (a) Responsável: Homero Pinto Vallada Filho Pesquisador (a) Executante: Daniela Silva Martinez

CEP-FMUSP, 10 de Junho de 2015.

$$
\text { Rlhemm. }
$$

Prof. Dr. Roger Chammas Coordenador

Comitê de Ética em Pesquisa 


\section{REFERÊNCIAS}

Al-Attas OS, Al-Daghri NM, Alokail MS, Alkharfy KM, Alfadda AA, McTernan P, et al. Circulating leukocyte telomere length is highly heritable among families of Arab descent. BMC Med Genet. 2012;13:38.

Allsopp RC, Vaziri H, Patterson C, Goldstein S, Younglai EV, Futcher AB, et al. Telomere length predicts replicative capacity of human fibroblasts. Proc Natl Acad Sci U S A. 1992;89(21):10114-8.

Almasy L, Blangero J. Multipoint quantitative-trait linkage analysis in general pedigrees. Am J Hum Genet. 1998;62(5):1198-211.

Alonso J, Petukhova M, Vilagut G, Chatterji S, Heeringa S, Ustun TB, et al. Days out of role due to common physical and mental conditions: results from the WHO World Mental Health surveys. Mol Psychiatry. 2011;16(12):1234-46.

American Psychiatry Association. Diagnostic and statistical manual of mental disorders. 5th ed. Arlington (VA): APA; 2013.

Andrade L, Walters EE, Gentil V, Laurenti R. Prevalence of ICD-10 mental disorders in a catchment area in the city of Sao Paulo, Brazil. Soc Psychiatry Psychiatr Epidemiol. 2002;37(7):316-25.

Andrew T, Aviv A, Falchi M, Surdulescu GL, Gardner JP, Lu X, et al. Mapping genetic loci that determine leukocyte telomere length in a large sample of unselected female sibling pairs. Am J Hum Genet. 2006;78(3):480-6.

Angst J, Preisig M. Outcome of a clinical cohort of unipolar, bipolar and schizoaffective patients. Results of a prospective study from 1959 to 1985. Schweiz Arch Neurol Psychiatr (1985). 1995;146(1):17-23.

Arsenis NC, You T, Ogawa EF, Tinsley GM, Zuo L. Physical activity and telomere length: Impact of aging and potential mechanisms of action. Oncotarget. 2017;8(27):45008-19. 
Asghar M, Bensch S, Tarka M, Hansson B, Hasselquist D. Maternal and genetic factors determine early life telomere length. Proc Biol Sci. 2015;282(1799):20142263.

Astuti Y, Wardhana A, Watkins J, Wulaningsih W. Cigarette smoking and telomere length: A systematic review of 84 studies and meta-analysis. Environ Res. 2017;158:480-9.

Atzmon G, Cho M, Cawthon RM, Budagov T, Katz M, Yang X, et al. Evolution in health and medicine Sackler colloquium: Genetic variation in human telomerase is associated with telomere length in Ashkenazi centenarians. Proc Natl Acad SciU S A. 2009;107 Suppl 1:1710-7.

Aubert G, Lansdorp PM. Telomeres and aging. Physiol Rev. 2008;88(2):557-79. Autexier C, Greider CW. Telomerase and cancer: revisiting the telomere hypothesis. Trends Biochem Sci. 1996;21(10):387-91.

Aviv A, Valdes AM, Spector TD. Human telomere biology: pitfalls of moving from the laboratory to epidemiology. Int J Epidemiol. 2006;35(6):1424-9.

Barbe-Tuana FM, Parisi MM, Panizzutti BS, Fries GR, Grun LK, Guma FT, et al. Shortened telomere length in bipolar disorder: a comparison of the early and late stages of disease. Rev Bras Psiquiatr. 2016;38(4):281-6.

Baum AE, Akula N, Cabanero M, Cardona I, Corona W, Klemens B, et al. A genome-wide association study implicates diacylglycerol kinase eta (DGKH) and several other genes in the etiology of bipolar disorder. Mol Psychiatry. 2008;13(2):197-207.

Bebbington P, Ramana R. The epidemiology of bipolar affective disorder. Soc Psychiatry Psychiatr Epidemiol. 1995;30(6):279-92.

Birmaher B, Gill MK, Axelson DA, Goldstein BI, Goldstein TR, Yu H, et al. Longitudinal trajectories and associated baseline predictors in youths with bipolar spectrum disorders. Am J Psychiatry. 2014;171(9):990-9.

Blackburn EH. Switching and signaling at the telomere. Cell. 2001;106(6):66173. 
Blackburn EH. Telomere states and cell fates. Nature. 2000;408(6808):53-6.

Blasco MA. The epigenetic regulation of mammalian telomeres. Nat Rev Genet. 2007;8(4):299-309.

Brietzke E, Kauer Sant'anna M, Jackowski A, Grassi-Oliveira R, Bucker J, Zugman A, et al. Impact of childhood stress on psychopathology. Rev Bras Psiquiatr. 2012;34(4):480-8.

Broer L, Codd V, Nyholt DR, Deelen J, Mangino M, Willemsen G, et al. Metaanalysis of telomere length in 19,713 subjects reveals high heritability, stronger maternal inheritance and a paternal age effect. Eur $J$ Hum Genet. 2013;21(10):1163-8.

Burton PR. Genome-wide association study of 14,000 cases of seven common diseases and 3,000 shared controls. Nature. 2007;447(7145):661-78.

Cai N, Chang S, Li Y, Li Q, Hu J, Liang J, et al. Molecular signatures of major depression. Curr Biol. 2015;25(9):1146-56.

Cawthon RM, Smith KR, O'Brien E, Sivatchenko A, Kerber RA. Association between telomere length in blood and mortality in people aged 60 years or older. Lancet. 2003;361(9355):393-5.

Cawthon RM. Telomere length measurement by a novel monochrome multiplex quantitative PCR method. Nucleic Acids Res. 2009;37(3):e21.

Cawthon RM. Telomere measurement by quantitative PCR. Nucleic Acids Res. 2002;30(10):e47.

Chang CK, Hayes RD, Perera G, Broadbent MT, Fernandes AC, Lee WE, et al. Life expectancy at birth for people with serious mental illness and other major disorders from a secondary mental health care case register in London. PLOS One. 2011;6(5):e19590.

Charlson FJ, Baxter AJ, Dua T, Degenhardt L, Whiteford HA, Vos T. Excess Mortality from Mental, Neurological, and Substance Use Disorders in the Global Burden of Disease Study 2010. In: Patel V, Chisholm D, Dua T, Laxminarayan R, Medina-Mora ME, editors. Mental, Neurological, and Substance Use 
Disorders: Disease Control Priorities. 3rd ed. Washington (DC): The International Bank for Reconstruction and Development/The World Bank; 2016.

Chengappa KN, Levine J, Gershon S, Kupfer DJ. Lifetime prevalence of substance or alcohol abuse and dependence among subjects with bipolar I and II disorders in a voluntary registry. Bipolar Disord. 2000;2(3 Pt 1):191-5.

Codd V, Nelson CP, Albrecht E, Mangino M, Deelen J, Buxton JL, et al. Identification of seven loci affecting mean telomere length and their association with disease. Nat Genet. 2013;45(4):422-7, 7e1-2.

Colpo GD, Leffa DD, Kohler CA, Kapczinski F, Quevedo J, Carvalho AF. Is bipolar disorder associated with accelerating aging? A meta-analysis of telomere length studies. J Affect Disord. 2015;186:241-8.

Costa Dde S, Rosa DV, Barros AG, Romano-Silva MA, Malloy-Diniz LF, Mattos $P$, et al. Telomere length is highly inherited and associated with hyperactivityimpulsivity in children with attention deficit/hyperactivity disorder. Front $\mathrm{Mol}$ Neurosci. 2015;8:28.

Craddock N, Jones I. Genetics of bipolar disorder. J Med Genet. 1999;36(8):585-94.

Craddock N, Sklar P. Genetics of bipolar disorder. Lancet. 2013;381(9878):1654-62.

Cummings MR. Human heredity: Principles and issues. 9a ed. Boston, MA, United States: Brooks/Cole Cengage Learning; 2010. p. 103.

Cuomo A, Nikolova VL, Yalin N, Arnone D, Fagiolini A, Young AH. Pharmacological treatment of mixed states. CNS Spectr. 2017;22(2):186-95.

Darrow SM, Verhoeven JE, Revesz D, Lindqvist D, Penninx BW, Delucchi KL, et al. The Association Between Psychiatric Disorders and Telomere Length: A Meta-Analysis Involving 14,827 Persons. Psychosom Med. 2016;78(7):776-87. 
de Abreu LN, Nery FG, Harkavy-Friedman JM, de Almeida KM, Gomes BC, Oquendo MA, et al. Suicide attempts are associated with worse quality of life in patients with bipolar disorder type I. Compr Psychiatry. 2011;53(2):125-9.

de Andrade $\mathrm{M}$, Amos $\mathrm{Cl}$, Thiel TJ. Methods to estimate genetic components of variance for quantitative traits in family studies. Genet Epidemiol. 1999;17(1):64-76.

De Meyer T, Eisenberg DT. Possible technical and biological explanations for the 'parental telomere length inheritance discrepancy' enigma. Eur J Hum Genet. 23. England2015. p. 3-4.

De Meyer T, Rietzschel ER, De Buyzere ML, De Bacquer D, Van Criekinge W, De Backer GG, et al. Paternal age at birth is an important determinant of offspring telomere length. Hum Mol Genet. 2007;16(24):3097-102.

Deelen J, Uh HW, Monajemi R, van Heemst D, Thijssen PE, Bohringer S, et al. Gene set analysis of GWAS data for human longevity highlights the relevance of the insulin/IGF-1 signaling and telomere maintenance pathways. Age (Dordr). 2011;35(1):235-49.

Djojosubroto MW, Choi YS, Lee HW, Rudolph KL. Telomeres and telomerase in aging, regeneration and cancer. Mol Cells. 2003;15(2):164-75.

Eisenberg DT, Hayes MG, Kuzawa CW. Delayed paternal age of reproduction in humans is associated with longer telomeres across two generations of descendants. Proc Natl Acad Sci U S A. 2012;109(26):10251-6.

Eisenberg DT, Tackney J, Cawthon RM, Cloutier CT, Hawkes K. Paternal and grandpaternal ages at conception and descendant telomere lengths in chimpanzees and humans. Am J Phys Anthropol. 2017;162(2):201-7.

Elvsashagen T, Vera E, Boen E, Bratlie J, Andreassen OA, Josefsen D, et al. The load of short telomeres is increased and associated with lifetime number of depressive episodes in bipolar II disorder. J Affect Disord. 2011;135(1-3):43-50.

Endicott J, Spitzer RL. A diagnostic interview: the schedule for affective disorders and schizophrenia. Arch Gen Psychiatry. 1978;35(7):837-44. 
Engelhardt M, Finke J. Does telomere shortening count? Blood. $2001 ; 98(3): 888-90$.

Epel ES, Blackburn EH, Lin J, Dhabhar FS, Adler NE, Morrow JD, et al. Accelerated telomere shortening in response to life stress. Proc Natl Acad Sci U S A. 2004;101(49):17312-5.

Fagan E, Sun F, Bae H, Elo I, Andersen SL, Lee J, et al. Telomere length is longer in women with late maternal age. Menopause. 2017;24(5):497-501.

Ferlin A, Rampazzo E, Rocca MS, Keppel S, Frigo AC, De Rossi A, et al. In young men sperm telomere length is related to sperm number and parental age. Hum Reprod. 2013;28(12):3370-6.

Ferreira MA, O'Donovan MC, Meng YA, Jones IR, Ruderfer DM, Jones L, et al. Collaborative genome-wide association analysis supports a role for ANK3 and CACNA1C in bipolar disorder. Nat Genet. 2008;40(9):1056-8.

Forero DA, Gonzalez-Giraldo Y, Lopez-Quintero C, Castro-Vega LJ, Barreto GE, Perry G. Meta-analysis of Telomere Length in Alzheimer's Disease. J Gerontol A Biol Sci Med Sci. 2016;71(8):1069-73.

Frans EM, Sandin S, Reichenberg A, Lichtenstein P, Langstrom N, Hultman CM. Advancing paternal age and bipolar disorder. Arch Gen Psychiatry. 2008;65(9):1034-40.

Frenck RW, Jr., Blackburn EH, Shannon KM. The rate of telomere sequence loss in human leukocytes varies with age. Proc Natl Acad Sci $U S A$. 1998;95(10):5607-10.

Gitlin MJ, Swendsen J, Heller TL, Hammen C. Relapse and impairment in bipolar disorder. Am J Psychiatry. 1995;152(11):1635-40.

Goodwin FK, Jamison KR. Manic-Depressive Illness. 1a ed. New York, NY: Oxford University Press; 1990.

Grande I, Berk M, Birmaher B, Vieta E. Bipolar disorder. Lancet. 2016;387(10027):1561-72. 
Greenwood TA, Badner JA, Byerley W, Keck PE, McElroy SL, Remick RA, et al. Heritability and genome-wide SNP linkage analysis of temperament in bipolar disorder. J Affect Disord. 2013;150(3):1031-40.

Greider CW, Blackburn EH. Telomeres, telomerase and cancer. Sci Am. 1996;274(2):92-7.

Guilleret I, Benhattar J. Demethylation of the human telomerase catalytic subunit (hTERT) gene promoter reduced hTERT expression and telomerase activity and shortened telomeres. Exp Cell Res. 2003;289(2):326-34.

Harley CB, Futcher AB, Greider CW. Telomeres shorten during ageing of human fibroblasts. Nature. 1990;345(6274):458-60.

Hartmann N, Boehner M, Groenen F, Kalb R. Telomere length of patients with major depression is shortened but independent from therapy and severity of the disease. Depress Anxiety. 2010;27(12):1111-6.

Hendrick V, Altshuler LL, Gitlin MJ, Delrahim S, Hammen C. Gender and bipolar illness. J Clin Psychiatry. 2000;61(5):393-6; quiz 7.

Hirschfeld RM, Lewis L, Vornik LA. Perceptions and impact of bipolar disorder: how far have we really come? Results of the national depressive and manicdepressive association 2000 survey of individuals with bipolar disorder. J Clin Psychiatry. 2003;64(2):161-74.

Honig LS, Kang MS, Cheng R, Eckfeldt JH, Thyagarajan B, Leiendecker-Foster $\mathrm{C}$, et al. Heritability of telomere length in a study of long-lived families. Neurobiol Aging. 2015;36(10):2785-90.

Issler CK, Monkul ES, Amaral JA, Tamada RS, Shavitt RG, Miguel EC, et al. Bipolar disorder and comorbid obsessive-compulsive disorder is associated with higher rates of anxiety and impulse control disorders. Acta Neuropsychiatr. 2010;22(2):81-6.

Jacoby AS, Vinberg M, Poulsen HE, Kessing LV, Munkholm K. Increased DNA and RNA damage by oxidation in patients with bipolar I disorder. Trans/ Psychiatry. 2016;6(8):e867. 
Jenkins EC, Ye L, Krinsky-McHale SJ, Zigman WB, Schupf N, Silverman WP. Telomere longitudinal shortening as a biomarker for dementia status of adults with Down syndrome. Am J Med Genet B Neuropsychiatr Genet. 2016;171b(2):169-74.

Jensen CM, Steinhausen HC. Time Trends in Lifetime Incidence Rates of FirstTime Diagnosed Bipolar and Depressive Disorders Across 16 Years in Danish Psychiatric Hospitals: A Nationwide Study. J Clin Psychiatry. 2016;77(12):e1570-e5.

Kessler RC, McGonagle KA, Zhao S, Nelson CB, Hughes M, Eshleman S, et al. Lifetime and 12-month prevalence of DSM-III-R psychiatric disorders in the United States. Results from the National Comorbidity Survey. Arch Gen Psychiatry. 1994;51(1):8-19.

Kessler RC, Rubinow DR, Holmes C, Abelson JM, Zhao S. The epidemiology of DSM-III-R bipolar I disorder in a general population survey. Psychol Med. 1997;27(5):1079-89.

Kimura M, Cherkas LF, Kato BS, Demissie S, Hjelmborg JB, Brimacombe M, et al. Offspring's leukocyte telomere length, paternal age, and telomere elongation in sperm. PLoS Genet. 2008;4(2):e37.

Klapper W, Parwaresch R, Krupp G. Telomere biology in human aging and aging syndromes. Mech Ageing Dev. 2001;122(7):695-712.

Koch GG. Intraclass correlation coefficient. Encyclopedia of Statistical Sciences. New York: Wiley, 2006.

Kose Cinar R. Telomere length and hTERT in mania and subsequent remission. Rev Bras Psiquiatr. 2017:0.

Kupfer DJ, Frank E, Grochocinski VJ, Cluss PA, Houck PR, Stapf DA. Demographic and clinical characteristics of individuals in a bipolar disorder case registry. J Clin Psychiatry. 2002;63(2):120-5.

Lange K. Mathematical and Statistical Methods for Genetic Analysis. 2a ed. New York: Springer-Verlag; 2002. 
Leckman JF, Weissman MM, Pauls DL, Kidd KK. Family-genetic studies and identification of valid diagnostic categories in adult and child psychiatry. $\mathrm{Br} J$ Psychiatry. 1987;151:39-44.

Lecrubier $Y$. The influence of comorbidity on the prevalence of suicidal behaviour. Eur Psychiatry. 2001;16(7):395-9.

Lima IM, Barros A, Rosa DV, Albuquerque M, Malloy-Diniz L, Neves FS, et al. Analysis of telomere attrition in bipolar disorder. J Affect Disord. 2015;172:43-7.

Lin JP, Cupples LA, Wilson PW, Heard-Costa N, O'Donnell CJ. Evidence for a gene influencing serum bilirubin on chromosome $2 q$ telomere: a genomewide scan in the Framingham study. Am J Hum Genet. 2003;72(4):1029-34.

Lindqvist D, Epel ES, Mellon SH, Penninx BW, Revesz D, Verhoeven JE, et al. Psychiatric disorders and leukocyte telomere length: Underlying mechanisms linking mental illness with cellular aging. Neurosci Biobehav Rev. 2015;55:33364.

Lish JD, Dime-Meenan S, Whybrow PC, Price RA, Hirschfeld RM. The National Depressive and Manic-depressive Association (DMDA) survey of bipolar members. J Affect Disord. 1994;31(4):281-94.

Malaspina D, Dracxler R, Walsh-Messinger J, Harlap S, Goetz RR, Keefe D, et al. Telomere length, family history, and paternal age in schizophrenia. Mol Genet Genomic Med. 2014;2(4):326-31.

Maletic V, Raison C. Integrated neurobiology of bipolar disorder. Front Psychiatry. 2014;5:98.

Martinsson L, Wei Y, Xu D, Melas PA, Mathe AA, Schalling M, et al. Long-term lithium treatment in bipolar disorder is associated with longer leukocyte telomeres. Transl Psychiatry. 2013;3:e261.

McGuffin P, Farmer A, Harvey I. A polydiagnostic application of operational criteria in studies of psychotic illness. Development and reliability of the OPCRIT system. Arch Gen Psychiatry. 1991;48(8):764-70. 
Merikangas KR, Jin R, He JP, Kessler RC, Lee S, Sampson NA, et al. Prevalence and correlates of bipolar spectrum disorder in the world mental health survey initiative. Arch Gen Psychiatry. 2011;68(3):241-51.

Muneer A. Mixed States in Bipolar Disorder: Etiology, Pathogenesis and Treatment. Chonnam Med J. 2017;53(1):1-13.

Murray CJ, Lopez AD. Global mortality, disability, and the contribution of risk factors: Global Burden of Disease Study. Lancet. 1997;349(9063):1436-42.

Nawrot TS, Staessen JA, Gardner JP, Aviv A. Telomere length and possible link to X chromosome. Lancet. 2004;363(9408):507-10.

Nery FG, Stanley JA, Chen HH, Hatch JP, Nicoletti MA, Monkul ES, et al. Bipolar disorder comorbid with alcoholism: a $1 \mathrm{H}$ magnetic resonance spectroscopy study. J Psychiatr Res. 2009;44(5):278-85.

Njajou OT, Cawthon RM, Damcott CM, Wu SH, Ott S, Garant MJ, et al. Telomere length is paternally inherited and is associated with parental lifespan. Proc Natl Acad Sci U S A. 2007;104(29):12135-9.

Opresko PL, Shay JW. Telomere-associated aging disorders. Ageing Res Rev. 2017;33:52-66.

Osby U, Brandt L, Correia N, Ekbom A, Sparen P. Excess mortality in bipolar and unipolar disorder in Sweden. Arch Gen Psychiatry. 2001;58(9):844-50.

Otsuka I, Izumi T, Boku S, Kimura A, Zhang Y, Mouri K, et al. Aberrant telomere length and mitochondrial DNA copy number in suicide completers. Sci Rep. $2017 ; 7(1): 3176$.

Owen R, Gooding P, Dempsey R, Jones S. The Reciprocal Relationship between Bipolar Disorder and Social Interaction: A Qualitative Investigation. Clin Psychol Psychother. 2017;24(4):911-8.

Perugi G, Akiskal HS, Micheli C, Toni C, Madaro D. Clinical characterization of depressive mixed state in bipolar-I patients: Pisa-San Diego collaboration. $J$ Affect Disord. 2001;67(1-3):105-14. 
Perugi G, Toni C, Akiskal HS. Anxious-bipolar comorbidity. Diagnostic and treatment challenges. Psychiatr Clin North Am. 1999;22(3):565-83, viii.

Powell TR, Dima D, Frangou S, Breen G. Telomere Length and Bipolar Disorder. Neuropsychopharmacology. 2017.

Prescott J, Du M, Wong JY, Han J, De Vivo I. Paternal age at birth is associated with offspring leukocyte telomere length in the nurses' health study. Hum Reprod. 2012;27(12):3622-31.

Pru JK. Late maternal age at last childbirth and telomere homeostasis. Menopause. 2017;24(5):478-9.

Purcell SM, Wray NR, Stone JL, Visscher PM, O'Donovan MC, Sullivan PF, et al. Common polygenic variation contributes to risk of schizophrenia and bipolar disorder. Nature. 2009;460(7256):748-52.

Rizzo LB, Costa LG, Mansur RB, Swardfager W, Belangero SI, Grassi-Oliveira $\mathrm{R}$, et al. The theory of bipolar disorder as an illness of accelerated aging: implications for clinical care and research. Neurosci Biobehav Rev. 2014;42:157-69.

Rizzo LB, Do Prado CH, Grassi-Oliveira R, Wieck A, Correa BL, Teixeira AL, et al. Immunosenescence is associated with human cytomegalovirus and shortened telomeres in type I bipolar disorder. Bipolar Disord. 2013;15(8):832-8.

Rode L, Nordestgaard BG, Weischer M, Bojesen SE. Increased body mass index, elevated C-reactive protein, and short telomere length. J Clin Endocrinol Metab. 2014;99(9):E1671-5.

Romano GH, Harari Y, Yehuda T, Podhorzer A, Rubinstein L, Shamir R, et al. Environmental stresses disrupt telomere length homeostasis. PLoS Genet. 2013;9(9):e1003721.

Sajatovic M. Bipolar disorder: disease burden. Am J Manag Care. 2005;11(3 Suppl):S80-4. 
Scott LJ, Muglia $\mathrm{P}$, Kong $\mathrm{XQ}$, Guan $\mathrm{W}$, Flickinger $\mathrm{M}$, Upmanyu $\mathrm{R}$, et al. Genome-wide association and meta-analysis of bipolar disorder in individuals of European ancestry. Proc Natl Acad Sci U S A. 2009;106(18):7501-6.

Serretti A, Mandelli L. The genetics of bipolar disorder: genome 'hot regions,' genes, new potential candidates and future directions. Mol Psychiatry. 2008;13(8):742-71.

Shulman KI, Herrmann N. Bipolar disorder in old age. Can Fam Physician. 1999;45:1229-37.

Simon NM, Smoller JW, McNamara KL, Maser RS, Zalta AK, Pollack MH, et al. Telomere shortening and mood disorders: preliminary support for a chronic stress model of accelerated aging. Biol Psychiatry. 2006;60(5):432-5.

Sipos A, Rasmussen F, Harrison G, Tynelius P, Lewis G, Leon DA, et al. Paternal age and schizophrenia: a population based cohort study. BMJ. 2004;329(7474):1070.

Sklar P, S R, Scott LJ, Schalling M. Large-scale genome-wide association analysis of bipolar disorder identifies a new susceptibility locus near ODZ4. Nat Genet. 2011;43(10):977-83.

Sklar P, Smoller JW, Fan J, Ferreira MA, Perlis RH, Chambert K, et al. Wholegenome association study of bipolar disorder. Mol Psychiatry. 2008;13(6):55869.

Slagboom PE, Droog S, Boomsma DI. Genetic determination of telomere size in humans: a twin study of three age groups. Am J Hum Genet. 1994;55(5):87682.

Smith EN, Bloss CS, Badner JA, Barrett T, Belmonte PL, Berrettini W, et al. Genome-wide association study of bipolar disorder in European American and African American individuals. Mol Psychiatry. 2009;14(8):755-63.

Soerensen M, Thinggaard M, Nygaard M, Dato S, Tan Q, Hjelmborg J, et al. Genetic variation in TERT and TERC and human leukocyte telomere length and 
longevity: a cross-sectional and longitudinal analysis. Aging Cell. $2011 ; 11(2): 223-7$.

Sonne SC, Brady KT. Substance abuse and bipolar comorbidity. Psychiatr Clin North Am. 1999;22(3):609-27, ix.

Spitzer RL, Endicott J, Robins E. Research diagnostic criteria. Psychopharmacol Bull. 1975;11(3):22-5.

Squassina A, Pisanu C, Congiu D, Caria P, Frau D, Niola P, et al. Leukocyte telomere length positively correlates with duration of lithium treatment in bipolar disorder patients. Eur Neuropsychopharmacol. 2016;26(7):1241-7.

Squassina A, Pisanu C, Corbett N, Alda M. Telomere length in bipolar disorder and lithium response. Eur Neuropsychopharmacol. 2015.

Suppes T, Leverich GS, Keck PE, Nolen WA, Denicoff KD, Altshuler LL, et al. The Stanley Foundation Bipolar Treatment Outcome Network. II. Demographics and illness characteristics of the first 261 patients. J Affect Disord. 2001;67(13):45-59.

Svenson U, Nordfjall K, Baird D, Roger L, Osterman P, Hellenius ML, et al. Blood cell telomere length is a dynamic feature. PLoS One. 2011;6(6):e21485.

Szadoczky E, Papp Z, Vitrai J, Rihmer Z, Furedi J. The prevalence of major depressive and bipolar disorders in Hungary. Results from a national epidemiologic survey. J Affect Disord. 1998;50(2-3):153-62.

Szebeni A, Szebeni K, DiPeri T, Chandley MJ, Crawford JD, Stockmeier CA, et al. Shortened telomere length in white matter oligodendrocytes in major depression: potential role of oxidative stress. Int $J$ Neuropsychopharmacol. 2014;17(10):1579-89.

Taylor L, Faraone SV, Tsuang MT. Family, twin, and adoption studies of bipolar disease. Curr Psychiatry Rep. 2002;4(2):130-3.

Tearne JE, Robinson M, Jacoby P, Allen KL, Cunningham NK, Li J, et al. Older maternal age is associated with depression, anxiety, and stress symptoms in young adult female offspring. J Abnorm Psychol. 2016;125(1):1-10. 
Tollefsbol TO, Andrews LG. Mechanisms for telomerase gene control in aging cells and tumorigenesis. Med Hypotheses. 2001;56(6):630-7.

Tsuang MT, Dempsey GM, Dvoredsky A, Struss A. A family history study of schizo-affective disorder. Biol Psychiatry. 1977;12(3):331-8.

Vasconcelos-Moreno MP, Fries GR, Gubert C, Dos Santos B, Fijtman A, Sartori $J$, et al. Telomere Length, Oxidative Stress, Inflammation and BDNF Levels in Siblings of Patients with Bipolar Disorder: Implications for Accelerated Cellular Aging. Int J Neuropsychopharmacol. 2017;20(6):445-54.

von Zglinicki T. Oxidative stress shortens telomeres. Trends Biochem Sci. 2002;27(7):339-44.

Weir BS, Anderson AD, Hepler AB. Genetic relatedness analysis: modern data and new challenges. Nat Rev Genet. 2006;7(10):771-80.

Weissman MM, Bland RC, Canino GJ, Faravelli C, Greenwald S, Hwu HG, et al. Cross-national epidemiology of major depression and bipolar disorder. Jama. 1996;276(4):293-9.

Weissman MM, Leaf PJ, Tischler GL, Blazer DG, Karno M, Bruce ML, et al. Affective disorders in five United States communities. Psychol Med. 1988;18(1):141-53.

Wolkowitz OM, Mellon SH, Epel ES, Lin J, Dhabhar FS, Su Y, et al. Leukocyte telomere length in major depression: correlations with chronicity, inflammation and oxidative stress--preliminary findings. PLoS One. 2011;6(3):e17837.

World Health Organization. International Statistical Classification of Diseases and Related Health Problems (ICD-10). 10th revision. Geneva: WHO; 2010.

$\mathrm{Xi} \mathrm{H}$, Li C, Ren F, Zhang $\mathrm{H}$, Zhang L. Telomere, aging and age-related diseases. Aging Clin Exp Res. 2013;25(2):139-46.

Yassa R, Nair V, Nastase C, Camille Y, Belzile L. Prevalence of bipolar disorder in a psychogeriatric population. J Affect Disord. 1988;14(3):197-201.

Zhang D, Cheng L, Craig DW, Redman M, Liu C. Cerebellar telomere length and psychiatric disorders. Behav Genet. 2010;40(2):250-4. 
Zhang X, Zhao Q, Zhu W, Liu T, Xie SH, Zhong LX, et al. The Association of Telomere Length in Peripheral Blood Cells with Cancer Risk: A Systematic Review and Meta-analysis of Prospective Studies. Cancer Epidemiol Biomarkers Prev. 2017;26(9):1381-90.

Zhu Y, Voruganti VS, Lin J, Matsuguchi T, Blackburn E, Best LG, et al. QTL mapping of leukocyte telomere length in American Indians: the Strong Heart Family Study. Aging (Albany NY). 2013;5(9):704-16.

Zivanovic O, Nedic A. Kraepelin's concept of manic-depressive insanity: one hundred years later. J Affect Disord. 2012;137(1-3):15-24. 


\section{Apêndice}

Apêndice A - Descrição e avaliação do apoio institucional recebido

O presente estudo foi desenvolvido em parte no ProGene (ligado ao LIM-23), no Instituto de Psiquiatria (IPq) do HC-FMUSP e outra parte no Laboratório de Genética Molecular e Cardiologia (LGCM) do Instituto do Coração (InCor) do HC-FMUSP. O LGCM contribuiu em grande parte na discussão sobre as análises estatísticas e interpretação dos resultados. Os laboratórios ofereceram toda a infraestrutura necessária para 0 desenvolvimento do projeto ( $n^{\circ}$ processo FAPESP: 2015/14614-6) e CNPq ( $n^{\circ}$ processo: 448735/2014-8).

Além do apoio local, e a partir de colaborações previamente estabelecidas, o presente projeto contou também com a colaboração de pesquisadores do Instituto Karolinska (Martin Schalling \& Catharina Lavebratt) da Suécia. 
Apêndice B - Produções acadêmicas durante o mestrado

1. Resumos publicados em anais de congresso:

"Association of lithium response to telomere length in Bipolar Disorder in a Brazilian cohort'. MICHELON, L.; MARTINEZ, D. S.; CHILE, T.; GOUVEIA, G.; CAMILO, C.; SCHALLING, M.; VALLADA, H.. Painel apresentado no XXIII World Congress of Psychiatric Genetics (WCPG) em Toronto em Outubro de 2015.

"High heritability of telomere length in families with Bipolar Disorder". MARTINEZ, D. S.; MILLISCHER, V.; MICHELON, L.; CAMILO, C.; BRENTANI, H.; ESTEBAN, N.; KRIEGER, J.; PEREIRA, A.; LAVEBRATT, C.; SCHALLING, M.; VALLADA, H.. Painel apresentado no XXIV World Congress of Psychiatric Genetics (WCPG) em Jerusalem em Outubro de 2016.

"PER3 Polymorphisms, Morningness-Eveningness and Depression: Preliminary Evidence in a Brazilian Family-Based Cohort, the Baependi Heart Study". RUIZ, F. S.; TAPOROSKI; T. P.; MARTINEZ, D. S.; BEALE, A.; BEIJAMINI, F.; NEGRÃO, A. B.; KRIEGER, J. E.; KNUTSON, K. L.; PEREIRA, A. C.; PEDRAZZOLI, M.; VALLADA, H.; SCHANTZ, M. Painel apresentado no XXV World Congress of Psychiatric Genetics (WCPG) em Orlando/EUA em Outubro de 2017.

"Maternal Age at Birth is Associated with Offspring Leukocyte Telomere Length in Families with Bipolar Disorder". MARTINEZ, D. S.; MILLISCHER, V.; MICHELON, L.; ESTEBAN, N.; PEREIRA, A.; LAVEBRATT, C.; SCHALLING, M.; VALLADA, H. Painel apresentado no XXV World Congress of Psychiatric Genetics (WCPG) em Orlando/EUA em Outubro de 2017. Prêmio Early Career Investigator Program - ECIP - Travel Award. 
2. Lista dos trabalhos submetidos e preparados para publicação, respectivamente:

"High heritability of telomere length in families with Bipolar Disorder". MARTINEZ, D. S.; MILLISCHER, V.; MICHELON, L.; CAMILO, C.; BRENTANI, H.; ESTEBAN, N.; KRIEGER, J.; PEREIRA, A.; LAVEBRATT, C.; SCHALLING, M.; VALLADA, H. (Já submetido).

"Maternal Age at Birth is Associated with Offspring Leukocyte Telomere Length in Families with Bipolar Disorder". MARTINEZ, D. S.; MILLISCHER, V.; MICHELON, L.; ESTEBAN, N.; PEREIRA, A.; LAVEBRATT, C.; SCHALLING, M.; VALLADA, H. Esse manuscrito ainda está em redação, mas espera-se submetê-lo até o final de janeiro. 